Measuring sound absorption using local field assumptions

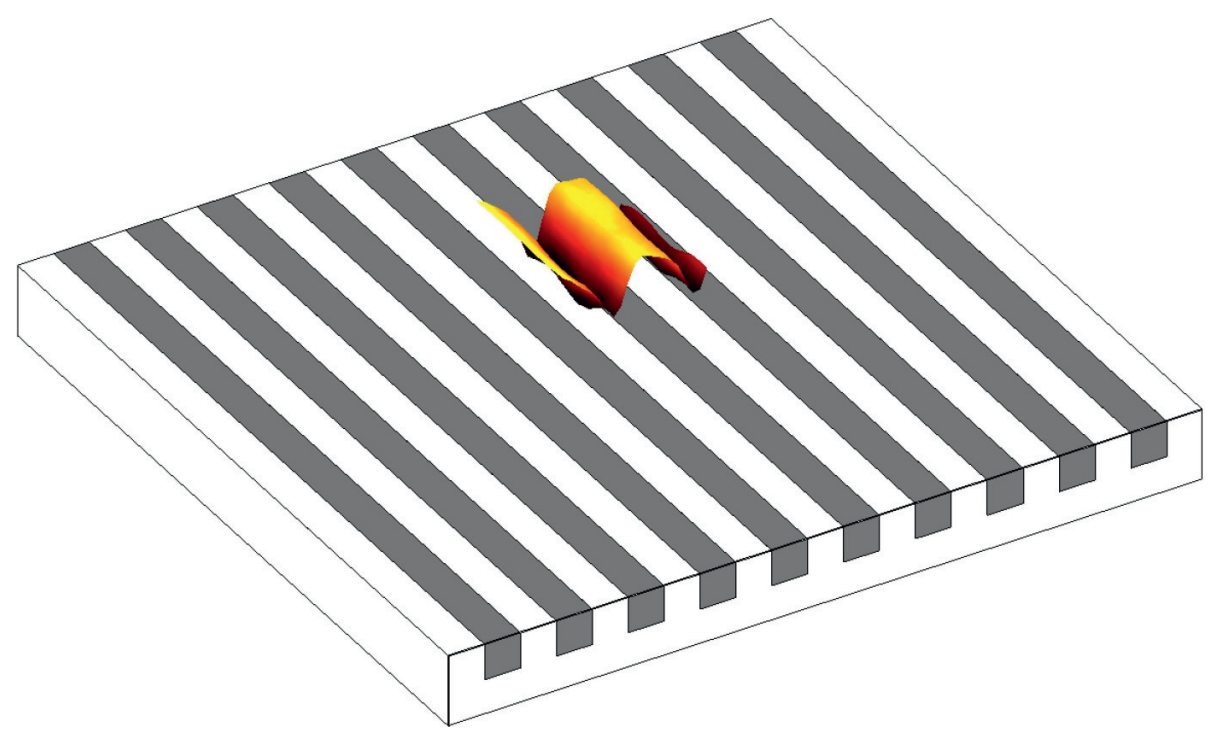

Erwin Kuipers 
Measuring sound absorption using local field assumptions

Erwin Kuipers 
De promotiecommissie is als volgt samengesteld:

Voorzitter en secretaris:

Prof.dr.ir. F. Eising

Universiteit Twente

Promotor:

Prof.dr.ir. A. de Boer

Universiteit Twente

Assistent-promotor:

Dr.ir. Y.H. Wijnant

Universiteit Twente

Leden (in alfabetische volgorde):

Prof.dr. D. Botteldooren

Universiteit Gent

Prof.dr. E. Gerretsen

TU Eindhoven

Prof.dr.ir. H.W.M. Hoeijmakers Universiteit Twente

Prof.dr.ir. G.J.M. Krijnen Universiteit Twente

Prof.dr. S. Luding

Universiteit Twente

Measuring sound absorption using local field assumptions

Kuipers, Erwin Reinder

PhD thesis, University of Twente, Enschede, The Netherlands

August 2013

ISBN 978-90-365-04737

DOI 10.3990/1.9789036504737

Subject headings: sound absorption, acoustics, measurement Copyright (C) 2013 by E.R. Kuipers, Delden, The Netherlands

Printed by Ipskamp Drukkers, Enschede, The Netherlands

Cover page:

Image of the distribution of the sound absorption coefficient of an area of the surface of a periodic absorber (measured data) 


\title{
MEASURING SOUND ABSORPTION USING \\ LOCAL FIELD ASSUMPTIONS
}

\author{
PROEFSCHRIFT
}

ter verkrijging van

de graad van doctor aan de Universiteit Twente,

op gezag van de rector magnificus,

prof.dr. H. Brinksma,

volgens besluit van het College voor Promoties

in het openbaar te verdedigen

op woensdag 4 september 2013 om 16.45 uur

door

Erwin Reinder Kuipers

geboren op 29 maart 1972

te Stedum 
Dit proefschrift is goedgekeurd door de promotor:

Prof.dr.ir. A. de Boer

en de assistent-promotor

Dr.ir. Y.H. Wijnant 


\section{Summary}

To more effectively apply acoustically absorbing materials, it is desirable to measure angle-dependent sound absorption coefficients, preferably in situ. Existing measurement methods are based on an overall model of the acoustic field in front of the absorber, and are therefore sensitive to deviations in the actual setup from the assumed measurement setup. In order not to be restricted to ideal measurement setups only, two novel methods are developed with the research described in this thesis.

These methods, the Local Plane Wave (LPW) method and the Local Specular Plane Wave (LSPW) method, are both based on a local field decomposition. It is assumed that the acoustic field can be approximated locally with a combination of one incidentand one reflected wave. The LSPW-method encompasses the LPW-method, and is therefore the most universal variant. This method requires measurement of two acoustic pressures or measurement of acoustic pressure and particle velocity in the surface normal direction to determine the angle-dependent sound absorption coefficient.

The effect of area-averaging is investigated both numerically and experimentally. The results show that area-averaging is effective in reducing undesirable effects, as for instance caused by reflections from the environment of the setup. In combination with area-averaging, the LPW- and LSPW-method have potential for application in situ. In addition, as many kinds of absorbing surfaces have an inhomogeneous structure or material, an area-averaged sound absorption coefficient is a more appropriate indicator than a point-based coefficient.

A very welcome spin-off from the present research is the development of a novel type of 3D sound intensity probe. The application of 8 small MEMS-microphones, and the chosen placement thereof, allow increased accuracy of sound absorption measurements that are performed with the LPW- or LSPW-method, in particular for poorly absorbing surfaces. In addition, a novel free-field probe calibration method is presented. An advantage of this method is that the directivity characteristics of the sound source do not need to be known a priori. 


\section{Samenvatting}

Om akoestisch absorberende materialen effectiever in te kunnen zetten is het wenselijk hoekafhankelijke geluidabsorptiecoëfficienten te kunnen meten, bij voorkeur in situ. De meeste bestaande meetmethoden zijn gebaseerd op een model van het gehele geluidsveld voor het te meten oppervlak. Een nadeel hiervan is dat dergelijke methoden gevoelig zijn voor afwijkingen in de werkelijke- ten opzichte van de aangenomen meetopstelling. Om deze reden zijn, met behulp van het in dit proefschrift beschreven onderzoek, twee nieuwe meetmethoden ontwikkeld.

Deze methoden, de Local Plane Wave (LPW)- en Local Specular Plane Wave (LSPW)methode, zijn lokale veld-decompositie-methoden. Beide zijn gebaseerd op de aanname dat het geluidsveld lokaal benaderd kan worden door één invallende en één gereflecteerde vlakke golf. De LSPW-methode omvat de LPW-methode en is daarom de meest universele variant. Hierbij is meting van twee geluidsdrukken of combinatie van één geluidsdruk en één deeltjessnelheid in normaalrichting van het oppervlak voldoende.

Ook het effect van oppervlaktemiddeling is zowel numeriek als experimenteel onderzocht. De resultaten laten zien dat oppervlaktemiddeling een effectieve methode is voor het reduceren van ongewenste effecten, zoals veroorzaakt door bijvoorbeeld omgevingsreflecties. Met oppervlaktemiddeling bieden de LPW- en LSPW-methode daarom potentieel voor toepassing in situ. Bovendien doet het concept van een oppervlaktegemiddelde absorptiecoëfficient meer recht aan de vaak voorkomende inhomogeniteit in structuur en materiaal van veel typen absorberende oppervlakken.

Een welkom bijproduct van het onderzoek is de ontwikkeling van een nieuw type 3D intensiteitssonde bestaande uit 8 kleine MEMS-microfoons. De gekozen plaatsing hiervan maakt het mogelijk de nauwkeurigheid van metingen uitgevoerd met de LPWof LSPW-methode te verhogen. Dit is in het bijzonder het geval voor zwak absorberende oppervlakken. Verder is voor deze sonde een nieuwe vrije veld kalibratiemethode ontwikkeld, met als voordeel dat hiervoor het afstraalgedrag van de bron niet a priori bekend hoeft te zijn. 



\section{Contents}

Summary v v v v ver

Samenvatting vii

Contents viii

1 Introduction $\quad 1$

1.1 Sound and absorption of sound . . . . . . . . . . . . . . 1

1.1.1 Acoustical behavior of surfaces . . . . . . . . . . . . 3

1.1 .2 Scattering . . . . . . . . . . . . . . 5

1.1.3 Diffraction . . . . . . . . . . . . . . . . 5

1.2 Measurement of sound absorption .............. . . . . 6

1.2.1 The sound absorption coefficient . . . . . . . . . . . 6

1.2 .2 Laboratory methods . . . . . . . . . . . . . . . . . . . 7

1.2 .3 In situ methods . . . . . . . . . . . . . . . . . . . . 9

1.2.4 Practice in measurement of oblique incidence sound absorption coefficients . . . . . . . . . . . . . . . 10

1.3 Objective, approach and scope . . . . . . . . . . . . . . . . . 10

1.4 Outline . . . . . . . . . . . . . . . . . . . . . . . . . . . . . . . . . . . . . . . . . .

References . . . . . . . . . . . . . . . . . . . 13

2 Development and calibration of a sound intensity probe 17

2.1 Introduction . . . . . . . . . . . . . . . . . . . . . . 18

2.2 Description of the 8 p-probe . . . . . . . . . . . . . . . . . 19

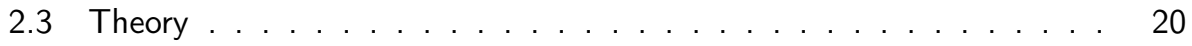

2.4 Calibration procedure ... . . . . . . . . . . . . 22

2.4.1 Correction of the cross-spectral density matrix . . . . . . . . 25

2.5 Considerations on accuracy . . . . . . . . . . . . . . . . 26

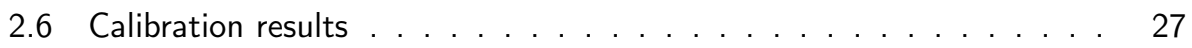

2.7 Conclusions . . . . . . . . . . . . . . . . . . . . . . . . . . . . . 33

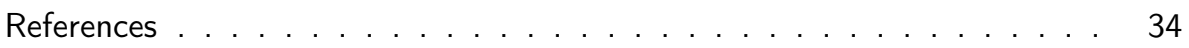


3 Numerical study of the LPW-method 37

3.1 Introduction . . . . . . . . . . . . . . . . . . . . . . . . . . . . . . . . . 37

3.2 Theory . . . . . . . . . . . . . . . . . . . . . . . 38

3.3 Investigation of the accuracy of the LPW-method . . . . . . . . . . 40

3.4 Conclusions . . . . . . . . . . . . . . . . . . . . . . 44

References . . . . . . . . . . . . . . . . . . . . . . . 44

4 Considerations on the measurement of the active acoustic power $\quad 47$

4.1 Introduction . . . . . . . . . . . . . . . . . . . . 48

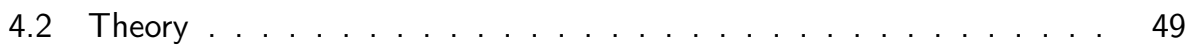

4.2.1 Theory of the LPW-method . . . . . . . . . . . . . . 49

4.2 .2 Formulation for a pu-probe . . . . . . . . . . . . . 52

4.2.3 Formulation for a pp-probe . . . . . . . . . . . . . 53

4.3 Analysis of the sound field in front of an acoustically hard surface . . 55

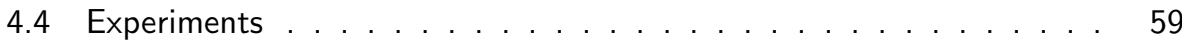

4.4 .1 Introduction . . . . . . . . . . . . . . . . 59

4.4 .2 Aluminum plate . . . . . . . . . . . . . . . . . 59

4.4 .3 Foam sheet . . . . . . . . . . . . . . . . . . 62

4.5 Conclusions and further work . . . . . . . . . . . . . . . 65

4.A Formulations in terms of power spectral densities . . . . . . . . . 66

4.B Accuracy of measurement of the active acoustic intensity for oblique incidence . . . . . . . . . . . . . . . . 67

References . . . . . . . . . . . . . . . . . . 68

5 Measuring oblique incidence sound absorption $\quad 71$

5.1 Introduction . . . . . . . . . . . . . . . . . . 72

5.2 Theory of the LSPW-method . . . . . . . . . . . . . . . . . . . . . . . . . . . . . . . .

5.3 Implementation . . . . . . . . . . . . . . . . . . . 78

5.4 Measurements . . . . . . . . . . . . . . . . . . 80

5.4.1 Sample 1: sound absorbing foam ........... . . . 80

5.4.2 Sample 2: periodic absorber ............. . . . . . 85

5.5 Conclusions . . . . . . . . . . . . . . . . . . . . . . . . . . . 88

References . . . . . . . . . . . . . . . . . . . . . 89

6 Conclusions and recommendations $\quad 91$

6.1 Conclusions . . . . . . . . . . . . . . . . . . . . . . . . 91

6.2 Recommendations and outlook ................. . . . 93

References . . . . . . . . . . . . . . . . . . . . . 94

$\begin{array}{ll}\text { Nomenclature } & 95\end{array}$

$\begin{array}{lr}\text { Publications } & 99\end{array}$

$\begin{array}{ll}\text { Dankwoord } & 101\end{array}$ 


\section{Chapter 1}

\section{Introduction}

\subsection{Sound and absorption of sound}

Sound is everywhere. From a discussion with a colleague to listening to a classical concert, perception of sound is essential in life. Thanks to our ears, healthy humans can perceive a wide range of sounds. Human ears, indeed, are a pair of very sensitive acoustic sensors; typically enabling one to hear sounds varying more than 6 orders in magnitude. Unfortunately, this sensitivity makes us get annoyed by noise as well. Traffic noise (road, railway and aircraft noise), neighbor noise, and industrial noise are examples that affect millions of people worldwide. In fact, it has become hard to find a place in the world where one is not subjected to emissions of man-made noise. Whereas excessive noise levels can impair your ability to hear, the ongoing presence of less loud noise can also be harmful to human health and well-being [38].

Besides sound transmission, absorption of sound is one of the key elements in reducing noise immission. Sound absorption takes place along the noise propagation path, from the source to the receiving environment. Near the source, sound absorbing materials are used to reduce noise emission, for example if machinery is encapsulated in a sound insulating and absorbing housing. During propagation, attenuation of acoustic waves in the air by atmospheric absorption takes place. If the location of immission is a room, noise levels are influenced greatly by the amount of sound absorptive surfaces in that room.

Secondly, sound absorbers are essential in creating a good acoustical climate for the perception of speech. The location, type, and surface area of sound absorbing surfaces are essential parameters in obtaining good speech intelligibility in classrooms and auditoria.

The last application of sound absorbing surfaces mentioned here is in rooms for musical performances. Sound absorption is one of the key quantities that determines the 
(a)

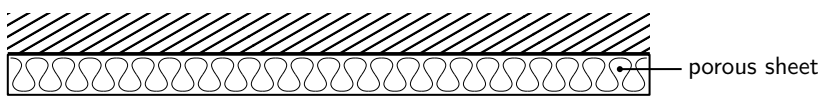

(b)

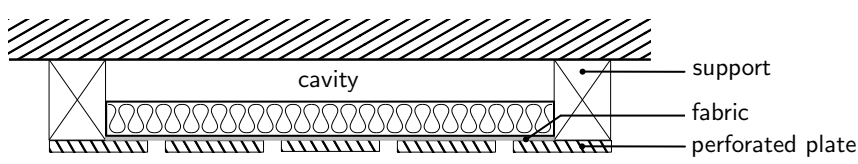

(c)

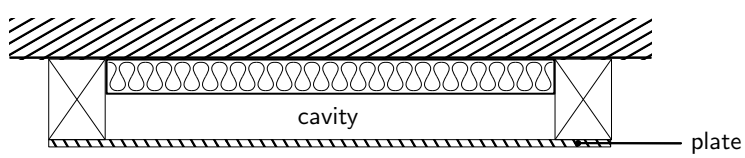

(d)

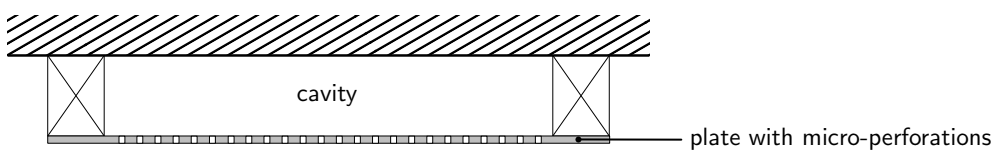

Figure 1.1: Overview of different absorber types, based on Fuchs [19]. (a) porous absorber, (b) perforated or slotted absorber, (c) plate absorber, and (d) microperforated absorber.

amount of reverberation. In concert halls, as well as in a local community center in a small village, sound absorption plays a key role in obtaining a pleasant perception of music.

Acoustic engineers and architects have the burden of selecting the appropriate solution from a wide range of commercially available absorber types. An indicative overview of different absorber types is shown in Fig. 1.1. Porous absorbers undoubtedly form the most widely applied class of absorbers. Perforated- or slit-absorbers, micro-perforated absorbers, and plate absorbers are other well-known absorber types. Often, combinations of different types are used. An example of such a combination is the application of a porous sheet in a perforated absorber, as shown in Fig. 1.1(c). For an extensive overview of absorber types, and descriptions of modern absorbers, the reader is referred to Fuchs [19]. It is pointed out that in selecting an absorber type, other design criteria have to be considered as well. These criteria mostly stem from building physics, and depend on thermal, humidity, and fire safety requirements.

In order to be able to select a suitable absorber for a certain purpose, or to be able to perform room acoustic simulations, acoustic engineers have to know its absorptive characteristics. Even if an accurate prediction of these characteristics is possible, the 
necessary calculations can be difficult and are often very elaborate. Therefore, the absorptive characteristics are measured. Before discussing methods for doing so, a few essential properties of sound absorbing surfaces will be elucidated first.

\subsubsection{Acoustical behavior of surfaces}

Depending on the way a surface responds to acoustic irradiation, its behavior can be classified as locally reactive, extensively reactive, or non-locally reactive. Fig. 1.2 schematically indicates these three descriptions.

$$
Z_{\mathrm{S}}=C
$$
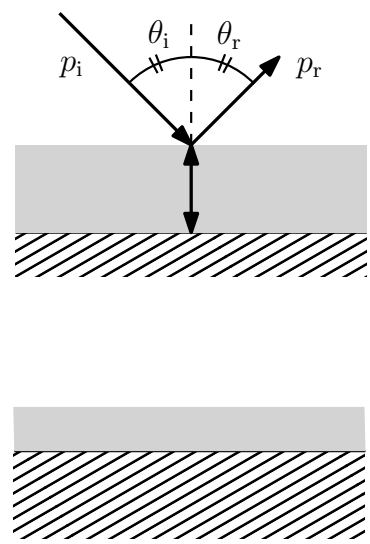

(a)

$$
Z_{\mathrm{S}}=f(\theta)
$$
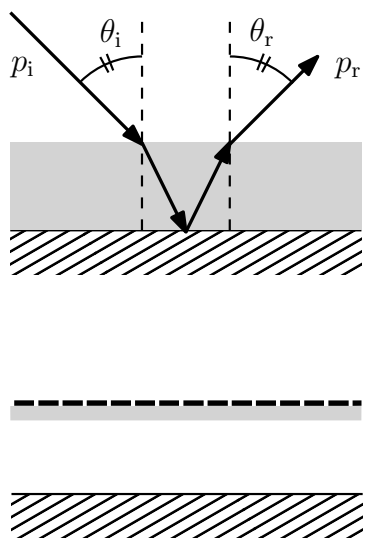

(b)$$
Z_{\mathrm{S}}=f(\mathbf{r}, \theta)
$$
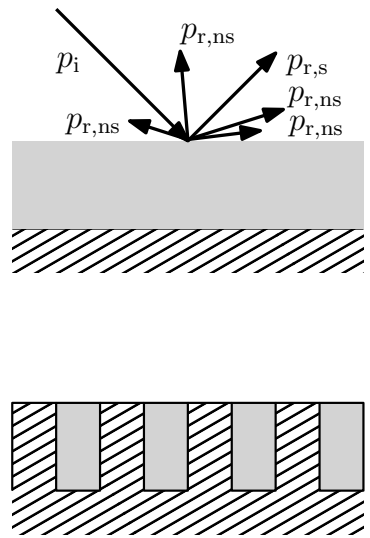

(c)

Figure 1.2: Classification of the acoustical behavior of absorbers and examples of their realizations. The incident wave is indicated with $p_{\mathrm{i}}$. (a) Locally reactive - thin porous absorber, (b) extensively reactive - suspended porous absorber with perforated cover sheet, (c) non-locally reactive - periodic absorber.

Locally reactive surface. A surface is said to be locally reactive if one may assume that the response of a certain point on that surface is independent of the response of other points. That is the response of a point upon the surface only depends on the local acoustic pressure. The normal acoustic surface impedance $Z_{\mathrm{s}}$ is independent of position and angle of incidence in this case. For porous materials, this implies that the speed of sound inside the material must be much less than it is in air, as then, the acoustic waves inside the material propagate in the direction of the surface normal vector, see Fig. 1.2(a).

Although the local reaction assumption is widely applied, it is important to recognize where it falls short. Allard [6, p.35] states that "It is a good approximation for several engineered materials such as honeycombs and acceptable for a number of thin 
Chapter 1. Introduction

porous materials." Cases where the local reaction model is also not appropriate are those involving large angles of incidence and porous materials with low flow resistivity. Indeed, experiments carried out by Davies and Mulholland [16], and Klein and Cops [23] showed that the assumption of local reaction is only valid for small angles of incidence and thin layers of porous material.

Extensively reactive surface. In this case, the normal acoustic surface impedance $Z_{\mathrm{s}}$ depends on the angle of incidence. Inside porous materials, the angle of refraction is accounted for, see Fig. 1.2(b). This angle is dependent on the angle of incidence. Multiple models for describing the acoustical behavior of extensively reactive surfaces are available. For a comprehensive overview of such models, the reader is referred to the work by Allard and Atalla [6].

Non-locally reactive surfaces. This is the case if the acoustical behavior of the surface cannot be adequately described with models that describe locally- or extensively reactive models. Generally, the normal acoustic surface impedance $Z_{\mathrm{s}}$ becomes a function of the space vector $\mathbf{r}$ and the angle of incidence $\theta_{\mathrm{i}}$. Examples are surfaces that scatter sound, i.e. besides the specularly reflected wave $p_{\mathrm{r}, \mathrm{s}}$, see Fig 1.2(c), other waves $p_{\mathrm{r}, \mathrm{ns}}$ are reflected in other, non-specular, directions. An example of a scattering surface is a periodic absorber above its first cut-on frequency, as also shown in Fig 1.2(c). An extreme case of a non-locally reactive surface would be a virtual planar surface used to represent the diffuser shown in Fig. 1.3(a), along with its polar response in Fig. 1.3(b). Also worth mentioning is the fact that diffusers can be good sound absorbers, as shown by Mechel [26], Wu [39], and Yang [40].

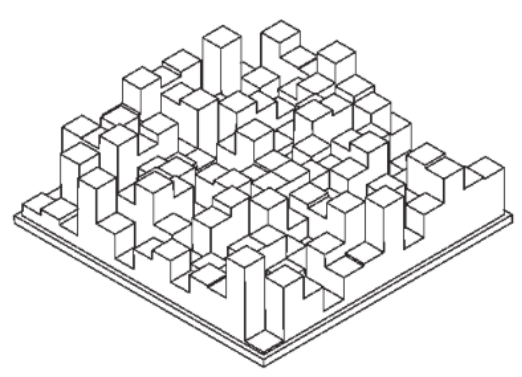

(a)

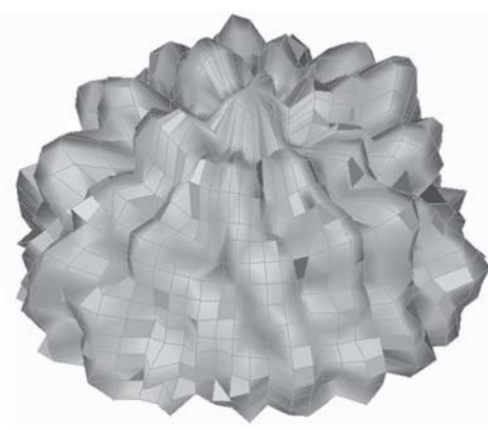

(b)

Figure 1.3: (a) "Skyline" Diffuser. (b) 3D Polar response of the diffuser to the left for normal incidence at $2 \mathrm{kHz}$. Both figures are reproduced from Cox [14].

It is pointed out that the naming of the extensively reactive surface assumption is not consistent in the literature. Extensively reactive surfaces are sometimes also referred to as bulk- [11], or laterally reactive surfaces [8]. Allard and Attala [6], and others, refer to extensively reactive surfaces as non-locally reactive surfaces, thus not being able to distinguish between surfaces that scatter sound and those that do not. For 
locally reactive surfaces, luckily, there seems to be a wide consensus. All authors follow the definition as given above, in line with the description in the well-known textbook on acoustics of sound absorbing materials by Zwikker and Kosten [41].

\subsubsection{Scattering}
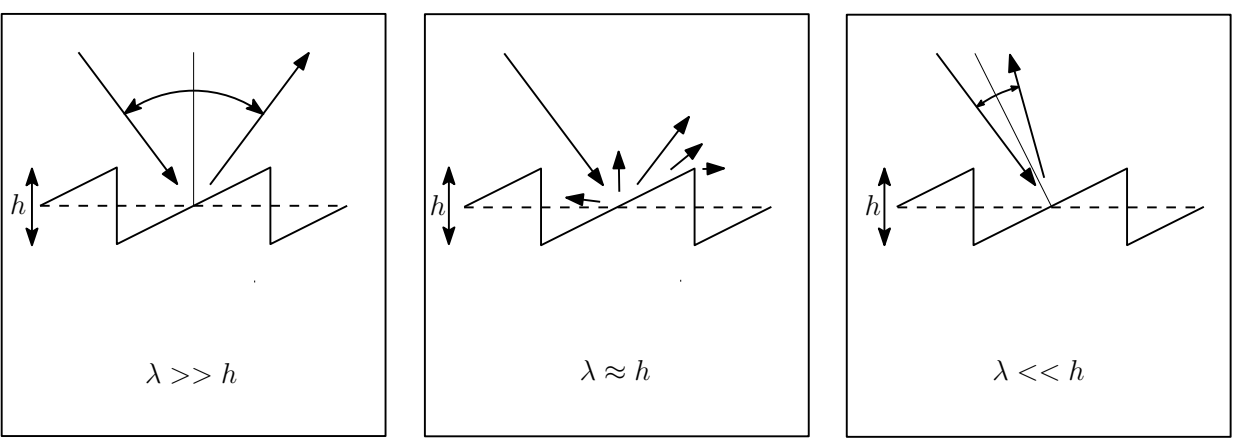

Figure 1.4: Dependency of the type of reflection of a structured surface with the wavelength $\lambda$ and characteristic surface dimension $h$.

The way acoustic waves are reflected by a non-flat or rough homogeneous surface is determined by the characteristic dimensions of the geometric variations of that surface. Figure 1.4 illustrates this dependency. For large wavelengths, specular reflection with respect to the mean surface occurs (left picture). Scattering, or diffuse reflection, occurs when the wavelength is of the same order of magnitude as the variations of the surface geometry (center picture). At wavelengths that are much shorter than the characteristic dimensions, individual parts of the surface will lead to a change in reflection (right picture). Similarly to the concept of optical resolution, one may speak here of acoustical resolution.

\subsubsection{Diffraction}

The final aspect discussed here is diffraction. The term diffraction is used when referring to the apparent bending of acoustic waves around objects, as for instance occurs in the acoustic field behind road noise barriers, see Fig. 1.5. Due to acoustic diffraction, acoustic waves are present in the field behind the barrier, reducing its effect. The term diffraction is often also used when describing the disturbance of a sound field due to the presence of objects, as for instance occurs when a microphone or intensity probe is placed in an acoustic field. 


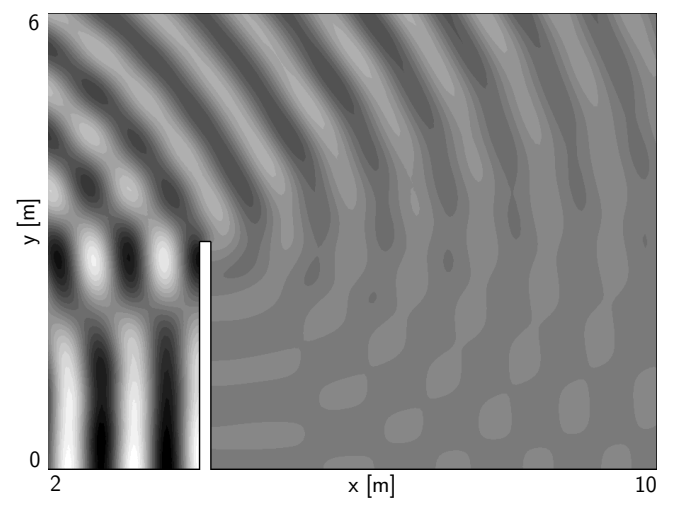

Figure 1.5: Diffraction of acoustic waves over a screen placed on an acoustically hard surface. The waves are produced by a line source at $(x, y)=(-2,0.5)[\mathrm{m}]$. Frequency: $400 \mathrm{~Hz}$. Dimensions of the screen: $\mathrm{h} \times \mathrm{w}=3 \times 0.15 \mathrm{~m}$.

\subsection{Measurement of sound absorption}

\subsubsection{The sound absorption coefficient}

In room- and building acoustics, the amount of sound absorption in a room is often expressed in terms of the surface area $A$ of a perfectly absorbing surface. W.C. Sabine [30] was the first to relate the reverberation time $T_{60}$ with the volume $V$, and absorbing area $S_{\text {abs }}$ of a room:

$$
T_{60}=0.16 \frac{V}{S_{\text {abs }}}
$$

The absorbing area $S_{\text {abs }}$ is often expressed as the product of the totally available surface area in a room, and an effective mean sound absorption coefficient $\alpha_{m}$ :

$$
S_{\mathrm{abs}}=\alpha_{m} S
$$

If this surface area approaches the maximum possible area, a room is said to be $d r y$. On the contrary, a value approaching 0 indicates a very reverberant room. The area $S_{\text {abs }}$ has been expressed as square meters of open window, or metric sabins, after W.C. Sabine. This way of indicating $S_{\text {abs }}$ is not very common anymore. The absorbing area $S_{\text {abs }}$ is rather worthless in evaluating the effectivity with which sound absorption occurs. Therefore, the more meaningful sound absorption coefficient (sometimes called the sound power absorption coefficient) $\alpha$ is used, expressing the capability of a surface to dissipate acoustic energy when exposed to a certain, well-defined incident acoustic field. On a linear scale, a value of 1 indicates complete absorption, whereas a value of 0 denotes complete reflection.

A number of methods is available for the measurement of sound absorption coeffi- 
cients, of which some have been standardized. In such methods, the measurement is performed in an acoustic field that is both well-defined and reproducible. The sound absorption coefficient of surfaces that are exposed to an undefined acoustic field is called the effective sound absorption coefficient, see for instance Beranek [10]. An example of such a coefficient is the average apparent sound absorption coefficient of a room, as determined by measuring the reverberation time and application of Sabine's formula. Generally, the effective sound absorption coefficient is dependent on the position of the sound source. Although effective sound absorption coefficients can generally not be compared, one can obtain a useful indication of the effectiveness of sound absorbers in the actual application in this way.

Sound absorption coefficients can be measured with laboratory- or in situ methods. These are presented in the following two sections.

\subsubsection{Laboratory methods}

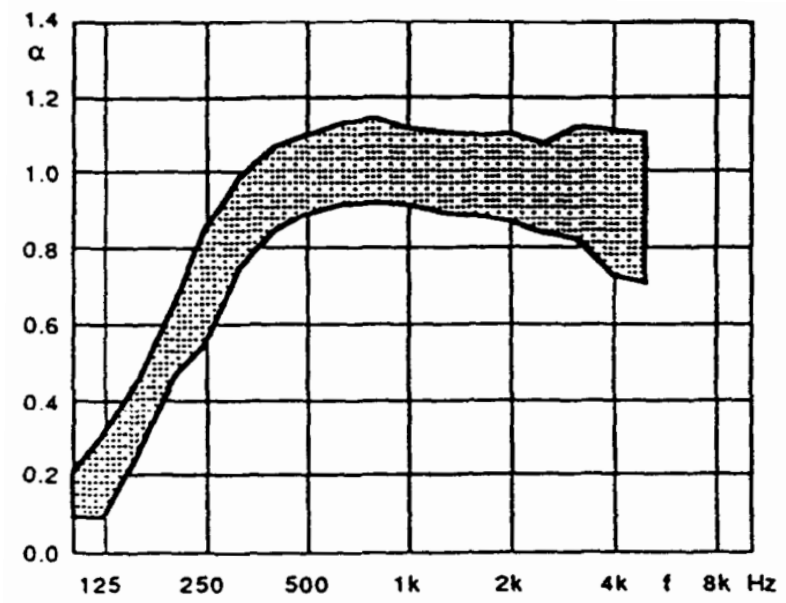

Figure 1.6: Inter-laboratory variation of the statistical sound absorption coefficient of the same sample, tested in 19 different laboratories, after Cops et al. [13]

Despite more than a century of developments in acoustic measurement methods, measurement of the sound absorption coefficient of a sample is still non-trivial. Representative for this statement is the method for measurement of the statistical sound absorption coefficient $\alpha_{\mathrm{S}}$ in a reverberation room according to ISO 354 [4]. A particular drawback of this method is the inter-laboratory variability in the obtained sound absorption curve, as found in a round robin test in the early 1980s wherein 19 laboratories participated. Fig. 1.6 shows the range in which the measured statistical sound absorption coefficient varied. Cops [13] investigated the sensitivity of the reverberation room method to changes in the measurement setup, and showed that, among other factors, the position of the source and the sample, as well as the presence of diffusers in 
the room can have a significant influence on the result. In addition, unphysical values of the sound absorption coefficient greater than 1.0 are common for well-absorbing materials [34]. Remarkably, P.E. Sabine (not to be confused with W.C. Sabine) already noticed some of these phenomena according to a paper dated back to the year 1929 [29].

The statement that standardization does not imply that a method is beyond dispute, is also applicable to normal incidence measurements by means of the transfer function method acc. to ISO 10534-2 [1]. This method, performed with an impedance tube (also called a standing wave tube, plane wave tube, or Kundt's tube in the literature), is sensitive to the mounting conditions of the sample as shown by analyses by Cummings [15], and Vigran et al. [35].

A large class of free-field methods, though non-standardized, is available for measurement of the normal acoustic surface impedance. For those methods that assume a locally reactive surface, a measurement under normal incidence suffices to also predict the sound absorption coefficient for oblique incidence. Nevertheless, oblique incidence measurements are required for extensively reactive surfaces, and are useful in verifying whether a local reaction assumption could be valid.

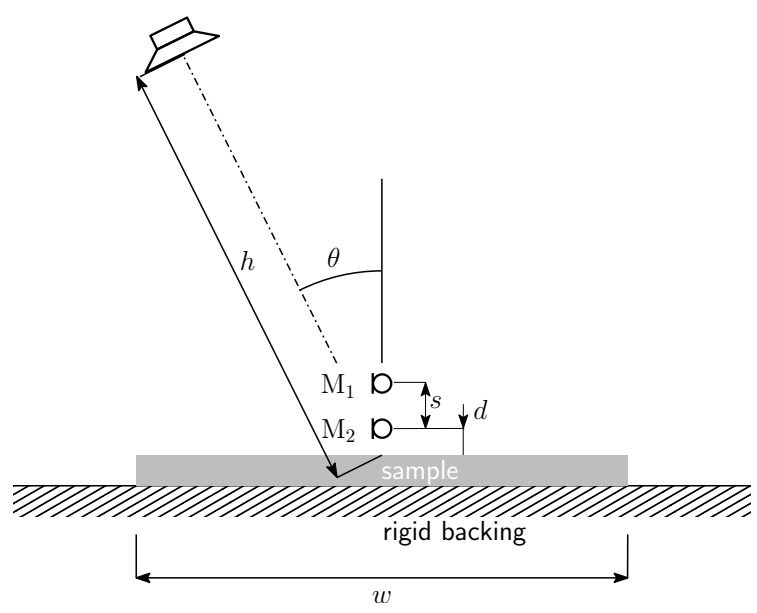

Figure 1.7: Typical setup for oblique incidence measurement in a free field using two microphones.

A typical two-microphone setup is shown in Fig. 1.7. There are also many methods employing a pu-probe instead of a two-microphone setup. For a more detailed review of laboratory methods, the reader is referred to the book by Cox and d'Antonio [14]. 


\subsubsection{In situ methods}

The term in situ methods is mostly used to describe methods with which the normal acoustic surface impedance (and sound absorption coefficient) can be measured for the surface of interest in its actual state. The actual state here means that the surface is in its actual mounting condition, but that it is irradiated with well-defined acoustic waves. The latter aspect is important in enabling comparability of results between different in situ measurements, or between an in situ measurement and a laboratory measurement.

Accordingly, a well-defined acoustic field is required, demanding absence of spurious reflections and edge-diffracted waves. As a consequence, one must either perform the measurement such that these unwanted waves cannot influence the measurement, or remove these from the measurement. An example of the first case is the spot method for reflective surfaces acc. to ISO13472-2 [5]. This method is merely a variation of ISO 10534-2 [1] with the difference that the impedance tube is now placed upon the surface of interest. In the second case, unwanted waves are removed from the measurement by truncation of the measured impulse response. Standardized impulse response-based methods are the so-called Adrienne method acc. to CEN/TS 17935 [3], and the extended surface method for road surfaces, acc. to ISO 13472-1 [2].

Other, non-standardized, impulse response-based in situ methods are those by Wilms and Heinz [37], Garai [20], Mommertz [27], Nocke [28], and Dutilleux et al. [18]. As measurements at low frequencies demand a sufficiently long time-window, such measurements can only be performed in large spaces, where spurious reflections are absent. To avoid edge-diffracted waves, the sample size must be large as well. Nocke [28] calculated a minimum of $12 \mathrm{~m}^{2}$ for frequencies down to $80 \mathrm{~Hz}$ by considering Fresnel zones. Kimura [22] experimentally found a minimum surface area of $16 \mathrm{~m}^{2}$ for frequencies down to $400 \mathrm{~Hz}$.

In the case of ground surfaces, one typically has a semi-free field, so that removal of spurious reflections is only necessary if the surface of interest is small. Examples of measurement methods are the transfer function method by Kruse [24], or methods relying on measurement of excess attenuation, see for instance the work by Attenborough [9] or Taherzadeh [31].

Although designated as in situ methods, the methods by Lanoye et al. [25], Alvarez and Jacobsen [7], and by Tijs and Druyvesteyn [33] are actually free-field methods, principally demanding a semi-free field as previously discussed in Sec. 1.2.2. Hirosawa [21] and Brandão [12] showed that the influence of edge-diffracted waves can be reduced by choosing a small source distance and a small distance of the pu-sensor to the surface.

Finally, Takahashi et al. [32] used background noise as the sound source, assuming plane waves and that this noise is diffusely incident. They obtained reproducible sound absorption coefficient curves in different measurement environments up to $1500 \mathrm{~Hz}$. 
For a very detailed discussion of in situ measurement methods, the reader is referred to De Geetere [17].

\subsubsection{Practice in measurement of oblique incidence sound ab- sorption coefficients}

For oblique incidence measurements, free-field methods are the standard. For most in situ methods this holds as well, as the truncated impulse response represents a freefield measurement. Furthermore, locally reactive surfaces are generally assumed. By doing so, a single measurement of the normal acoustic surface impedance (typically at normal incidence) is sufficient to be able to predict the oblique incidence sound absorption coefficient.

All measurement methods are based on an overall model of the acoustic field in front of the surface of interest. The adjective overall is used here to express that the model can be used to calculate the whole acoustic field. Such overall models describe either plane- or spherical wave incidence upon a planar, locally-, or extensively reactive surface of infinite extent in an otherwise free field. Accordingly, any deviation in the actual field compared to the assumed field may lead to errors in the obtained results. A number of possible causes for such errors is summarized in the following list.

- Incident waves are different from the assumed type of waves, mostly plane or spherical waves.

- The surface model may be inadequate. A surface may be extensively- or nonlocally reactive instead of locally reactive.

- Finite sample size leads to edge-diffracted waves.

- Spurious reflections are present.

The above causes lead to errors that are, in fact, induced by the use of an overall model of the acoustic field above the sample. In addition, measurement errors may occur. Examples of such errors are positioning errors, and phase- and amplitude mismatch errors.

\subsection{Objective, approach and scope}

Applying existing measurement techniques, the sources of error listed in Sec. 1.2.4, lead to inaccuracies in the measured sound absorption coefficient. This is a dissatisfying situation, in particular for in situ measurements, as edge-diffraction and non-locally reactive surfaces often cannot be avoided. Therefore, it makes sense to develop an alternative approach that does not put stringent requirements on the measurement setup. That is, a method that can be applied in non-ideal acoustic fields, where, in 
this context, ideal refers to acoustic fields that are computable. Therefore, the objective of the present work is formulated as follows:

Development of a novel method for the measurement of the normal- and oblique incidence sound absorption coefficient, suitable for application in nonideal sound fields.

Research approach. In order to determine the sound absorption coefficient, the incident acoustic intensity and active acoustic intensity must be known. To be able to do this, the acoustic field must be separated or decomposed in such a way that the amplitude of the incident waves can be determined. Actually, there is no need to employ an overall model of the acoustic field for this purpose. Following the original idea by Wijnant, Wijnant et al. [36] showed that a local decomposition may suffice. This is the approach followed in this thesis.

A second aspect of the research approach is the concept of area-averaged measurements, which was also introduced in the same paper by Wijnant et al. [36]. Measurement of an area-averaged sound absorption coefficient instead of a point-based sound absorption coefficient is useful for two reasons. The first reason is the fact that the sound absorbing capacity of inhomogeneous or structured surfaces is more functionally expressed in an area-averaged sense. The second reason is related to the presence of disturbing waves, such as room reflections or edge-diffracted waves. A point-based measurement is more likely to be influenced by the presence of such waves than one that is area-based. Therefore, the concept of area-averaging might be helpful in performing measurements in non-ideal, or even in situ, acoustic fields. For these reasons, the concept of area-averaging is investigated as well.

Scope. The scope of the present research is confined to stationary acoustic fields and linear acoustics. Application of the developed method(s) in non-ideal acoustic environments is targeted.

The resulting method(s) will ideally be capable of determining the sound absorption coefficient for a wide variety of surfaces. These may be of the locally-, extended-, or non-locally reacting type. It is not the objective of this work to also determine the acoustic surface impedance. Accordingly, the obtained results can be used in quality control or in ray-based room acoustic simulations, but not in boundary element- or finite element simulations. The latter also holds for outdoor sound propagation models that require the acoustic surface impedance of the ground as an input parameter. Further applications are quality control and engineering measurements. 


\subsection{Outline}

The present research has led to 4 research papers, each of which is presented in a separate chapter. The advantage of this way of presentation is that one may read a single chapter without missing information as the papers are self-contained. However, as the papers partly share some content, redundancies in the presentation of information could not be avoided. The author apologizes for any inconvenience in this respect.

Chapter 2: In this chapter, the characterization of a novel 3D MEMS-microphone based sound intensity probe is presented. Although this subject differs quite a lot from that of the following chapters, the realization of this 3D probe has been indispensable in obtaining the experimental results in this work. This chapter describes the design of the probe, and presents a novel free-field calibration method with which its relative amplitude and phase errors can be determined.

Chapter 3: The first measurement method that has been developed is the Local Plane Wave (LPW) method. This method inherited its name from the underlying local plane wave assumption, and is suitable for near-normal incidence. The incident acoustic intensity at a certain point in the field can be determined by local measurement of the acoustic pressure and particle velocity. Accordingly, a puor pp-probe can be applied. The LPW-method is investigated numerically in this chapter. The effect of area-averaging is investigated for different absorbers, in the presence of reflected waves from an adjacent boundary. The results are compared with an existing point-based method. Finally, the sensitivity of the sound absorption coefficient to the measurement distance is investigated.

Chapter 4: Following the conclusions of the preceding chapter, further investigations on the influence of the measurement distance are carried out. An approach is developed to compensate for the amount of active acoustic power that leaks away from, or that enters the space between the measurement surface and the material surface. To be able to include this compensation in measurements, the probe described in chapter 2 is applied. The effectiveness of the compensation is investigated by performing experiments on two different surfaces. In addition, the effect of variation of the area of the measurement surface is investigated.

Chapter 5: For measurement of the normal- or oblique incidence sound absorption coefficient, a different field assumption has been conceived. This assumption is referred to as the Local Specular Plane Wave assumption, hence, the method is called the LSPW-method. Except for the underlying assumption, the LSPWmethod is identical to the LPW-method. This chapter presents the theory of this method, along with experimental results.

Chapter 6: This chapter presents the conclusions of the present research. Finally, recommendations for further work on this topic are given. 


\section{References}

[1] ISO 10534-2:1998: Acoustics - Determination of sound absorption coefficient and impedance in impedance tubes - Part 2: Transfer-function method, 1998.

[2] ISO 13472-1:2002: Acoustics - Measurement of sound absorption properties of road surfaces in situ - Part 1: Extended surface method, 2002.

[3] CEN/TS 1793-5: Road traffic noise reducing devices - Test method for determining the acoustic performance - Part 5: Intrinsic characteristics - In situ values of sound reflection and airborne sound insulation, 2003.

[4] ISO 354:2003: Acoustics - Measurement of sound absorption in a reverberation room, 2003.

[5] ISO 13472-2:2010: Acoustics - Measurement of sound absorption properties of road surfaces in situ - Part 2: Spot method for reflective surfaces, 2010.

[6] J.F. Allard and N. Atalla. Propagation of sound in porous media. John Wiley \& Sons Ltd., UK, 1st edition, 2009.

[7] J.D.B. Alvarez and F. Jacobsen. An iterative method for determining the surface impedance of acoustic materials in situ. In Inter-Noise, Shanghai, 2008. I-INCE.

[8] M. Aretz and M. Vorländer. Efficient modelling of absorbing boundaries in room acoustic FE simulations. Acta Acust. Acust., 96(6):1042-1050, November 2010.

[9] K. Attenborough. A note on short-range ground characterization. J. Acoust. Soc. Am., 95(6):3103-3108, 1994.

[10] L. Beranek. Analysis of Sabine and Eyring equations and their application to concert hall audience and chair absorption. J. Acoust. Soc. Am., 120(3):1399, 2006.

[11] D.A. Bies and C.H. Hansen. Engineering noise control: theory and practice. E \& FN Spon, Abingdon, UK, 4th edition, 2009.

[12] E. Brandão, A. Lenzi, and J. Cordioli. Estimation and minimization of errors caused by sample size effect in the measurement of the normal absorption coefficient of a locally reactive surface. Appl. Acoust., 73:543-556, 2012.

[13] A. Cops, J. Vanhaecht, and K. Leppens. Sound absorption in a reverberation room: Causes of discrepancies on measurement results. Applied Acoustics, 46(3):215 - 232, 1995.

[14] T. Cox and P. D'Antonio. Acoustic absorbers and diffusers: Theory, design and application. Taylor \& Francis, Abingdon, 2009.

[15] A. Cummings. Impedance tube measurements on porous media: the effects of air-gaps around the sample. J. Sound Vib., 151(1):63-75, 1991.

[16] J.C. Davies and K.A. Mulholland. An impulse method of measuring normal impedance at oblique incidence. J. Sound Vib., 67(1):135-149, 1979.

[17] de Geetere L. Analysis and improvement of the experimental techniques to assess the acoustical reflection coefficient of boundary surfaces. PhD thesis, KU Leuven, Belgium, 2004.

[18] G. Dutilleux, T.E. Vigran, and U.R. Kristiansen. An in situ transfer function technique for the assessment of the acoustic absorption of materials in buildings. Appl. Acoust., 62:555-572, 2001.

[19] H.V. Fuchs. Schallabsorber und Schalldämpfer. Springer, Berlin, Germany, first edition, 2007.

[20] M. Garai. Measurement of the sound-absorption coefficient in situ: The reflection method using periodic pseudo-random sequences of maximum length. Appl. Acoust., 
39:119-139, 1993.

[21] K. Hirosawa, K. Takashima, H. Nakagawa, M. Kon, A. Yamamoto, and W. Lauriks. Comparison of three measurement techniques for the normal absorption coefficient of sound absorbing materials in the free field. J. Acoust. Soc. Am., 126(6):3020-3027, 2009.

[22] K. Kimura and K. Yamamoto. The required sample size in measuring oblique incidence absorption coefficient - Experimental study. Applied Acoust., 63(5):567-578, 2002.

[23] C. Klein and A. Cops. Angle dependence of the impedance of a porous layer. Acustica, 44:258-264, 1980.

[24] R. Kruse. Application of the two-microphone method for in-situ ground impedance measurements. Acta Acust. Acust., 93:837 - 842, 2007.

[25] R. Lanoye, G. Vermeir, W. Lauriks, R. Kruse, and V. Mellert. Measuring the free field acoustic impedance and absorption coefficient of sound absorbing materials with a combined particle velocity-pressure sensor. J. Acoust. Soc. Am., 119(5):2826-2831, 2006.

[26] F.P. Mechel. The wide-angle diffuser - a wide-angle absorber? Acustica, 81:379-401, 1995.

[27] E. Mommertz. Angle-dependent in-situ measurements of reflection coefficients using a subtraction technique. Appl. Acoust., 46(3):251-263, 1995.

[28] C. Nocke. In-situ acoustic impedance measurement using a free-field transfer function method. Appl. Acoust., 59(3):253-264, 2000.

[29] P.E. Sabine. The measurement of sound absorption coefficients. J. Frankl. Inst., 207(4):341-368, 1929.

[30] W.C. Sabine. Collected papers on acoustics. Harvard University Press, Cambridge, Mass., USA, 1923.

[31] S. Taherzadeh and K. Attenborough. Deduction of ground impedance from measurements of excess attenuation spectra. J. Acoust. Soc. Am., 105(3):2039-2042, 1999.

[32] Y. Takahashi, T. Otsuru, and R. Tomiku. In situ measurements of surface impedance and absorption coefficients of porous materials using two microphones and ambient noise. Appl. Acoust., 66(7):845-865, 2005.

[33] E. Tijs and E. Druyvesteyn. An intensity method for measuring absorption properties in situ. Acta Acust. Acust., 98(2):342-353, 2012.

[34] M.L.S. Vercammen. How to improve the accuracy of the absorption measurement in the reverberation chamber. In NAG/DAGA, Rotterdam, 2009. DEGA, Berlin.

[35] T.E. Vigran, L. Kelders, W. Lauriks, P. Leclaire, and T.F. Johansen. Prediction and measurements of the influence of boundary conditions in a standing wave tube. Acustica, 83(3):419-423, 1997.

[36] Y.H. Wijnant, E.R. Kuipers, and A. de Boer. Development and application of a new method for the in-situ measurement of sound absorption. In ISMA 31, Leuven, Belgium, 2010.

[37] U. Wilms and R. Heinz. In-situ Messung komplexer Reflexionsfaktoren von Wandflachen. Acustica, 75:28-39, 1991.

[38] World Health Organization. Burden of disease from environmental noise Quantification of healthy years lost in Europe. Technical report, WHO Regional Office for Europe, Copenhagen, Denmark, 2011.

[39] T. Wu, T.J. Cox, and Y.W. Lam. From a profiled diffuser to an optimized absorber. J. Acoust. Soc. Am., 108(2):643-650, 2000. 
[40] J. Yang, Y. Shen, and H. Wang. On the sound absorption of quadratic residue diffuser groups with various shapes and combinations. J. Acoust. Soc. Am., 119(6):3546-3548, 2006.

[41] C. Zwikker and C.W. Kosten. Sound absorbing materials. Elsevier, Amsterdam, 1st edition, 1949. 



\section{Chapter 2}

\section{Development and calibration of a MEMS-microphone based 3D sound intensity probe $^{1}$}

\section{Abstract}

This paper describes a novel three-dimensional sound intensity probe consisting of 8 MEMS (micro-electromechanical systems) microphones and a novel free-field calibration method. The use of MEMS-microphones allows for a very compact design compared to probes that employ 1/2-inch condenser microphones. A novel free-field calibration method, based on the principle of microphone interchange, is developed to determine the relative amplitude- and phase errors. An advantage of this method is that is does not require knowledge of the radiation characteristics of the sound source. By repeating the calibration at different positions from the source, a relative amplitude accuracy of less than $2 \%$ and relative phase accuracy of less than $0.2^{\circ}$ are obtained between 1300 and $3000 \mathrm{~Hz}$. Using the calibration results, the measured cross-spectral density matrix can straightforwardly be corrected. Such a correction is useful up to $3000 \mathrm{~Hz}$, as above this frequency, probe-induced diffraction becomes noticeable.

\footnotetext{
${ }^{1}$ Reproduced from: E.R. Kuipers, Y.H. Wijnant, and A. de Boer, Development and calibration of a MEMS-microphone based 3D sound intensity probe. Submitted to Applied Acoustics
} 


\subsection{Introduction}

With the advent of micro-electromechanical systems (MEMS) in consumer electronics, the application of MEMS-microphones in acoustical engineering is now advancing as well. Relative to their size and cost (typically less than $\$ 3$ per piece), modern MEMS-microphones offer an excellent performance. Despite their small size, MEMSmicrophones have a self-noise level that is comparable to that of $1 / 4$ "-condenser measurement microphones. A further advantage of MEMS-microphones is their lower sensitivity to vibration compared to condenser measurement microphones or electret condenser microphones [13]. Application is critical a) in cases of high sound levels, due to the occurrence of high harmonic distortion, and b) in cases involving low sound levels at low frequencies.

Their low cost and small size gives them a considerable advantage over condenser measurement microphones, in particular when applied in microphone arrays, as for instance described by Arnold et al. [3], and Hafizovic et al. [9]. Another application of MEMS-microphones that could benefit in terms of cost and size is in sound intensity probes. In this paper, we present such a probe. It is a $3 \mathrm{D}$ probe consisting of 8 digital MEMS-microphones, referred to as $8 p$-probe in the following. The term digital emphasizes that these microphones produce a digital output signal, as opposed to those that produce analog output signals.

3D intensity probes can be used for many purposes. Besides the measurement of sound intensity and -power, such probes can be used as energy density sensors [6, 19] and used for source localization [10]. The envisioned purpose of the 8p-probe is in measurement of the sound absorption coefficient, as reported by Kuipers et al. $[15,14,16]$. Nevertheless, this probe can be used for the aforementioned purposes as well.

Minimization of relative amplitude- and phase errors is of high importance in accurately determining sound intensity, as discussed by Jacobsen and De Bree [11]. One possible way to calibrate the probe is to use an impedance tube. However, the dimensions of the $8 \mathrm{p}$-probe require a tube with an inner diameter of at least $10 \mathrm{~cm}$, causing the maximum frequency of the calibration to be lower than $2000 \mathrm{~Hz}$. This value is much lower than the desired maximum calibration frequency of $6000 \mathrm{~Hz}$.

Therefore, a free-field method is considered to be a better alternative. Miah and Hixson [17] applied such a method for a 3D intensity probe consisting of 7 microphones. Calibration of their probe was straightforwardly performed by aligning all microphones on a single plane. After absolute amplitude calibration of the center microphone with a reference microphone, the relative amplitudes and phases are determined using a free-

field measurement. As the microphones of our 8p-probe cannot easily be brought into one plane, this approach cannot be followed. Nagata et al. [18] used a combination of a reference intensity probe and rotation of the probe in front of a loudspeaker to determine the phase errors. A disadvantage of this approach is that the accuracy of the 
calibration depends on the amplitude- and phase errors of the reference intensity probe.

For a pu-probe, Jacobsen and Jaud [12] applied a free-field method using different source types. Basten and De Bree [4] performed calibration measurements in an anechoic room using a speaker in a spherical housing. Both approaches have in common that the behavior of the source has to be known a priori. Deviations from the assumed radiated sound field therefore lead to inaccuracies in the calibration. To overcome the aforementioned issues, we have developed a novel free-field calibration method. This method is based on the concept of microphone interchange as employed in the transfer function method for normal incidence absorption measurements using an impedance tube $[7,2]$.

This paper is structured as follows: First, the design of the probe is presented in Sec. 2.2. This section is followed by a discussion of the determination of the sound intensity vector in Sec. 2.3. The calibration method is elucidated in Sec. 2.4 after which a few factors influencing the accuracy of the calibration are discussed in Sec. 2.5. The results of the calibration are discussed in Sec 2.6.

\subsection{Description of the 8p-probe}

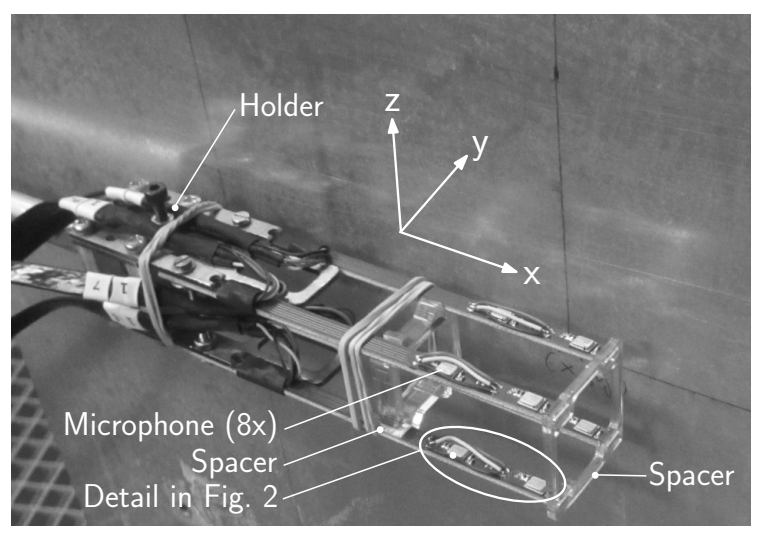

Figure 2.1: Prototype 3D sound intensity probe.

A prototype of the 8p-probe is shown in Figs. 2.1 and 2.2. It consists of 4 electronic prints, each of which carries 2 MEMS-microphones. The microphone spacing equals $20.0 \mathrm{~mm}$ in the $x$ - and $y$-directions, and $23.1 \mathrm{~mm}$ in the z-direction. Two precisely manufactured spacers with a dimensional tolerance of less than $0.1 \mathrm{~mm}$ are used to maintain the spacing. The main features of the probe are the small microphones, enabling measurements close to the surface of a sample in sound absorption measurements, and its slender design, to minimize probe-induced diffraction. 


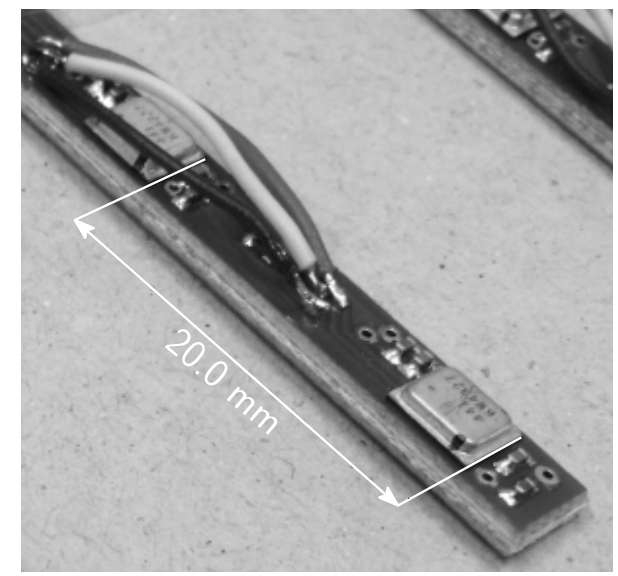

Figure 2.2: Detail of Fig. 2.1.

The microphones are type ADMP441 produced by Analog Devices [1]. These microphones are bottom-ported; i.e. the acoustic waves enter the microphone port through a small hole in the electronic print. The small diameter of this port $(0.25 \mathrm{~mm})$ ensures an omnidirectional characteristic. The dimensions of the microphones are $4.72 \times 3.76 \times 1.00 \mathrm{~mm}$. The main specifications of the microphones, listed in [1], are shown in Table 2.1 .

\begin{tabular}{lcr}
\hline Sensitivity at 94 dB SPL & -26 & $\mathrm{dBFS}$ \\
Frequency response $(60-15000 \mathrm{~Hz})$ & $-3 /+2$ & $\mathrm{~dB}$ \\
Signal to noise ratio (SNR) & 61 & $\mathrm{~dB}(\mathrm{~A})$ \\
Equivalent input noise (EIN) & 33 & $\mathrm{~dB}(\mathrm{~A})$ \\
Maximum sound pressure level & 120 & $\mathrm{~dB}$ \\
THD at $104 \mathrm{~dB}$ SPL & 3 & $\%$ \\
Dynamic range & 87 & $\mathrm{~dB}$ \\
Sample rate & 48 & $\mathrm{kHz}$ \\
\hline
\end{tabular}

Table 2.1: Microphone specifications, after [1]

\subsection{Theory}

In this section, the determination of the active acoustic intensity vector with the $8 \mathrm{p}$ probe is presented. The most straightforward way to determine this vector is to proceed similarly as for a 3D probe that consists of three pairs of 2 microphones (a $6 p$-probe). This way, one can apply the theory for a unidirectional pp-probe for each orthogonal direction separately. In the following, linear acoustics and pure tones are assumed, i.e. the sound field fulfills the Helmholtz-equation. We use the $e^{i \omega t}$ convention, i.e. 
$p(\mathbf{r}, t)=\operatorname{Re}\left[P(\mathbf{r}) e^{i \omega t}\right]$, capitals denote quantities in the frequency domain, and bold printed letters indicate vectors or matrices.

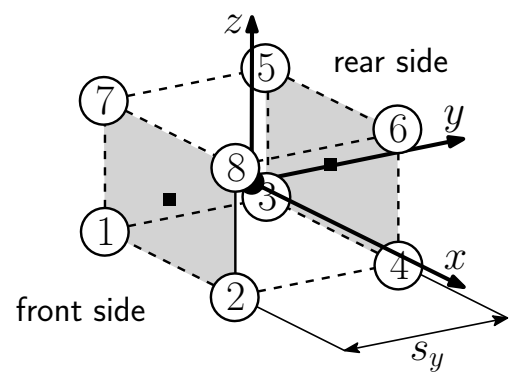

Figure 2.3: Numbering of the microphones. The origin of the coordinate system coincides with the geometric center of the probe.

The theory is shown for the $y$-direction as an example. For the other directions, one can proceed likewise. Figure 2.3 shows the definition of the directions, and the numbering of the microphones. As an example, we consider the active acoustic intensity in the positive $y$-direction. To this purpose, we define a front $(f)$ and a rear (b) side (both indicated with gray color), see Fig. 2.3. The front acoustic pressure is the acoustic pressure at the square marker, defined as the average of the acoustic pressures of microphones 1, 2, 7, and 8. Accordingly for the rear acoustic pressure, microphones $3,4,5$,and 6 are used. The spectral density of the active acoustic intensity in the ydirection can be determined using the formulation for a unidirectional pp-probe given by Fahy [8]:

$$
I_{\mathrm{ac}, y}(\omega)=\frac{-\operatorname{Im}\left[G_{\mathrm{fr}}(\omega)\right]}{\rho_{0} \omega s_{y}},
$$

where $\rho_{0}$ is the mass density of air, $\omega$ the radial frequency, and $s_{y}$ the microphone spacing in the y-direction. According to the definition by Bendat and Piersol [5, p.71], $G_{\mathrm{fr}}$ is the single-sided cross-power spectral density of the complex acoustic pressures $P_{\mathrm{f}}$ and $P_{\mathrm{r}}$, obtained by averaging over $n_{q}$ data segments:

$$
G_{\mathrm{fr}}=\frac{2}{n_{q} T} \sum_{q=1}^{n_{q}}\left(\overline{P_{\mathrm{f}}}\right)_{q}\left(P_{\mathrm{r}}\right)_{q},
$$

where $q$ is the index of the data segment, $n_{q}$ the total number of data segments in one measurement, $T$ the duration of one data segment, and the overbar denotes complex conjugation. The dependence on $\omega$ is omitted for brevity. $P_{\mathrm{f}}$ and $P_{\mathrm{r}}$ are the finite Fourier Transforms of the acoustic pressures in data segment $q$. The mean acoustic pressures at the front- and rear side are given by 


$$
\begin{aligned}
& P_{\mathrm{f}}=\frac{1}{4}\left(P_{1}+P_{2}+P_{7}+P_{8}\right), \\
& P_{\mathrm{r}}=\frac{1}{4}\left(P_{3}+P_{4}+P_{5}+P_{6}\right) .
\end{aligned}
$$

The calculation of $G_{\mathrm{fr}}$ in Eq. (2.2) using expressions (2.3) and (2.4) results in averaging of 16 cross-spectral densities. As the active acoustic intensity is also to be determined for the other two orthogonal directions, it is useful to use the cross-spectral density matrix. This matrix is defined as

$$
\mathbf{C}=\frac{2}{n_{q} T} \sum_{q=1}^{n_{q}} \mathbf{P}_{q}^{\mathrm{H}} \mathbf{P}_{q},
$$

where $\mathbf{P}_{q}=\left[P_{1} \ldots P_{8}\right]_{q}$ is a row vector containing the finite Fourier Transforms of data segment $q$ for a certain frequency $\omega$. The superscript ${ }^{H}$ indicates the Hermitian transpose. Then, the multiplication of the two terms in brackets in Eq. (2.2) results in simply taking the mean of the corresponding 16 elements of the cross-spectral density matrix:

$$
\begin{aligned}
G_{\mathrm{fr}}= & \frac{1}{16} \times[ \\
& C_{13}+C_{14}+C_{15}+C_{16}+ \\
& C_{23}+C_{24}+C_{25}+C_{26}+ \\
& C_{73}+C_{74}+C_{75}+C_{76}+ \\
& \left.C_{83}+C_{84}+C_{85}+C_{86}\right] .
\end{aligned}
$$

The spectral density of the reactive acoustic intensity in the y-direction for the 8p-probe becomes

$$
I_{\mathrm{re}}=\frac{G_{\mathrm{ff}}-G_{\mathrm{rr}}}{2 \rho_{0} \omega s_{y}},
$$

where $G_{\mathrm{ff}}$ and $G_{\mathrm{rr}}$ are the average auto-power spectral densities of the acoustic pressures measured at front and rear side, respectively.

\subsection{Calibration procedure}

In this section, a novel free-field method for the amplitude- and phase calibration of the 8p-probe is presented. This procedure can also be applied for calibration of other probes that consist of multiple microphones. The calibration setup consists of two configurations, shown in Figs. 2.4(a) and (b). Configuration A shows a sound source with the probe at position $y=h$ on the axis of the source. The second 
configuration, $B$, is identical to configuration $A$, but the microphone positions are interchanged by a $180^{\circ}$ rotation of the probe. This rotation has to be performed about the geometric center of the probe, indicated by the black dot in the figure. It is assumed that the source has a radially symmetric directivity characteristic, so that the amplitude and phase of the acoustic waves is equal at all microphones that lie upon a plane at a distance $h$ from the source.

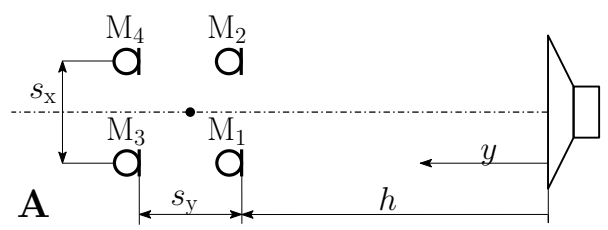

(a)

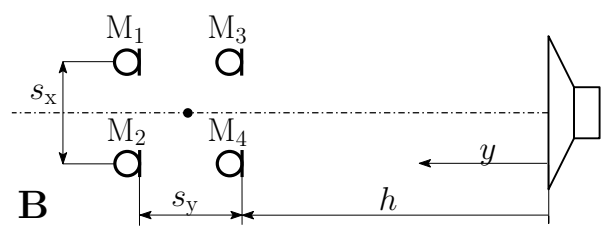

(b)

Figure 2.4: Calibration setup. (a) Configuration A. (b) Configuration B.

First, a measurement is performed in configuration $A$. Then, the probe is rotated and a measurement in configuration $B$ is carried out. The cross-spectral density matrix obtained by the first measurement in configuration $A$, is designated by $\mathbf{C}_{\mathrm{A}}^{\prime}$. Accordingly, the cross-spectral density matrix for the second measurement is designated by $\mathbf{C}_{\mathrm{B}}^{\prime}$. The prime indicates that these matrices still contain amplitude and phase errors. The measured cross-spectral density between channel $m$ and $n$ in configuration $\mathrm{A}, C_{m n}^{\prime}(\mathrm{A})$, can be expressed as the product of a complex error term and the true cross-power spectral density $C_{m n}^{(\mathrm{A})}$ :

$$
C_{m n}^{\prime(\mathrm{A})}=\hat{M}_{m} \hat{M}_{n} e^{i\left(\phi_{n}-\phi_{m}\right)} C_{m n}^{(\mathrm{A})},
$$

where $\hat{M}_{m}$ and $\hat{M}_{n}$ are the amplitude errors of microphones $m$ and $n$, and $\phi_{n}-\phi_{m}$ is the relative phase error between microphones $m$ and $n$. Normalization of this expression with the measured auto-power spectral density of channel 1 yields

$$
\frac{C_{m n}^{\prime(\mathrm{A})}}{C_{11}^{\prime(\mathrm{A})}}=\hat{M}_{m} \hat{M}_{n} e^{i\left(\phi_{n}-\phi_{m}\right)} \frac{C_{m n}^{(\mathrm{A})}}{C_{11}^{\prime(\mathrm{A})}}
$$

As $C_{11}^{\prime}(\mathrm{A})=\hat{M}_{1}^{2} C_{11}^{(\mathrm{A})}$, where $M_{1}^{2}$ is the squared amplitude error of channel 1 , the above expression can be formulated as 


$$
H_{m n}^{\prime(\mathrm{A})}=E_{m n} H_{m n}^{(\mathrm{A})}
$$

where

$$
\begin{aligned}
& H_{m n}^{\prime(\mathrm{A})}=\frac{C_{m n}^{\prime(\mathrm{A})}}{C_{11}^{\prime(\mathrm{A})}}, \\
& H_{m n}^{(\mathrm{A})}=\frac{C_{m n}^{(\mathrm{A})}}{C_{11}^{(\mathrm{A})}},
\end{aligned}
$$

and

$$
E_{m n}=\frac{\hat{M}_{m} \hat{M}_{n} e^{i\left(\phi_{n}-\phi_{m}\right)}}{\hat{M}_{1}^{2}}
$$

is element $(m, n)$ of the error matrix $\mathbf{E}$ containing the relative amplitude and phase errors. $\mathrm{H}_{m n}^{(\mathrm{A})}$ in Eq. $(2.10)$ is element $(m, n)$ of the true normalized cross-spectral matrix.

For configuration B, Eq. (2.10) becomes

$$
H_{m n}^{\prime(\mathrm{B})}=\mathrm{E}_{m n} H_{m n}^{(\mathrm{B})}
$$

Because the microphone positions are interchanged in configuration $B$, the following equality holds:

$$
H_{m n}^{(\mathrm{B})}=\frac{1}{H_{m n}^{(\mathrm{A})}} .
$$

This expression relates Eq. (2.10) with Eq. (2.14), so that one can solve for $E_{m n}$ to obtain

$$
E_{m n}=\sqrt{H_{m n}^{\prime(\mathrm{A})} H_{m n}^{\prime(\mathrm{B})}}
$$

In this way, the matrix $\mathbf{E}$ containing the relative amplitude and phase errors is obtained from the element-wise product of the two measured transfer function matrices for configurations $A$ and $B$. In matrix form, Eq. (2.16) reads:

$$
\mathbf{E}=\sqrt{\mathbf{H}^{\prime}(\mathrm{A}) \circ \mathbf{H}^{\prime}(\mathrm{B})}
$$

where the operator $\circ$ denotes the Hadamard product, indicating element-wise multiplication, the square root sign indicates taking the element-wise square root, and 


$$
\begin{aligned}
& \mathbf{H}^{\prime(\mathrm{A})}=\frac{\mathbf{C}^{\prime(\mathrm{A})}}{C_{11}^{\prime(\mathrm{A})}}, \\
& \mathbf{H}^{\prime(\mathrm{B})}=\frac{\mathbf{C}^{\prime(\mathrm{B})}}{C_{11}^{\prime(\mathrm{B})}} .
\end{aligned}
$$

With Eq. (2.17), one can readily evaluate the relative amplitude and phase errors of the probe by solely considering the first row of $\mathbf{E}$, as channel 1 was chosen to be the reference channel.

To further reduce the influence of random errors, it is proposed to spatially average matrix $\mathbf{E}$ by repeating the procedure above at multiple positions $y$, see Fig. 2.4, according to

$$
\mathbf{E}_{\mathrm{av}}=\frac{1}{N} \sum_{j=1}^{N} \mathbf{E}
$$

\subsubsection{Correction of the cross-spectral density matrix}

Once the spatially averaged matrix $\mathbf{E}_{\mathrm{av}}$, according to Eq. (2.20), containing the relative amplitude and phase errors, is known, one can employ it to correct the crossspectral matrix with which the sound intensity vector is calculated. From Eq. (2.9) and Eq. (2.13), it follows that element $(m, n)$ of the measured cross-spectral matrix can be expressed in terms of the true cross-spectral density matrix by

$$
C_{m n}^{\prime}=\hat{M}_{1}^{2} E_{m n} C_{m n}
$$

Solving for $\mathrm{C}_{m n}$, and switching to matrix form, it follows that the true cross-spectral matrix can be calculated with

$$
\mathbf{C}=\frac{1}{\hat{M}_{1}^{2}} \mathbf{E}_{\mathrm{av}}^{*} \circ \mathbf{C}^{\prime}
$$

where the star * indicates taking the element-wise reciprocal value:

$$
E_{m n}^{*}=\frac{1}{E_{m n}} .
$$

The only remaining unknown in Eq.(2.22) is the amplitude error of microphone $\hat{M}_{1}$. Determination of this quantity is only required if one is interested in absolute sound intensity levels, and can be performed with a reference microphone or with a plane wave tube. However, for purposes where only relative quantities are of interest, for instance when measuring sound absorption or localizing sources, this is not necessary. 


\subsection{Considerations on accuracy}

In this section, we discuss a few possible sources of error in the calibration method. First, a possible rotation of the probe in a plane wave field is considered. A deviation in the orientation of the probe in either one of the configurations $A$ or $B$, see Fig. 2.5, is not problematic, as long as the probe is rotated from this state about $180^{\circ}$ in the other configuration. If, in only one of the configurations, an orientation error (angle $\theta$ ) is present, significant phase errors may result. In Fig. 2.5, a rotation about a small angle $\theta$ leads to a phase difference $\Delta \phi=k \Delta x \approx k s_{x} \theta$ between microphones 1 and 2 . This implies that, for a spacing $s_{x}=20 \mathrm{~mm}$, a rotation of about $1^{\circ}$ already leads to a phase difference of $0.37^{\circ}$ at $1000 \mathrm{~Hz}$. On the contrary, the rotation-induced phase error between microphones 1 and 3 , or 2 and 4 , is much smaller, only $0.003^{\circ}$.

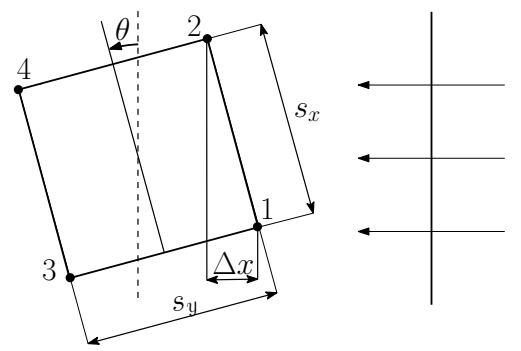

Figure 2.5: Rotation of the probe about its geometric center, plane waves are incident from the right.

Following this analysis, one should ensure that the probe rotation between configurations $\mathrm{A}$ and $\mathrm{B}$ matches $180^{\circ}$ as well as possible. That is, only allowing for a very small tolerance, say $180^{ \pm 0.3^{\circ}}$ to ensure that the maximum rotation-induced phase difference does not exceed $0.2^{\circ}$ at $1000 \mathrm{~Hz}$.

If one does not succeed in achieving such narrow tolerances, it is advisable to limit the phase calibration to those channels that are not on the same $y$-plane as the reference microphone. For the configuration shown in Fig. 2.5, this implies that only the relative phase errors of microphones 3 and 4 with respect to microphone 1 are determined. In 3 dimensions, this would be microphones 3, 4, 5, and 6, see Fig. 2.3. To determine the relative phase errors of the remaining microphones, one has to repeat the calibration procedure two times, each time with a differently oriented probe, resulting in a total of 6 series of measurements. In our setup, we used 2 machined parts to ensure that the rotation of the probe would match $180^{\circ}$. Accordingly, the results of our calibration in Sec. 2.6 were obtained with only 2 measurements.

Incidence of non-plane waves is another aspect that can lead to a reduction of the accuracy. If this is the case, the phase difference between a microphone located at $y=h$ and one located at $y=h+s_{y}$ will not exactly equal $k s_{y}$, see Fig. 2.6. Figure 2.7 shows the phase error between microphones 2 and 4 caused by spherical- instead of plane wave incidence as a function of the distance to a point source for three different 


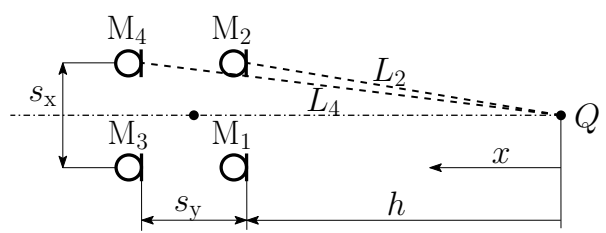

Figure 2.6: Configuration $\mathrm{A}$, in which the source is replaced with a point source $Q$.

frequencies. At $10 \mathrm{kHz}$, the phase error can easily be reduced to below $0.1^{\circ}$ by choosing a source distance $y \geq 0.32 \mathrm{~m}$.

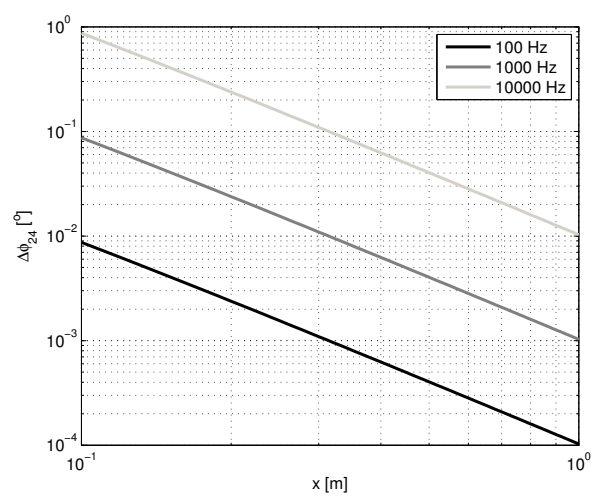

Figure 2.7: Phase error caused by spherical- instead of plane wave incidence between two microphones that are both $10 \mathrm{~mm}$ off-axis and having a spacing of $20 \mathrm{~mm}$.

A further source of error is instationarity of the environmental conditions. Although the calibration method does not require knowledge of the speed of sound or mass density of air, for validity of Eq. (2.15), it is important that the properties of the medium do not change with time. Therefore, favorable setups are those that allow a rapid switch to both measurement configurations.

\subsection{Calibration results}

The novel calibration method presented in Sec. 2.4 has been verified experimentally, using the setup shown in Fig. 2.8. In addition, a separate amplitude calibration measurement has been performed using an impedance tube. In the absence of an anechoic room, the free-field measurement setup is located in a large well-absorbing room with dimensions $6 \times 6 \times 5 \mathrm{~m}^{3}$. As other equipment was also present in this room, the setup was placed such that a minimum distance of $2 \mathrm{~m}$ to the equipment was maintained. To reduce reflections from the grid floor and a panel in the corner of the room, sheets of $50 \mathrm{~mm}$ thick melamine resin were used to partly cover these. This foam has a diffuse incidence sound absorption coefficient $\alpha_{\mathrm{S}}$ greater than 0.95 for frequencies 
above $1000 \mathrm{~Hz}$. Therefore, it is reasonable to assume free-field conditions above this frequency.

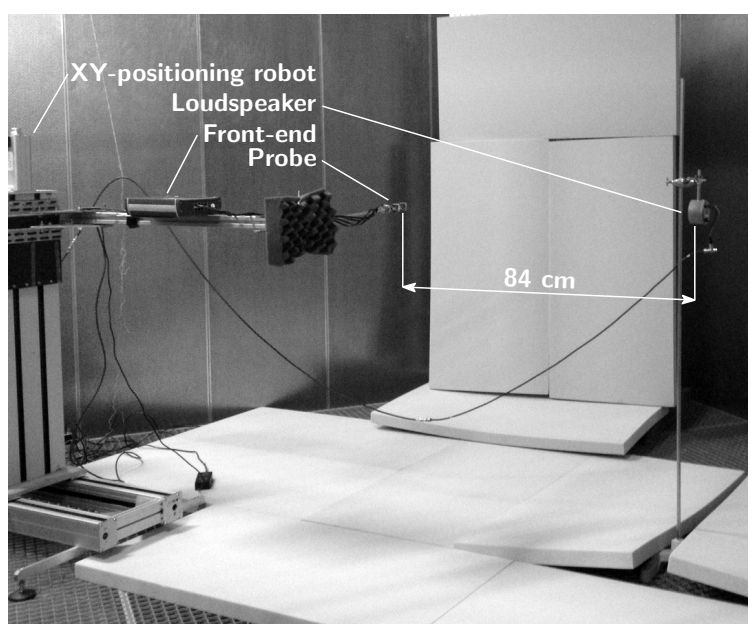

Figure 2.8: Setup for amplitude and phase calibration.

The probe to be calibrated, shown before in Fig 2.1, is mounted on a PC-controlled $x y$-positioning robot. The probe is aligned such that its direction of movement, and its geometric center, coincide with the axis of the loudspeaker, in accordance with Fig. 2.4(a). The robot has a positioning accuracy better than $1.0 \mathrm{~mm}$.

We used a small loudspeaker driven with white noise as a sound source. This loudspeaker is radially symmetric with respect to its axis and has a housing $80 \mathrm{~mm}$ in diameter. Its membrane diameter equals $23 \mathrm{~mm}$. Due to its small size, low frequencies were hardly radiated, causing the coherence between the microphone signals to fall below 0.95 for frequencies below $1300 \mathrm{~Hz}$. Correspondingly, results are shown above this frequency. Data-acquisition is realized with a 40-channel digital front-end that is connected to a PC.

The calibration measurement is performed as follows. First, 21 measurements are recorded at 21 different distances from the loudspeaker. After a $180^{\circ}$ rotation of the probe about its geometric center, this procedure is repeated. The probe moved 25 $\mathrm{mm}$ per step, so that a total distance of $0.5 \mathrm{~m}$ was covered. The initial distance of the probe $h$ to the membrane of the speaker was $0.84 \mathrm{~m}$.

The 8 acoustic pressure signals from the probe were recorded at a sample rate of $48 \mathrm{kHz}$. By using FFT-blocks of 4096 samples, we obtained a frequency resolution of 11.7 Hz. During each measurement, data was recorded during $10 \mathrm{~s}$. Including probe reversal, performing two series of 21 measurements took about $30 \mathrm{~min}$. Ambient pressure, temperature and relative humidity were monitored during the measurements, and 
did not show any changes on the monitoring device during the measurement, so that the environment can be considered stationary.

Following the procedure in Sec. 2.4, the relative amplitude and phase errors were obtained. Figure 2.9, shows the relative amplitude error vs. frequency for channels 1-4. Figure 2.10 contains the curves for channels 5-8. Channel 1 was chosen as the reference channel, and its absolute amplitude error was left undetermined as we only require a relative calibration. Therefore, the curve of channel 1 is set to a value of 1 . The gray curves represent the data obtained in the free-field, and the black curves were obtained with an impedance tube. The latter were only determined for channels 3, 5, and 7. The diameter of the impedance tube equaled $100 \mathrm{~mm}$, so that the first transversal mode is cut-on at approx. $2000 \mathrm{~Hz}$. Therefore, these results are only shown up to $1900 \mathrm{~Hz}$.

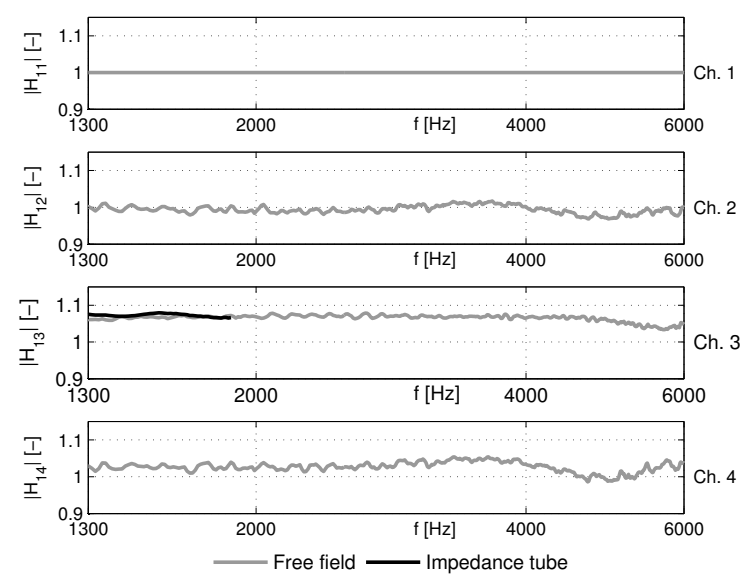

Figure 2.9: Amplitude errors for Ch. 1-4.

The curves obtained with the impedance tube agree well with those obtained with the quasi free-field method. A comparison of the results obtained with the impedance tube indicates that the accuracy of the amplitude calibration is better than $2 \%$ or $0.17 \mathrm{~dB}$ between 1300 and $1900 \mathrm{~Hz}$. All relative amplitude errors are within $\pm 10 \%$, or $0.83 \mathrm{~dB}$. These errors represent the combined effect of production variation and the whole data-acquisition chain.

Up to ca. $3000 \mathrm{~Hz}$, the amplitude errors seem to be independent of frequency. Above $3000 \mathrm{~Hz}$, some curves become distorted. As the curves of the unevenly numbered channels seem to show less distortion than those of the evenly numbered channels, we suspected that this distortion is caused by acoustic diffraction of the sound waves by the probe itself. To verify this, we simulated acoustic diffraction with an acoustic FEmodel of the probe with the FE-software package COMSOL. This simulation model represented the setup shown in Fig. 2.4. Cables, screws, and components smaller than $2 \mathrm{~mm}$ were not modeled. We performed a scattering analysis, assuming plane wave incidence. In Fig. 2.11, the magnitude of the simulated transfer function $H_{12}$ is 

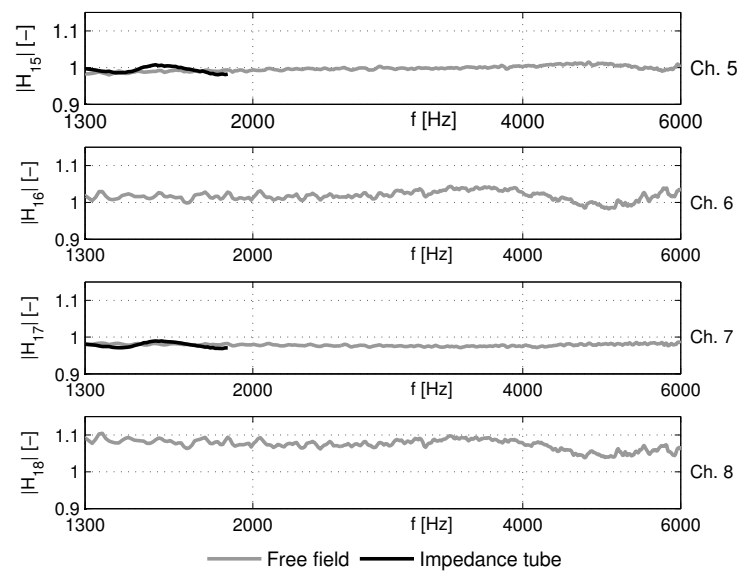

Figure 2.10: Amplitude errors for Ch. 5-8.

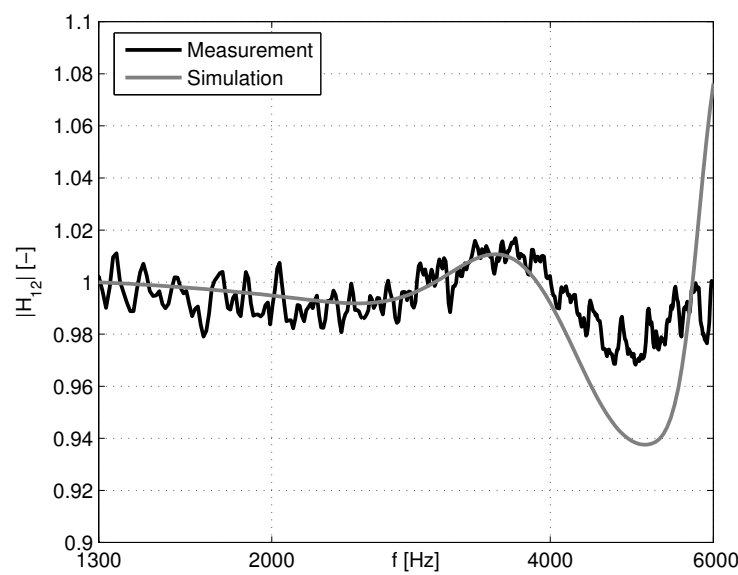

Figure 2.11: Measured and simulated amplitude error of channel 2 with respect to channel 1.

compared with the measured relative amplitude error between channels 1 and 2 . Up to $4 \mathrm{kHz}$ both curves agree very well. The deviation between the measured- and the simulated curve above $4 \mathrm{kHz}$, is likely to be caused by missing details in the model, such as the cables. The scattered wave at $4 \mathrm{kHz}$ is shown in Fig. 2.12. From this figure, it becomes clear that the main cause for scattering at this frequency is the holder of the probe, see Fig. 2.1. We conclude that the distortion of the amplitude error curves in Figs 2.9 and 2.10 is indeed caused by acoustic diffraction.

The relative phase errors are shown in Fig. 2.13 for channels 1-4 and in Fig. 2.14 for channels 5-8. The original curves (solid gray) are overlaid with a smoothed curve 


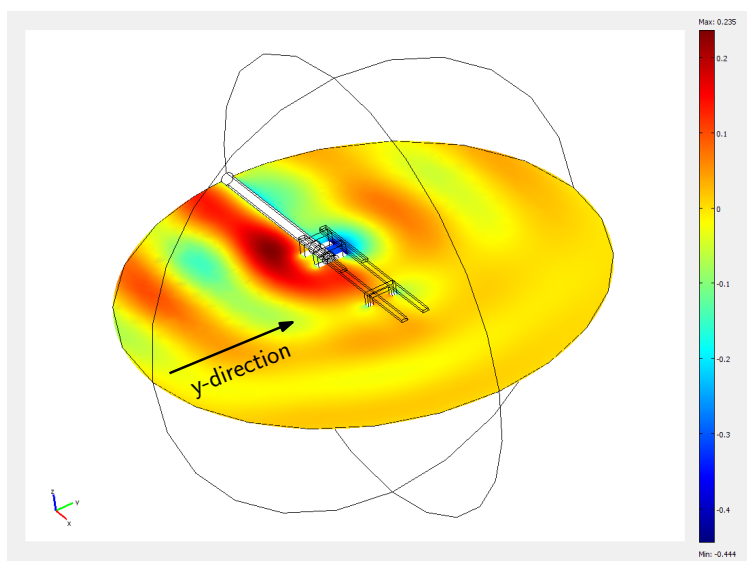

Figure 2.12: Scattered wave at $4000 \mathrm{~Hz}$. The incident plane waves have amplitude 1 [Pa] and propagate in the y-direction. In this figure, the pressure minimum (blue) is $-0.44[\mathrm{~Pa}]$, the pressure maximum (red) equals $0.24[\mathrm{~Pa}]$.

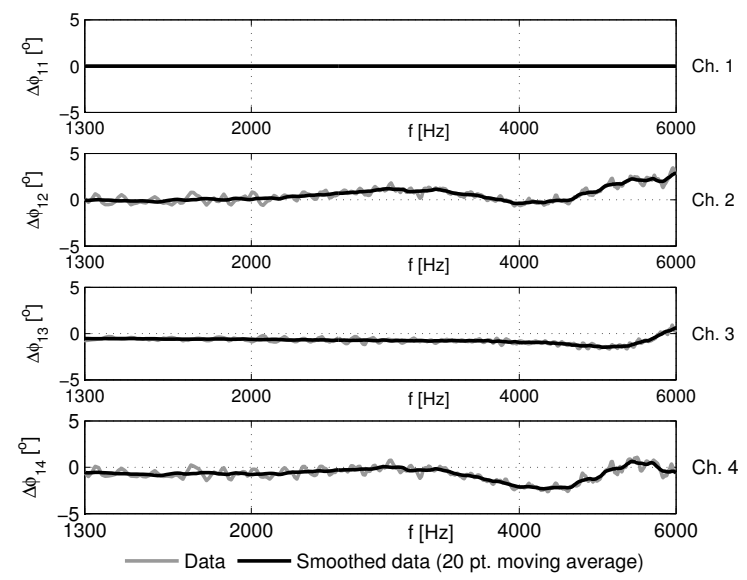

Figure 2.13: Phase errors for Ch. 1-4.

(solid black) that is obtained with a 20-point moving average filter covering all discrete frequencies in a $234 \mathrm{~Hz}$ wide band. The smoothed curve still contains random-like amplitude variations. These variations are approx. $\pm 0.2^{\circ}$.

The relative phase error curves are almost straight up to $3000 \mathrm{~Hz}$. Similar to the relative amplitude error curves, the curves become more distorted above this frequency, due to acoustic diffraction. Using the aforementioned acoustic FE-model of the probe, we also calculated the diffraction-induced phase error between channels 1 and 2. Figure 2.15 shows the measured and the simulated phase error. Although the curves do not match exactly, they certainly follow the same trend. 


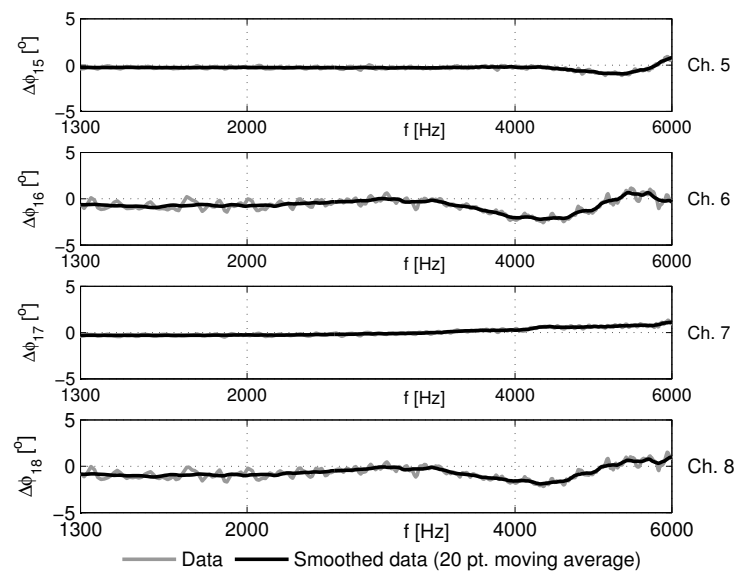

Figure 2.14: Phase errors for Ch. 5-8.

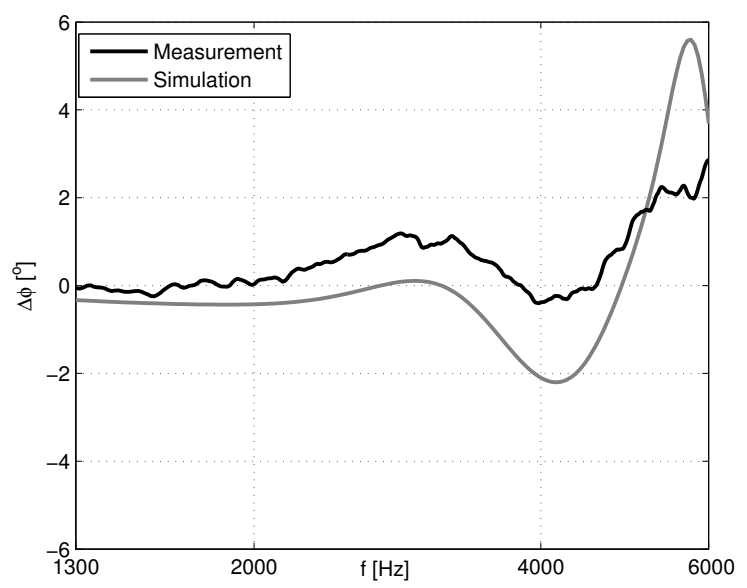

Figure 2.15: Measured and simulated phase error of channel 2 with respect to channel 1 .

Despite probe-induced diffraction, the maximum relative phase error stays under $3^{\circ}$ for frequencies up to $6000 \mathrm{~Hz}$. Below $3000 \mathrm{~Hz}$, a maximum relative phase error of $1.3^{\circ}$ is observed.

Small variations in the microphone spacing may also cause the relative phase error curves to be non-flat. Such variations lead to linear trends. If one switches to a linear frequency scale for channel 3 in Fig. 2.13, a linear trend is clearly visible. Apparently, the spacing between microphone 1 and 3 is slightly smaller than $20.0 \mathrm{~mm}$. Nevertheless, including small spacing errors and diffraction, the maximum relative phase error equals $1.3^{\circ}$ up to $3000 \mathrm{~Hz}$. Between 3000 and $6000 \mathrm{~Hz}$, this error can rise up to $3^{\circ}$. 
The curve of channel 7 in Fig. 2.14 is very flat, and is hardly distorted by diffraction. The explanation for this behavior lies in the symmetry of the probe with respect to the xy-plane, see Fig. 2.3, so that diffraction will have the same effect on channel 7 as it has on channel 1 for incidence in the y-direction. The flatness of the curve of channel 7 indicates that all used MEMS-microphones are probably tightly matched, but that diffraction reduces the degree of matching of the other microphones to microphone 1 .

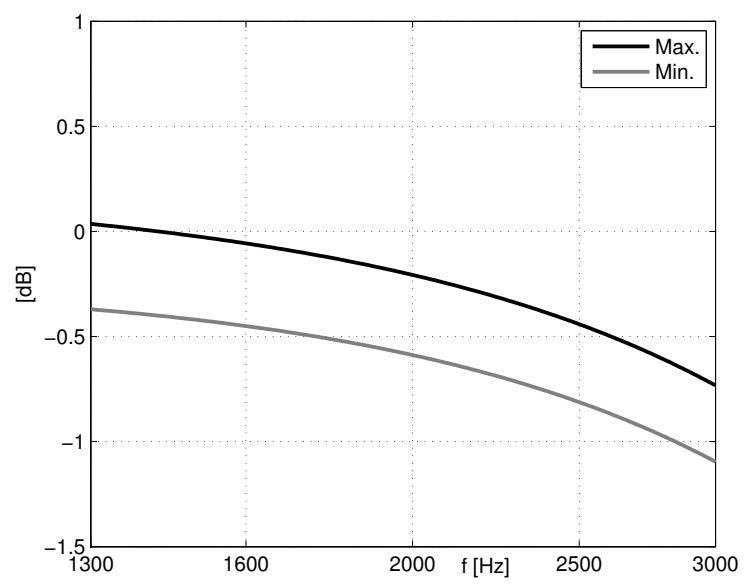

Figure 2.16: Error bounds for the sound intensity level accounting for relative amplitude errors up to $2 \%$ and phase errors up to $0.2^{\circ}$.

In Sec 2.4.1, it was shown that, using the calibration results, the measured crossspectral density matrix can be corrected. Doing so, and accounting for the remaining error after calibration of $2 \%$ in the relative amplitude and $0.2^{\circ}$ in the relative phase, one can calculate the maximum and minimum bounds of the active sound intensity. Doing so for a single component of the sound intensity vector, and following a worstcase approach, we obtained the error bounds for the sound intensity level shown in Fig. 2.16. The effect of the finite difference error $\sin (k s) / k s$ as described by Fahhy [8] is also included in this figure. The maximum error of the intensity level occurs at $3000 \mathrm{~Hz}$ and equals $-1.1 \mathrm{~dB}$. Excluding the finite difference error, the maximum error is equal to $0.3 \mathrm{~dB}$.

\subsection{Conclusions}

In this paper, a novel design for a 3D sound intensity probe is presented. It is shown that MEMS-microphones can be used to build a cost-effective, compact, and slender 3D intensity probe (8p-probe). The compactness of this probe makes it possible to perform measurements of the sound absorption coefficient close to the surface of interest. The active intensity vector is determined by considering the mean acoustic 
pressure of each side of the probe, so that each orthogonal component of the active intensity vector requires the calculation of 16 cross-spectra.

Furthermore, a novel amplitude- and phase calibration method is presented. This method can be applied for sound intensity probes that consist of multiple microphones. It is a free-field method and employs the principle of microphone interchange, known from measurement of the sound absorption coefficient in an impedance tube. Reduction of random errors is realized by repeating the measurements at different spatial positions. Using this calibration method, the relative amplitude- and phase errors in the cross-spectral density matrix can be compensated for. If absolute intensity levels are required, an additional absolute calibration of a single microphone of the probe is required.

Comparison with results obtained with an impedance tube indicates that the accuracy of the amplitude calibration is better than $2 \%$ or $0.17 \mathrm{~dB}$. By using a moving average filter, the variations of the phase error curves are reduced to $\pm 0.2^{\circ}$. The remaining amplitude- and phase errors lead to a maximum deviation of $\pm 0.3 \mathrm{~dB}$ in the sound intensity level of a single component of the intensity vector for frequencies $1300-3000 \mathrm{~Hz}$, compared to the theoretical case of a perfectly calibrated probe.

The results of the calibration measurements indicate that the probe is suitable for measuring sound intensity accurately up to approx. $3000 \mathrm{~Hz}$. Above this frequency, the amplitude- and phase errors increase due to probe-induced diffraction.

\section{References}

[1] Analog Devices: Datasheet - Omnidirectional Microphone with Bottom Port and I2S Digital Output ADMP441- available on www.analog.com, last visited 2013-05-24. Technical report, Norwood, MA, USA.

[2] ISO 10534-2:1998: Acoustics - Determination of sound absorption coefficient and impedance in impedance tubes - Part 2: Transfer-function method, 1998.

[3] D. Arnold, T. Nishida, L. Cattafesta, and M. Sheplak. A directional acoustic array using silicon micromachined piezoresistive microphones. J. Acoust. Soc. Am., 113(1):289-298, 2003.

[4] T.G.H. Basten and H.-E. de Bree. Full bandwidth calibration procedure for acoustic probes containing a pressure and particle velocity sensor. J. Acoust. Soc. Am., 127(1):264-270, January 2010.

[5] J.S. Bendat and A.G. Piersol. Engineering applications of correlation and spectral analysis. J. Wiley and Sons, New York, 1993.

[6] B.S. Cazzolato and C.H. Hansen. Errors arising from three-dimensional energy density sensing in one-dimensional sound fields. J. Sound Vib., 236(3):375-400, September 2000.

[7] J.Y. Chung and D.A. Blaser. Transfer function method of measuring in-duct acoustic properties. i. theory. J. Acoust. Soc. Am., 68(3):907-913, 1980.

[8] F.J. Fahy. Sound intensity. E \& FN Spon, London, 2nd edition, 1995. 
[9] I. Hafizovic, C.-I. Nilsen, M. Kjølerbakken, and V. Jahr. Design and implementation of a MEMS microphone array system for real-time speech acquisition. Appl. Acoust., 73(2):132-143, 2012.

[10] R. Hickling and A. Brown. Determining the direction to a sound source in air using vector sound-intensity probes. J. Acoust. Soc. Am., 129(1):219-24, 2011.

[11] F. Jacobsen and H.-E. de Bree. A comparison of two different sound intensity measurement principles. J. Acoust. Soc. Am., 118(3):1510-1517, 2005.

[12] F. Jacobsen and V. Jaud. A note on the calibration of pressure-velocity sound intensity probes. J. Acoust. Soc. Am., 120(2):830-837, 2006.

[13] A. Khenkin and J. Lewis. Application note AN-1003 rev. B - Recommendations for mounting and connecting the Analog Devices, Inc., bottom-ported MEMS microphones - available on www.analog.com, last visited 2013-05-24.

[14] E.R. Kuipers, Y.H. Wijnant, and A. de Boer. Measuring oblique incidence sound absorption using a local plane wave assumption. (submitted to Acta Acust. Acust. in May 2013). 2013.

[15] E.R. Kuipers, Y.H. Wijnant, and A. de Boer. Measuring sound absorption: considerations on the measurement of the active acoustic power. (submitted to Acta Acust. Acust. in March 2013). 2013.

[16] E.R. Kuipers, Y.H. Wijnant, and A. de Boer. Measuring the angle-dependent sound absorption coefficient with a small microphone array. In AIA-DAGA 2013 Merano, Italy. DEGA, Berlin, 2013.

[17] K.H. Miah and E.L. Hixon. Design and performance evaluation of a broadband three dimensional acoustic intensity measuring system. J. Acoust. Soc. Am., 127(4):2338-46, 2010.

[18] S. Nagata, K. Furihata, T. Wada, D. Asano, and T. Yanagisawa. A three-dimensional sound intensity measurement system for sound source identification and sound power determination by In models. J. Acoust. Soc. Am., 118(6):3691-3705, 2005.

[19] J.-C. Pascal and J.-F. Li. A systematic method to obtain 3D finite-difference formulations for acoustic intensity and other energy quantities. J. Sound Vib., 310(4-5):1093-1111, March 2008. 



\title{
Chapter 3
}

\section{A numerical study of a method for measuring the effective in situ sound absorption coefficient ${ }^{1}$}

\begin{abstract}
The accuracy of a method [Wijnant et al., "Development and application of a new method for the in-situ measurement of sound absorption", ISMA 31, Leuven, Belgium (2010)], for measurement of the effective area-averaged in situ sound absorption coefficient is investigated. Based on a local plane wave assumption, this method can be applied to sound fields for which a model is not available. Investigations were carried out by means of finite element simulations for a typical case. The results show that the method is a promising method for determining the effective area-averaged in situ sound absorption coefficient in complex sound fields.
\end{abstract}

\subsection{Introduction}

Measurement of the in situ sound absorption coefficient is hardly possible in small enclosures, such as cars or small rooms. This difficulty originates from the definition of the in situ sound absorption coefficient: it is the sound absorption coefficient for a specified angle of incidence for the in situ structure in a semi-anechoic field. See, for example, Brandão [2]. Accordingly, in situ sound absorption measurement methods are intended for measurements in semi-anechoic fields $[2,1,3,9,8]$. Exceptions are methods that employ a time-windowing technique $[7,10,11]$. However, in small enclosures, measurements at low frequencies cannot be performed as the length of the

\footnotetext{
${ }^{1}$ Reproduced from: E.R. Kuipers, Y.H. Wijnant, and A. de Boer, A numerical study of a method for measuring the effective in situ sound absorption coefficient, J. Acoust. Soc. Am. 132(3) (2012) EL236-EL242.
} 
time-window needs to be very short to gate out spurious reflections.

A measurement concept that is likely to function well in small enclosures, is the method described by Takahashi et al. [13]. Here, the normal surface acoustic impedance is measured while the sample is exposed to environmental ambient noise (EA-noise). Otsuru et al. [12] and Din et al. [5] analyzed this method in more detail, and showed that accurate results can be obtained, even at low frequencies. Otsuru et al. conclude that ensemble averaging over multiple spatially distributed incoherent sources is an effective means of reducing the undesirable effects of edge-diffracted waves and other interfering waves.

Instead, one could consider the concept of area-averaging to reduce the aforementioned effects. This is the approach followed by the measurement method discussed in this paper, as presented firstly by Wijnant et al. [14]. This method is based on a Local Plane Wave assumption, and is therefore hereafter referred to as the $L P W$-method. This method is devised for use in stationary sound fields, and generally yields the effective in situ sound absorption coefficient, being an indicator of the sound absorbing performance of an in situ structure in the actual sound field. Although the effective area-averaged in situ absorption coefficient is not directly comparable with laboratory coefficients, we believe that it is of practical value. Purposes are quality control or the evaluation of the absorbing performance of an absorber in the actual sound field, for instance, if room-acoustic performance indicators are out of specification.

In this paper, the accuracy of the LPW-method is investigated. To this purpose, we performed an acoustic finite element analysis to simulate the determination of the effective area-averaged sound absorption coefficient for a sound field with multiple reflections. Influences of the distance of the measurement surface to the surface of interest, the size of the surface area, and the surface impedance, were investigated. The results are compared with those obtained by an existing measurement method. The theory of the LPW-method is introduced in Sec. 3.2. The results of the investigations are presented and discussed in Sec. 3.3.

\subsection{Theory}

In this section, we introduce the LPW-method through a concise presentation of the theory given by Wijnant et al. [14]. The LPW-method has been devised for stationary sound fields, and therefore the theory will be shown for the case of pure tones. The objective of the LPW-method is to determine the effective area-averaged sound absorption coefficient $\alpha_{L P W}(\omega)$ of a measurement surface $S^{\prime}$ at a distance $d$ from the material surface $S_{m}$, see Fig. 3.1. It is reasonable to assume that this coefficient is an accurate estimate if $d$ is sufficiently small. Therefore, it is not necessary to have an overall sound field model with which the surface impedance at the material surface can be calculated. 
$\alpha_{L P W}(\omega)$ is defined as the ratio of the active and incident sound power with respect to surface $S^{\prime}$ :

$$
\alpha_{\mathrm{LPW}}(\omega)=\frac{\int_{S^{\prime}} \mathbf{I}_{\mathrm{ac}}(\mathbf{r}, \omega) \cdot \mathbf{n} \mathrm{d} S}{\int_{S^{\prime}} I_{\mathrm{in}}(\mathbf{r}, \omega) \mathrm{d} S},
$$

where $\mathbf{I}_{\mathrm{ac}}(\mathbf{r}, \omega)$ is the active sound intensity vector, $I_{\mathrm{in}}(\mathbf{r}, \omega)$ is the incident sound intensity perpendicular to the surface $S^{\prime}$, vector $\mathbf{r}$ indicates the spatial position, $\omega$ is the radial frequency, and the direction vector $\mathbf{n}=-\mathbf{n}_{S}$ where $\mathbf{n}_{S}$ is the surface normal. Determination of the active sound power is possible by using existing sound intensity measurement techniques [6, 4], and is therefore not discussed in this paper. It is the determination of the incident power that is addressed by the LPW-method. To this purpose, we formulated the local plane wave assumption, from which the LPW-method inherited its name: in any point on $S^{\prime}$, its location defined by $\mathbf{r}$, and in direction $\mathbf{n}$, we locally approximate the sound field by an incident plane wave with complex amplitude $A(\mathbf{r}, \omega)$ traveling towards $S_{m}$, and an oppositely directed reflected plane wave with complex amplitude $B(\mathbf{r}, \omega)$. According to this assumption, the sound pressure and particle velocity in direction $\mathbf{n}$ can be written as

$$
\begin{aligned}
P(\mathbf{r}, x, \omega) & =A(\mathbf{r}, \omega) e^{-i k x}+B(\mathbf{r}, \omega) e^{i k x} \\
\mathbf{U}(\mathbf{r}, x, \omega) \cdot \mathbf{n} & =\frac{1}{\rho_{0} c_{0}}\left[A(\mathbf{r}, \omega) e^{-i k x}-B(\mathbf{r}, \omega) e^{i k x}\right],
\end{aligned}
$$

where $\mathrm{x}$ is a spatial coordinate aligned with $\mathbf{n}, \rho_{0}$ is the density, $c_{0}$ the speed of sound, and $\mathrm{k}$ is the wavenumber. Setting $x=0$ at the point of consideration and solving for both $A(\mathbf{r}, \omega)$ and $B(\mathbf{r}, \omega)$ yields:

$$
\begin{aligned}
A(\mathbf{r}, \omega) & =\frac{1}{2}\left[P(\mathbf{r}, \omega)+\rho_{0} c_{0} \mathbf{U}(\mathbf{r}, \omega) \cdot \mathbf{n}\right], \\
B(\mathbf{r}, \omega) & =\frac{1}{2}\left[P(\mathbf{r}, \omega)-\rho_{0} c_{0} \mathbf{U}(\mathbf{r}, \omega) \cdot \mathbf{n}\right],
\end{aligned}
$$

$A(\mathbf{r}, \omega)$ and $B(\mathbf{r}, \omega)$ generally vary with position. Associating the incident sound intensity with the incident wave, the incident sound intensity becomes:

$$
I_{\mathrm{in}, \mathbf{n}, \mathrm{LPW}}(\mathbf{r}, \omega)=\frac{|A(\mathbf{r}, \omega)|^{2}}{2 \rho_{0} c_{0}} .
$$

The reflected sound intensity can be determined by replacing $A(\mathbf{r}, \omega)$ by $B(\mathbf{r}, \omega)$ in Eq. (3.6). After completion of a series of point measurements, the incident sound intensity distribution over $S^{\prime}$ is obtained. Together with the distribution of the active sound intensity, the effective in situ area-averaged sound absorption coefficient $\alpha_{L P W}(\omega)$ is calculated with Eq. (3.1). This coefficient becomes a regular in situ sound absorption coefficient for measurements in semi-anechoic sound fields where plane waves are normally incident upon a locally reacting surface. 


\subsection{Investigation of the accuracy of the LPW-method}

In this section, the accuracy of the LPW-method is investigated by applying an acoustic finite element analysis for the configuration shown in Fig. 3.1(a). This configuration is chosen for two reasons: a) a measurement with existing methods $[2,1,3,9,8,7,10,11]$ is not possible for this configuration and b) the incident intensity can be calculated analytically so that the accuracy of the LPW-method can be evaluated. The LPWmethod is applied to estimate the effective area-averaged sound absorption coefficient of the square surface section $S_{\mathrm{m}}$. The surface impedance $Z_{S}$, the side length $a$, and the distance $d$ are varied to study their effect on the accuracy.

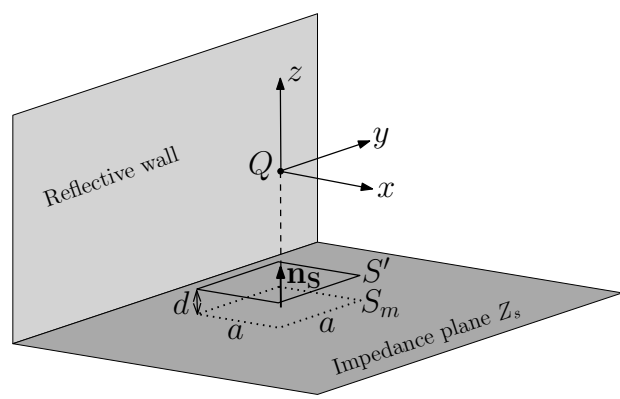

(a) Geometry of the studied configuration

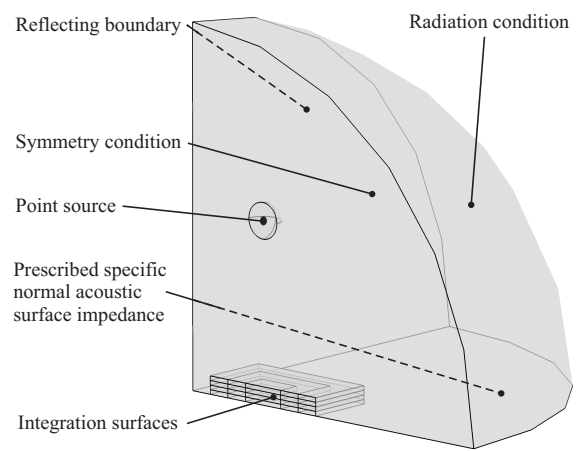

(b) Geometry of the FE-model

Figure 3.1: Configuration and FE-model: A point source $\mathrm{Q}$ is located at height $h=$ $1 \mathrm{~m}$. above a semi-infinite impedance plane. A square section with side length $a$ of this plane is defined as the material surface $S_{\mathrm{m}}$. The measurement surface $S^{\prime}$ also has side-length $a$, and has a distance $d$ to $S_{\mathrm{m}}$. A semi-infinite reflective wall is located at $x=-0.5 \mathrm{~m}$.

To demonstrate what happens if a semi-anechoic measurement method is applied to the (non-semi-anechoic) sound field studied here, we have also calculated the effective sound absorption coefficient with an existing in situ method, being the two-microphone method by Allard and Sieben [1]. This calculation is performed for a single point, $(x, y, z)=(0,0,-1) \mathrm{m}$, on the material surface $S_{\mathrm{m}}$. The acoustic pressures used for the calculation were taken at distances of $25 \mathrm{~mm},(x, y, z)=(0,0,-975) \mathrm{mm}$, and $50 \mathrm{~mm},(x, y, z)=(0,0,-950) \mathrm{mm}$, above the material surface.

The finite element model only represents half of the domain, making use of symmetry, see Fig. 3.1(b). To resemble a semi-infinite sound field, the boundary condition at the outer spherical boundary was set to a plane wave radiation condition. Preliminary simulations were carried out to determine the dimensions of the domain to ensure 
that reflections from this boundary will be negligible. The model consists of 154368 quadratic tetrahedral elements, yielding a total number of 215574 degrees of freedom. The maximum overall element size was set to $0.1 \mathrm{~m}$, resulting in a minimum of 4.8 nodes per wavelength at $1500 \mathrm{~Hz}$. In a region enclosing the integration surfaces, at least 23 nodes per wavelength are present. Spatial integration of the incident and active sound intensity is performed over the integration surfaces shown in figure 1(b). The accuracy of the numerical spatial integration was ensured by carrying out preliminary simulations for different mesh sizes of a modified model, in which the boundary condition of the plane $z=-1[\mathrm{~m}]$ was set to a radiation condition.

Simulations were performed for two values of the specific acoustic surface impedance $Z_{S}$, chosen such that they resemble a surface with a medium and low sound absorption coefficient. The first value is $Z_{S}=2 Z_{0}(1+i)$, and the second value equals $Z_{S}=20 Z_{0}$, where $Z_{0}=\rho_{0} c_{0} . Z_{S}$ is chosen to be independent of frequency so that variations of the resulting sound absorption coefficient curves are only caused by variations in the sound field. The simulations were carried out in the frequency range from 100 to $1500 \mathrm{~Hz}$, in steps of $25 \mathrm{~Hz}$. To analyze the accuracy of the LPW-method, the exact incident sound power is compared with the estimated sound power as obtained with LPW-method. The exact incident sound power is calculated by spatial integration of the incident sound intensity over surface $S_{\mathrm{m}}$, Eq. (3.7). This expression was obtained analytically by mimicking the effect of the reflective wall by a mirror source.

$$
\begin{aligned}
I_{\mathrm{in}, \mathbf{n}}\left(r_{1}, r_{2}, \omega\right)= & -\frac{h|C(\omega)|^{2}}{2 Z_{0}}\left[\frac{1}{r_{1}^{3}}+\frac{1}{r_{2}^{3}}+\cos \left[k\left(r_{1}-r_{2}\right)\right]\left(\frac{r_{1}+r_{2}}{r_{1}^{2} r_{2}^{2}}\right)+\right. \\
& \left.\sin \left[k\left(r_{1}-r_{2}\right)\right]\left(\frac{r_{1}^{2}+r_{2}^{2}}{k r_{1}^{3} r_{2}^{3}}\right)\right] .
\end{aligned}
$$

Where $C(\omega)$ is the complex amplitude of the point source so that $P\left(r_{1}, \omega\right)=\frac{C(\omega)}{r_{1}} e^{-i k r_{1}}$ for a free field, $r_{1}$ and $r_{2}$ are the respective distances to the point source and the mirror source. The estimated incident sound intensity is obtained by Eqs. (3.4) and (3.6), where $P(\mathbf{r}, \omega)$ and $U_{z}(\mathbf{r}, \omega)$ are taken from the finite element model. Both quantities are also used to calculate the active sound power flowing through surface $S^{\prime}$ by spatial integration of the active intensity in the negative $z$-direction, given by:

$$
I_{\mathrm{ac}, \mathbf{n}}(\omega)=-\frac{1}{2} \operatorname{Re}\left[P(\omega) \overline{U_{z}(\omega)}\right],
$$

where the minus sign originates from the chosen direction of $\mathbf{n}$. The distribution of the exact incident intensity $I_{\mathrm{in}, \mathbf{n}}(\omega)$ over a section of the material surface at a frequency of $1500 \mathrm{~Hz}$ is shown in Fig. 3.2(a). Note that this distribution must be independent of the surface impedance. Figures 3.2(b) and 3.2(c) show the estimated incident sound intensity distributions obtained by applying the LPW-method at a distance $d=25 \mathrm{~mm}$ (a measurement at exactly $d=0 \mathrm{~mm}$ is not possible in practice) for $Z_{S}=2 Z_{0}(1+i)$ and $Z_{\mathrm{S}}=20 Z_{0}$, respectively. The agreement between the estimated distributions in 


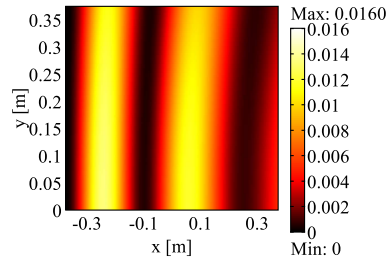

(a) Exact

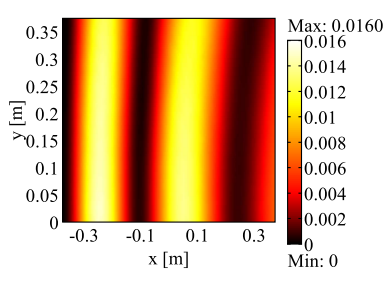

(b) Estimated, $Z_{\mathrm{S}}=2 Z_{0}(1+i)$

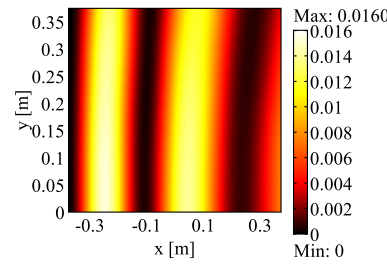

(c) Estimated, $Z_{\mathrm{S}}=20 Z_{0}$

Figure 3.2: Distribution of the exact incident sound intensity at surface $S^{\prime}$ at $d=0$ $\mathrm{mm}$, graph (a), and the estimated incident sound intensity as determined with the LPW-method for $Z_{\mathrm{S}}=2 Z_{0}(1+i)$ and $Z_{\mathrm{S}}=20 Z_{0}$, graphs (b) and (c), both at $d=25 \mathrm{~mm}$.

Figs 3.2(b) and 3.2(c) and the exact distribution in Fig. 3.2(a) is very good. Instead of comparing the estimated and exact incident sound powers, we have chosen to evaluate the estimated and exact sound absorption coefficients, being the quantities one is ultimately interested in.

Figure 3.3 shows the exact (black) and the estimated (LPW-method, blue) curves versus frequency of the effective, area-averaged, sound absorption coefficient vs. frequency for different combinations of $a$, the side length of the square integration area, and $d$, the distance. Although physically not measurable, the curves for distance $d=0$ $\mathrm{mm}$ are shown to illustrate the theoretically optimal case. The other distance values (25 and $50 \mathrm{~mm}$ ) were chosen because they are more representative for a measurement using a pp-probe. With a pu-probe, the sound pressure and the particle velocity can be measured within a few millimeters of the surface, correspondingly the curves for $d=0 \mathrm{~mm}$ may be taken to represent such a measurement. The left column of graphs was obtained for $Z_{S}=2 Z_{0}(1+i)$, the right column for $Z_{S}=20 Z_{0}$. Both top graphs also show the effective sound absorption coefficient obtained with the two-microphone method by Allard and Sieben [1].

Figures 3.3(a), 3.3(c) and 3.3(e), for $Z_{S}=2 Z_{0}(1+i)$, show that the curves of the estimated effective area-averaged sound absorption coefficient obtained with the LPW-method agree well with the exact curves for small distances $d$. The influence of the distance $d$ increases for decreasing surface integration area. One explanation for this observation is that propagation of acoustic energy towards or from the volume between the measurement surface and the material surface is not entirely captured since a part of the acoustic energy will pass through the circumferential area between both surfaces. This area is significant: for $d=50 \mathrm{~mm}$ and $a=0.25 \mathrm{~m}$, it equals $80 \%$ of the measurement surface area. It is expected that this increases for large incidence angles and for increasing ratios $\frac{d}{a}$. Therefore it is advantageous to minimize the distance $d$ between the material and measurement surface. 


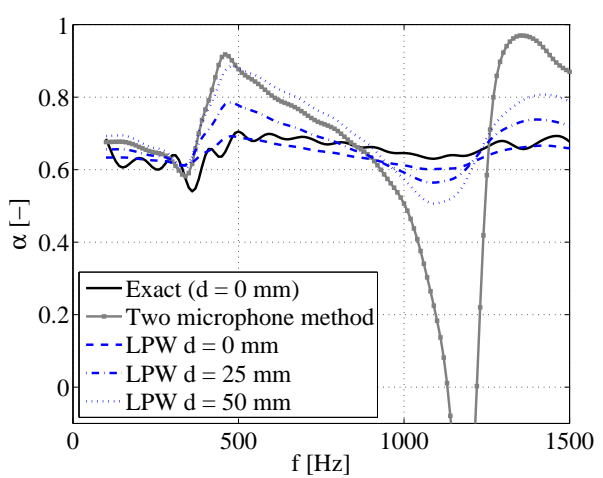

(a) $Z_{\mathrm{S}}=2 Z_{0}(1+i), a=0.25 \mathrm{~m}$

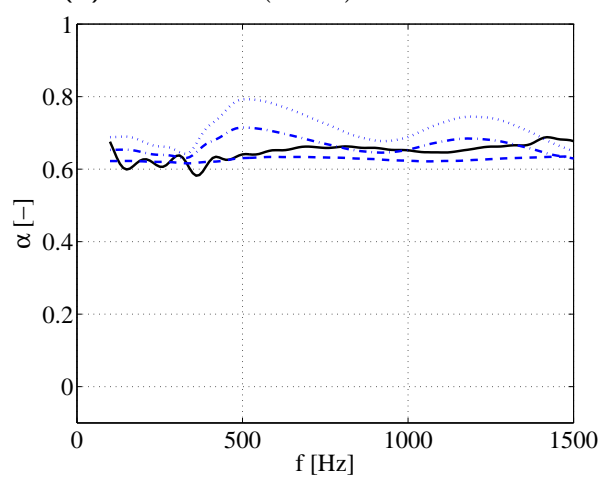

(c) $Z_{\mathrm{S}}=2 Z_{0}(1+i), a=0.50 \mathrm{~m}$

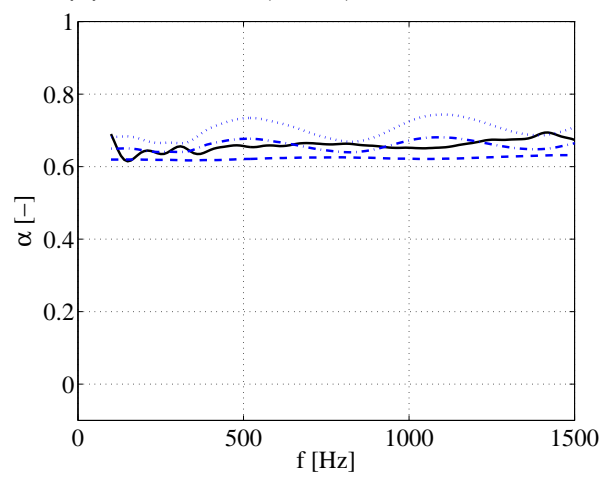

(e) $Z_{\mathrm{S}}=2 Z_{0}(1+i), a=0.75 \mathrm{~m}$

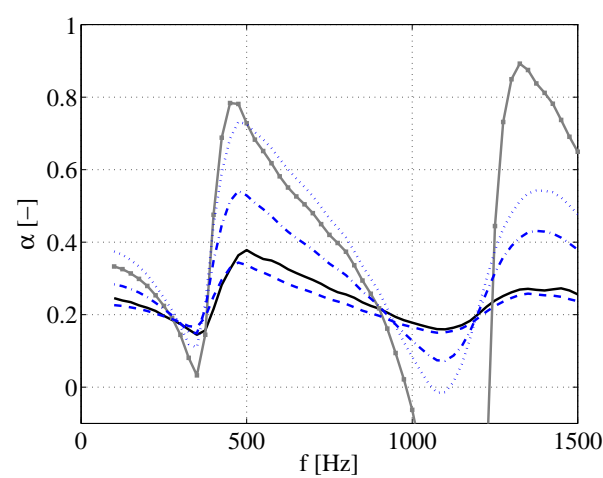

(b) $Z_{\mathrm{S}}=20 Z_{0}, a=0.25 \mathrm{~m}$

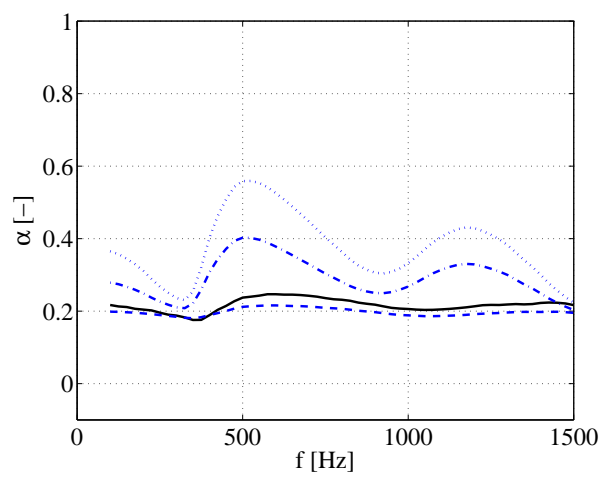

(d) $Z_{\mathrm{S}}=20 Z_{0}, a=0.50 \mathrm{~m}$

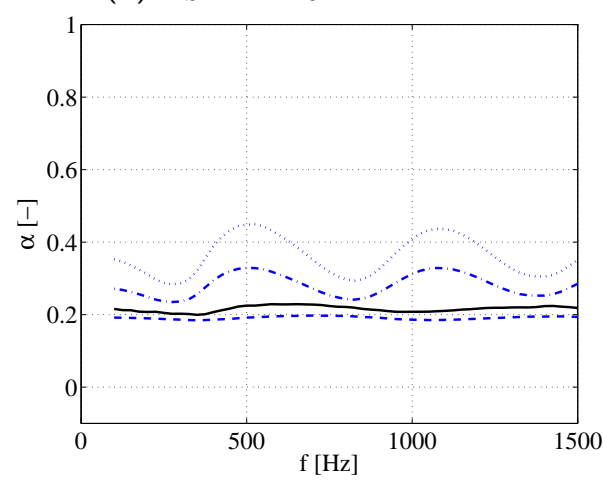

(f) $Z_{\mathrm{S}}=20 Z_{0}, a=0.75 \mathrm{~m}$

Figure 3.3: Exact (black) and estimated (LPW-method, blue) area-averaged sound absorption coefficient $\alpha$ as a function of frequency, evaluated for different integration area sizes and distances. Left column: $Z_{\mathrm{S}}=2 Z_{0}(1+i)$. Right column: $Z_{\mathrm{S}}=20 Z_{0}$. Both top figures also contain the curves obtained with the two-microphone method. 
An increase of the surface integration area (larger value of $a$ ) leads to a smoothing of the exact curves in Figure 3.3 due to area-averaging of local interferences. However, this increase leads to a reduced spatial resolution if local variations of the sound absorption coefficient are investigated. For $Z_{\mathrm{S}}=20 Z_{0}$, Figs. 3.3(b), 3.3(d) and 3.3(f), show that accurate estimates for the effective area-averaged sound absorption curves are only obtained when the distance $d$ is very small. A distance of less than $10 \mathrm{~mm}$ seems to be required in this case. Furthermore, the sensitivity of the effective areaaveraged sound absorption curves with respect to the distance $d$ and integration area is increased compared to the graphs for $Z_{\mathrm{S}}=2 Z_{0}(1+i)$ in the left column. Finally, it is observed that the effective area-averaged sound absorption curves obtained with the LPW-method lie close to the theoretical values of the sound absorption coefficient for purely normal incidence, being 0.62 and 0.18 , respectively.

The effective sound absorption coefficient obtained with the two-microphone method in Figs. 3.3(a) and 3.3(b) follows the LPW $d=50 \mathrm{~mm}$ curve partly. Interferences near $1200 \mathrm{~Hz}$ result in a negative effective sound absorption coefficient. Possible causes for this effect are a) that the actual sound field is different from the sound field assumed by the two-microphone method, and b), that interference effects cannot be reduced by area-averaging with a point-measurement. As such, the calculated surface impedance is strongly dependent on the local sound field near the two microphones.

\subsection{Conclusions}

The LPW-method is capable of estimating the incident sound intensity without a priori knowledge of the sound field, therefore an overall sound field model is not required. Acoustic finite element simulations for a typical case show that the accuracy of the method increases with decreasing distance to the surface of interest and with increasing surface area. The sensitivity of the accuracy on both parameters is influenced by the specific acoustic surface impedance. We conclude that the LPW-method, employing area-averaging, is a potentially useful technique to determine the effective area-averaged in situ sound absorption coefficient in sound fields with multiple reflections.

\section{References}

[1] J.F. Allard and B. Sieben. Measurements of acoustic impedance in a free field with two microphones and a spectrum analyzer. J. Acoust. Soc. Am., 77(4):1617-1618, 1985.

[2] E. Brandão, E. Tijs, A. Lenzi, and H.-E. de Bree. A Comparison of three methods to calculate the surface impedance and absorption coefficient from measurements under free field or in situ conditions. Acta Acust. Acust., 97(6):1025-1033, 2011.

[3] Y. Champoux, J. Nicolas, and J.F. Allard. Measurement of acoustic impedance at low frequencies. J. Sound Vib., 125(2):313-323, 1988. 
[4] H.-E. de Bree. An overview of Microflown technologies. Acta Acust. Acust., 89:163-172, 2003.

[5] N.B.C. Din, T. Otsuru, R. Tomiku, N. Okamoto, and K. Asniawaty. Measurement method with a pressure-velocity sensor for measuring surface normal impedance of materials using ensemble averaging: Comparison with other methods and its geometrical configuration. Acoust. Sci. Tech., 33(2):86-95, 2012.

[6] F.J. Fahy. Sound intensity. E \& FN Spon, London, 2nd edition, 1995.

[7] M. Garai. Measurement of the sound-absorption coefficient in situ: The reflection method using periodic pseudo-random sequences of maximum length. Appl. Acoust., 39:119-139, 1993.

[8] K. Hirosawa, K. Takashima, H. Nakagawa, M. Kon, A. Yamamoto, and W. Lauriks. Comparison of three measurement techniques for the normal absorption coefficient of sound absorbing materials in the free field. J. Acoust. Soc. Am., 126(6):3020-3027, 2009.

[9] R. Lanoye, G. Vermeir, W. Lauriks, R. Kruse, and V. Mellert. Measuring the free field acoustic impedance and absorption coefficient of sound absorbing materials with a combined particle velocity-pressure sensor. J. Acoust. Soc. Am., 119(5):2826-2831, 2006.

[10] E. Mommertz. Angle-dependent in-situ measurements of reflection coefficients using a subtraction technique. Appl. Acoust., 46(3):251-263, 1995.

[11] C. Nocke. In-situ acoustic impedance measurement using a free-field transfer function method. Appl. Acoust., 59(3):253-264, 2000.

[12] T. Otsuru, R. Tomiku, N.B.C. Din, N. Okamoto, and M. Murakami. Ensemble averaged surface normal impedance of material using an in-situ technique: preliminary study using boundary element method. J. Acoust. Soc. Am., 125(6):3784-91, 2009.

[13] Y. Takahashi, T. Otsuru, and R. Tomiku. In situ measurements of surface impedance and absorption coefficients of porous materials using two microphones and ambient noise. Appl. Acoust., 66(7):845-865, 2005.

[14] Y.H. Wijnant, E.R. Kuipers, and A. de Boer. Development and application of a new method for the in-situ measurement of sound absorption. In ISMA 31, Leuven, Belgium, 2010. 



\section{Chapter 4}

\section{Measuring sound absorption: considerations on the measurement of the active acoustic power ${ }^{1}$}

\section{Abstract}

Using a local plane wave assumption, one can determine the normal incidence sound absorption coefficient of a surface by measuring the acoustic pressure and the particle velocity normal to that surface. As the measurement surface lies in front of the material surface, the measured active and incident acoustic power will generally deviate from those at the material surface, leading to a possibly inaccurate sound absorption coefficient. This phenomenon is particularly pronounced for poorly absorbing surfaces if sound is not normally incident over the whole material surface. Based on an analytical model, it is shown that the accuracy can be improved by extending the measurement surface upon which the active acoustic power is measured. Experimental results demonstrate the usefulness of this approach, in particular for poorly absorbing surfaces.

\footnotetext{
${ }^{1}$ Reproduced from: E.R. Kuipers, Y.H. Wijnant, and A. de Boer, Measuring sound absorption: considerations on the measurement of the active acoustic power. Submitted to Applied Acoustics 2013.
} 


\subsection{Introduction}

For the measurement of the sound absorption coefficient, a large number of methods are available. These methods have in common that all of them rely on an overall sound field model. Examples are the diffuse sound field model in the reverberation room method according to ISO 354 [3] and the plane wave model in the tube-based methods according to parts 1 and 2 of ISO $10534[1,2]$. Whereas these methods are based on an overall plane wave assumption and a directional pattern, methods for measurement in a semi-free field generally rely on a typical sound field model that is more restrictive.

This sound field model consists of a semi-free field that is bounded by a planar, locally-reacting, surface, as for instance described by Attenborough [5]. It will be referred to as the reference model hereafter. A number of methods $[4,8,26,11]$ assume plane wave incidence, whereas other methods consider spherical wave incidence $[14,22,23,17,21,7,27,12]$. A different approach is applied in the in situ method by Takahashi et al. [26], further studied by Otsuru [24], and Din [11]. Although this method yields good results for a large variety of sound fields, it also relies on an overall model, comprising a planar, locally reacting surface subjected to diffuse incidence of plane waves.

The use of an overall reference model is likely to lead to inaccuracies if the actual sound field deviates from the model. The first cause for such a deviation may be the presence of reflections other than from the specimen, such as room reflections. A strategy to eliminate these, is to gate these so-called parasitic or spurious reflections out from the impulse response by employing a time-windowing technique $[14,22,23,17,12]$. For methods that do not use an impulse response, one may place the source near the surface [15] so that the relative amplitudes of the unwanted reflections are reduced.

Although such strategies can also be used to gate out, or reduce the effect of, edgediffracted waves, the use of an overall sound field model may still lead to inaccuracies, even if the measurement is performed in a semi-anechoic room. Possible causes are multiple, for instance non-omnidirectionally radiating sound sources, samples that are non-locally reacting, or samples having a non-planar surface. Fitting the reference model parameters to the measurement results will then typically lead to sound absorption coefficients that are inaccurate to a greater or lesser extent. [7, 10].

Therefore, we developed a measurement method that can deal with non-ideal sound fields. This novel measurement method employs a Local Plane Wave Assumption, and is therefore called the LPW-method. It yields the analytical sound absorption coefficient for normally incident plane waves, but also yields accurate results for nearnormal incidence, even if additional reflections are present $[28,18,20,19]$. By using the LPW-method, at a small distance from the surface of interest, one can straightforwardly determine the local, or, the area-averaged sound absorption coefficient. In 
the case of non-plane waves and not purely normal incidence, one obtains an effective sound absorption coefficient.

Numerical investigations [19] showed that accurate estimates for the normal incidence sound absorption coefficient can be obtained, even in the presence of interfering reflections. Hence, area-averaging seems effective in reducing the effects caused by such reflections. However, it was also observed that the measurement surface preferably needs to lie within $1 \mathrm{~cm}$ from the surface of interest to obtain accurate results, in particular for poorly absorbing surfaces. Measuring at such a small distance is not always possible or practical, considering, for instance, the dimensions of typical electroacoustic transducers, or non-flatness of the material surface.

In this paper, we investigate the influence of the measurement distance for a poorly absorbing surface on the measured sound absorption coefficient and propose an approach to produce accurate results for practical values of the measurement distance. To first familiarize the reader with the LPW-method, the theory, with formulations for pu- and pp-intensity probes, is presented in Section 4.2.1. This section is followed by a theoretical investigation of the sound field in front of an acoustically hard surface in Section 4.3. This investigation shows that measurements at a larger distance are possible if the measurement surface, upon which the active acoustic power is determined, is extended with the circumferential surface surrounding the volume between the material- and the measurement surface. Experimental results that demonstrate the effect of the proposed approach are shown and discussed in Section 4.4. Finally, in Section 4.5, conclusions and recommendations for further work are given.

\subsection{Theory}

\subsubsection{Theory of the LPW-method}

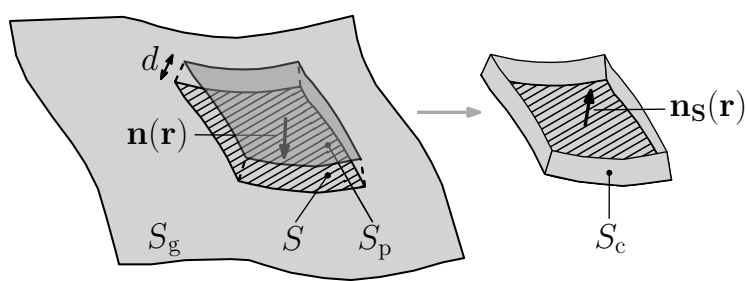

Figure 4.1: A general, arbitrarily shaped, surface $S_{\mathrm{g}}$, with the surface of interest $S$ (hatched) and $S_{\mathrm{p}}$, being the projection of $S$ at a distance $d$. $S$ and the circumferential surface $S_{\mathrm{c}}$ are shown separately for clarity. $\mathbf{n}_{\mathbf{S}}$ is the surface normal of $S$, and $\mathbf{n}$ is the surface normal vector of $S_{\mathrm{p}}$ (directed towards $S$ ).

In the following, we assume that the sound field satisfies the Helmholtz equation. Furthermore, the $e^{i \omega t}$-convention is used, i.e. $p(t)=\operatorname{Re}\left[P(\omega) e^{i \omega t}\right]$. Vector quanti- 
ties are bold-faced, and the explicit dependence of $\omega$ is omitted for quantities in the frequency domain.

The theory is presented based on the configuration shown in Fig. 4.1. We want to obtain an accurate estimate for the area-averaged normal incidence sound absorption coefficient of the surface area $S$, being a part of a general surface $S_{\mathrm{g}}$. To this purpose, we define a projected surface $S_{\mathrm{p}}$, being the projection of $S$ at a distance $d$. As the space between $S$ and $S_{\mathrm{p}}$ is generally source-free, it is reasonable to assume that the normal incidence sound absorption coefficient of $S$ can be accurately estimated if the distance between both surfaces is small and sound incidence is normal or at least near-normal.

The area-averaged sound absorption coefficient $\alpha$ is defined as the ratio of active and incident acoustic sound power

$$
\alpha=\frac{W_{\mathrm{ac}}}{W_{\mathrm{in}}}
$$

where $W_{\text {ac }}$ and $W_{\text {in }}$ are the frequency-dependent active and incident acoustic power. Formally, $\alpha$ is the effective area-averaged sound absorption coefficient if sound incidence occurs not purely normal over the surface area of interest. Both powers in Eq. (4.1) can be calculated by surface integration of their associated intensities over this surface area:

$$
\begin{aligned}
& W_{\mathrm{ac}}=\int_{S_{p}} \mathbf{I}_{\mathrm{ac}} \cdot \mathbf{n} \mathrm{d} S, \\
& W_{\mathrm{in}}=\int_{S_{p}} \mathbf{I}_{\mathrm{in}} \cdot \mathbf{n} \mathrm{d} S,
\end{aligned}
$$

where $\mathbf{I}_{\mathrm{ac}}$ is the active acoustic intensity vector, and $\mathbf{n}$ is the surface normal vector of $S_{\mathrm{p}}$, see figure 4.1. $\mathbf{I}_{\mathrm{in}}$ is the incident acoustic intensity vector, being the active acoustic intensity vector in the same position, but in a free-field, i.e. without the sample. Measurement of the active acoustic intensity in direction $\mathbf{n}$ can be performed with a pu- [9], or a pp-sound intensity probe [13]. However, the incident acoustic intensity normally cannot be determined directly from said measurement as the incident acoustic field cannot be distinguished within the acoustic field in front of the sample. To be able to estimate this quantity without the need for a separate measurement in a free-field, or without employing an overall sound field model, the acoustic field is locally approximated by employing a local plane wave assumption, as illustrated in Fig. 4.2. In any point on $S_{\mathrm{p}}$, the acoustic field is approximated by an incident plane wave with complex amplitude $A$, traveling in direction $\mathbf{n}$, and a reflected plane wave with complex amplitude $B$, traveling in the opposite direction. Accordingly, the approximated field consists of a spatial distribution of $A$ and one of $B$. 


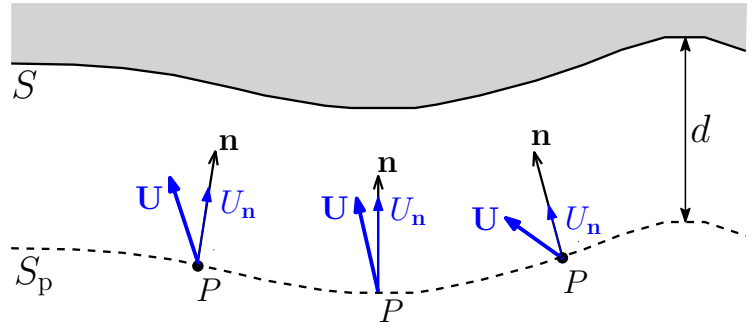

Actual field
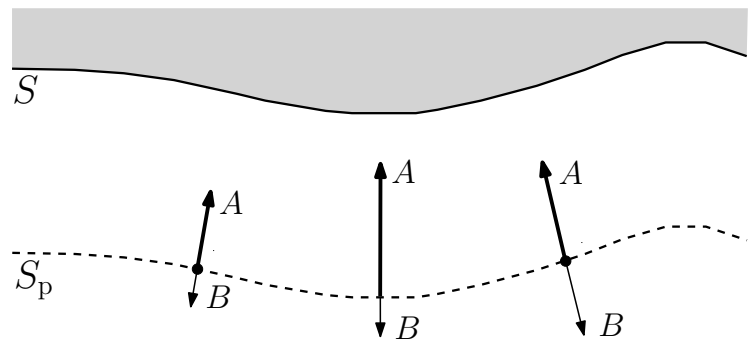

Approximated field

Figure 4.2: Upper part: arbitrary acoustic field in front of a material surface $S$; Lower part: approximated field using the local plane wave assumption.

Accordingly, in each point, defined by its spatial coordinate $\mathbf{r}$, upon $S_{\mathrm{p}}$, the complex acoustic pressure $P(\mathbf{r})$ and complex particle velocity in direction $\mathbf{n}, U_{\mathbf{n}}(\mathbf{r})=\mathbf{U}(\mathbf{r})$. $\mathbf{n}(\mathbf{r})$, can be written as

$$
\begin{aligned}
P(\mathbf{r}) & =A(\mathbf{r}, \mathbf{n})+B(\mathbf{r}, \mathbf{n}) \\
U_{\mathrm{n}}(\mathbf{r}) & =\frac{1}{\rho_{0} c_{0}}[A(\mathbf{r}, \mathbf{n})-B(\mathbf{r}, \mathbf{n})]
\end{aligned}
$$

where $k=\omega / c_{0}$ is the (real-valued) wavenumber, $c_{0}$ denotes the speed of sound, and $\rho_{0}$ the mass density of the acoustic medium. Solving for $A(\mathbf{r}, \mathbf{n})$ and $B(\mathbf{r}, \mathbf{n})$ yields:

$$
\begin{aligned}
A(\mathbf{r}) & =\frac{1}{2}\left[P(\mathbf{r})+\rho_{0} c_{0} U_{n}(\mathbf{r})\right], \\
B(\mathbf{r}) & =\frac{1}{2}\left[P(\mathbf{r})-\rho_{0} c_{0} U_{n}(\mathbf{r})\right],
\end{aligned}
$$

where the dependency on $\mathbf{n}$ has been removed, as $\mathbf{n}=\mathbf{n}(\mathbf{r})$. From Eqs. (4.6) and (4.7) it follows that $A(\mathbf{r})$ and $B(\mathbf{r})$ can be determined by measurement of the acoustic pressure and the component of the particle velocity in direction $\mathbf{n}$. Once $A(\mathbf{r})$ and $B(\mathbf{r})$ are known, the incident- and reflected acoustic intensity in directions $\mathbf{n}$ and $-\mathbf{n}$, respectively, can be calculated by 


$$
\begin{aligned}
I_{\text {in }}(\mathbf{r}) & =\frac{|A(\mathbf{r})|^{2}}{2 \rho_{0} c_{0}}, \\
I_{\text {refl }}(\mathbf{r}) & =\frac{|B(\mathbf{r})|^{2}}{2 \rho_{0} c_{0}} .
\end{aligned}
$$

The active power, given by Eq. (4.2), is determined by spatial integration of the well-known expression for the active acoustic intensity [13]:

$$
I_{\mathrm{ac}}(\mathbf{r})=\frac{1}{2} \operatorname{Re}\left[P(\mathbf{r}) \overline{U_{\mathrm{n}}(\mathbf{r})}\right] .
$$

Summarizing, using the LPW-method, the area-averaged sound absorption coefficient can be determined using a unidirectional sound intensity probe. Accordingly, formulations for pu- and pp-probes are given in the following two sections, and are presented in terms of power spectral densities, allowing a straightforward implementation on signal processing level.

\subsubsection{Formulation for a pu-probe}

As the LPW-method is already defined in terms of acoustic pressure and particle velocity, Eqs. (4.6) and (4.7) can be substituted directly into Eqs. (4.8) and (4.9) to obtain the incident and reflected acoustic intensity. Then, by following the procedure outlined in appendix 4.A, the spectral density of the incident and reflected acoustic intensity can be expressed as:

$$
\begin{array}{cl}
I_{\mathrm{in}}= & \frac{1}{4}\left[\frac{G_{\mathrm{pp}}}{\rho_{0} c_{0}}+\rho_{0} c_{0} G_{\mathrm{uu}}\right]+\frac{1}{2} \operatorname{Re}\left(G_{\mathrm{pu}}\right), \\
I_{\text {refl }}= & \frac{1}{4}\left[\frac{G_{\mathrm{pp}}}{\rho_{0} c_{0}}+\rho_{0} c_{0} G_{\mathrm{uu}}\right]-\frac{1}{2} \operatorname{Re}\left(G_{\mathrm{pu}}\right),
\end{array}
$$

where $G_{\mathrm{pp}}(\mathbf{r}), G_{\mathrm{uu}}(\mathbf{r})$, and $G_{\mathrm{pu}}(\mathbf{r})$ are single-sided auto- and cross-power spectral densities of the acoustic pressure and particle velocity. The explicit dependence on the spatial coordinate $\mathbf{r}$ is omitted here for readability. The spectral density of the active acoustic intensity [13] is:

$$
I_{\mathrm{ac}}=\operatorname{Re}\left(G_{\mathrm{pu}}\right),
$$

so that the last term in the right-hand side of Eqs. (4.11) and (4.12) equals to $\frac{1}{2} I_{\mathrm{ac}}$. One can prove that $I_{\mathrm{ac}}$ can never exceed $I_{\mathrm{in}}$, thus $\alpha \leq 1$. The active and incident acoustic power can now be calculated by spatial integration of both intensities over the projected surface $S_{\mathrm{p}}$, and the area-averaged sound absorption coefficient is readily obtained by equation (4.1). One can also use the local active- and incident acoustic intensity to calculate a local sound absorption coefficient, $\alpha_{\text {loc }}(\mathbf{r})$ given by 


$$
\begin{aligned}
\alpha_{\mathrm{loc}}(\mathbf{r}) & =1-\frac{|B(\mathbf{r})|^{2}}{|A(\mathbf{r})|^{2}} \\
& =1-\frac{I_{\mathrm{refl}}(\mathbf{r})}{I_{\mathrm{in}}(\mathbf{r})}
\end{aligned}
$$

\subsubsection{Formulation for a pp-probe}

Using the setup in Fig. 4.3, a pp-probe can be used to determine the acoustic pressure and particle velocity in the surface normal direction upon the measurement surface $S_{\mathrm{p}}$. Typically, the following equations are used to estimate the complex acoustic pressure $P(\mathbf{r})$ and the complex particle velocity $U_{n}(\mathbf{r})$ at the probe center [13]:

$$
\begin{aligned}
P(\mathbf{r}) & \approx \frac{1}{2}\left[P_{1}(\mathbf{r})+P_{2}(\mathbf{r})\right], \\
U_{n}(\mathbf{r}) & \approx \frac{i}{\rho_{0} \omega s}\left[P_{2}(\mathbf{r})-P_{1}(\mathbf{r})\right],
\end{aligned}
$$

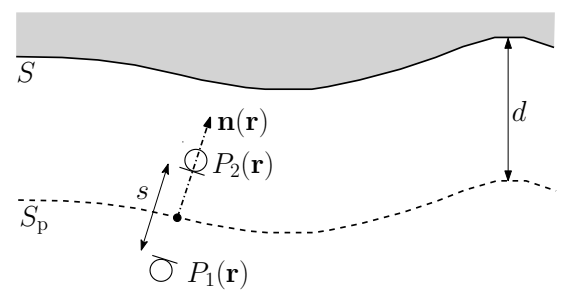

Figure 4.3: pp-probe with microphone spacing $s$.

where $s$ is the microphone spacing, and $P_{1}(\mathbf{r})=P\left(\mathbf{r}-\frac{s}{2} \mathbf{n}\right)$ and $P_{2}(\mathbf{r})=P\left(\mathbf{r}+\frac{s}{2} \mathbf{n}\right)$, where $\mathbf{r}$ is the spatial coordinate of the probe center. By substitution of Eqs. (4.15) and (4.16) in Eqs. (4.13) and (4.11), the spectral density of the active and incident acoustic intensity becomes:

$$
\begin{aligned}
I_{\mathrm{ac}, \mathrm{FD}}= & \frac{-\operatorname{Im}\left(G_{12}\right)}{\rho_{0} \omega s}, \\
I_{\mathrm{in}, \mathrm{FD}}= & \frac{1}{16 \rho_{0} c_{0}(k s)^{2}} \times \\
& \left\{\left[(k s)^{2}+4\right]\left[G_{11}+G_{22}\right]+\right. \\
& \left.2\left[(k s)^{2}-4\right] \operatorname{Re}\left(G_{12}\right)-8 k s \operatorname{Im}\left(G_{12}\right)\right\},
\end{aligned}
$$

where $G_{11}, G_{22}$, and $G_{12}$ are single-sided power spectral densities of the acoustic pressure signals $p_{1}(t)$ and $p_{2}(t)$, and the subscript $\mathrm{FD}$ indicates that both intensities are calculated using the finite-difference approximation for the particle velocity acc. 
Eq. (4.16).

For sound incidence in the direction of the axis of the pp-probe, one can derive a different formulation. In line with the local plane wave assumption, we can relate the complex acoustic pressures $P_{1}(\mathbf{r})$ and $P_{2}(\mathbf{r})$ to $A(\mathbf{r})$ and $B(\mathbf{r})$ as follows:

$$
\begin{aligned}
& P_{1}(\mathbf{r})=A(\mathbf{r}) e^{i k s / 2}+B(\mathbf{r}) e^{-i k s / 2}, \\
& P_{2}(\mathbf{r})=A(\mathbf{r}) e^{-i k s / 2}+B(\mathbf{r}) e^{i k s / 2},
\end{aligned}
$$

After solving for $A(\mathbf{r})$ and $B(\mathbf{r})$, substitution into Eqs. (4.8) and (4.9), application of the procedure in Appendix 4.A, one obtains the spectral densities of the incident and reflected intensity:

$$
\begin{aligned}
I_{\text {in }} & =\frac{G_{11}+G_{22}-2 \operatorname{Re}\left[G_{12} e^{-i k s}\right]}{4 \rho_{0} c_{0} \sin ^{2}(k s)}, \\
I_{\text {refl }} & =\frac{G_{11}+G_{22}-2 \operatorname{Re}\left[G_{12} e^{i k s}\right]}{4 \rho_{0} c_{0} \sin ^{2}(k s)},
\end{aligned}
$$

where the dependence on $\mathbf{r}$ is again omitted. By evaluating the complex acoustic pressure and particle velocity in terms of $A(\mathbf{r})$ and $B(\mathbf{r})$ at the probe center, and using Eq. (4.10), it follows that the spectral density of the active acoustic intensity equals

$$
I_{\mathrm{ac}}=\frac{-\operatorname{Im}\left(G_{12}\right)}{\rho_{0} c_{0} \sin (k s)}
$$

Eq. (4.23) matches with Eq. (11) in [25] for the active acoustic intensity in a plane wave sound field in a duct. For $k s<<1$, the term $\sin (k s)$ may be replaced by $k s$, and, as expected, Eq. (4.17) is obtained again.

The effect of using the $\sin (k s)$-formulation in Eqs. (4.21) and (4.23) versus the FD-formulation in Eqs. (4.17) and (4.18) is clearly visible in Fig. 4.4. In this figure the sound absorption curves are shown for both formulations, for normal plane wave incidence, and a microphone spacing $s=20 \mathrm{~mm}$. The FD-curves rapidly deviate from the exact value $(\alpha=0.5)$ with increasing frequency. Of course, for normal incidence, the $\sin (k s)$-curves are exact, except at $8.6 \mathrm{kHz}$ where a singularity occurs.

This singularity is caused by the presence of the $\sin ^{2}(k s)$-term in the denominator of the incident acoustic intensity in Eq. (4.21) and occurs if the wavelength equals twice the microphone spacing $s$. One may, of course, choose a smaller microphone spacing, but the sensitivity to phase-mismatch errors at low frequencies will increase, 
similar to measurement of the active acoustic intensity with a pp-probe [13]. For the FD-formulation, the absolute error may exceed 0.01 for frequencies above $1500 \mathrm{~Hz}$.

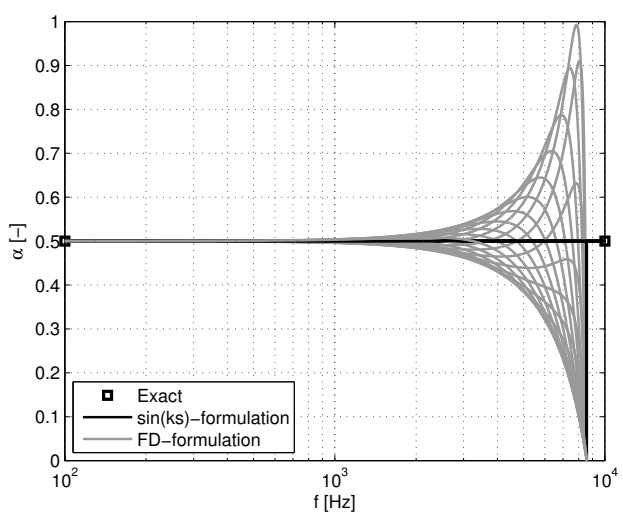

Figure 4.4: Sound absorption coefficient determined using the FD- and the $\sin (k s)$ formulation for normal incidence. Curves are calculated for 20 different phases of the reflected wave where the phase of the incident wave remained constant. Parameters: magnitudes of the complex amplitude of the incident and reflected wave: $1 \mathrm{~Pa}$, and $\frac{1}{2} \sqrt{2} \mathrm{~Pa} . \rho_{0}=1.2 \mathrm{~kg} / \mathrm{m}^{3}, c_{0}=343 \mathrm{~m} / \mathrm{s}$, and $s=20 \mathrm{~mm}$.

Although the $\sin (k s)$-formulation was derived for incidence in the direction of the ppprobe, similar calculations showed that this formulation leads to an absolute error of less than 0.01 for all frequencies below $5000 \mathrm{~Hz}$ even at an incidence angle of $10^{\circ}$. Considering that the LPW-method is applied for normal or near-normal incidence, we have chosen to use the $\sin (k s)$-formulation and have therefore applied Eqs. (4.21) and (4.23) in the preparation of the experimental results shown in Section 4.4 of this paper.

A somewhat more general comparison of the $\sin (k s)$ - and FD-formulations for obliquely incident plane waves is given in Appendix 4.B.

\subsection{Analysis of the sound field in front of an acoustically hard surface}

Previously [19], numerical investigations were performed to investigate the accuracy of the LPW-method. It was found that the accuracy increases with decreasing distance of the measurement surface to the material surface. A high accuracy over the whole simulated frequency range up to $1500 \mathrm{~Hz}$ was reached if the acoustic pressure and particle velocity were both determined within $1 \mathrm{~cm}$ from the material surface.

Furthermore, it was found that the accuracy decreased if the ratio $R_{\mathrm{S}}=A_{\mathrm{p}} / A_{\mathrm{c}}$ of the area $A_{\mathrm{p}}$ of the projected surface to the area $A_{\mathrm{c}}$ of the circumferential surface 
decreased. This effect was more pronounced when the material surface had a high acoustic surface impedance. From these observations, it is expected that the flow of acoustic power through the circumferential area $S_{c}$, see Figure 4.1, can be significant, particularly for poorly absorbing material surfaces. To investigate this hypothesis, we have analyzed the following theoretical example.

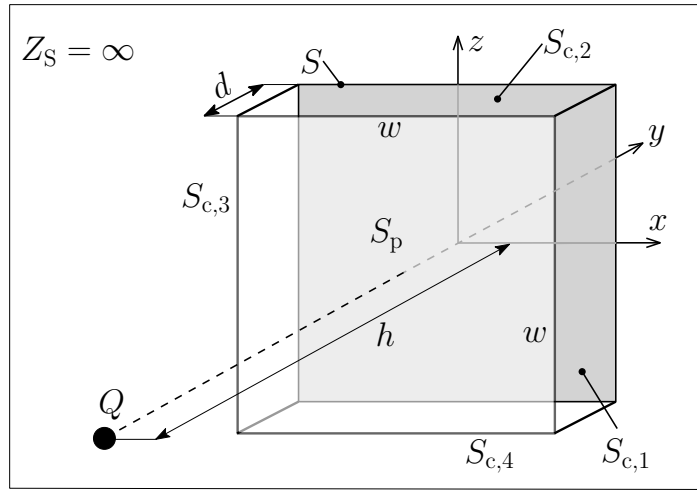

Figure 4.5: Point source $Q$ located in front of an acoustically hard surface (white). Upon this surface, a material surface area $S$ (dark-gray) is defined; its projected surface at distance $d$ is $S_{\mathrm{p}}$. The $x$ - and $z$-axis both lie upon $S$, whereas the $y$-axis points into the material.

We consider a semi-free field bounded by a planar material surface with infinite acoustic surface impedance $Z_{\mathrm{S}}$, subjected to incident sound generated by a point source, see Fig. 4.5. In this case, the (area-averaged) sound absorption coefficient of the material surface area $S$ equals zero per definition. Following a mirror-source approach, the sound field can be calculated analytically. The area-averaged effective sound absorption coefficient was determined analytically for a square surface area $S_{\mathrm{p}}$ with dimensions $w \times w=256 \times 256 \mathrm{~mm}^{2}$ for different distances $d$ and a source distance $h=1 \mathrm{~m}$. It is shown in Fig. 4.6 for three different values of the distance $d$.

Although one would expect values near zero in Fig. 4.6, values of $\alpha$ up to 0.37 can be obtained at low frequencies if the distance $d$ is $5 \mathrm{~cm}$. The cause for this behavior lies in the fact that there is a net outflow of acoustic power through the circumferential surface, as illustrated in Fig. 4.7.

To obtain an accurate estimate of the area-averaged sound absorption coefficient of $S$, we have to include the active acoustic power passing through the circumferential surface. I.e., we use the acoustic power balance for the source-free volume between $S_{\mathrm{p}}$ and $S$ :

$$
W_{\mathrm{ac}}=W_{\mathrm{ac}, \mathrm{p}}+\sum_{j=1}^{4} W_{\mathrm{ac}, \mathrm{c}, j},
$$




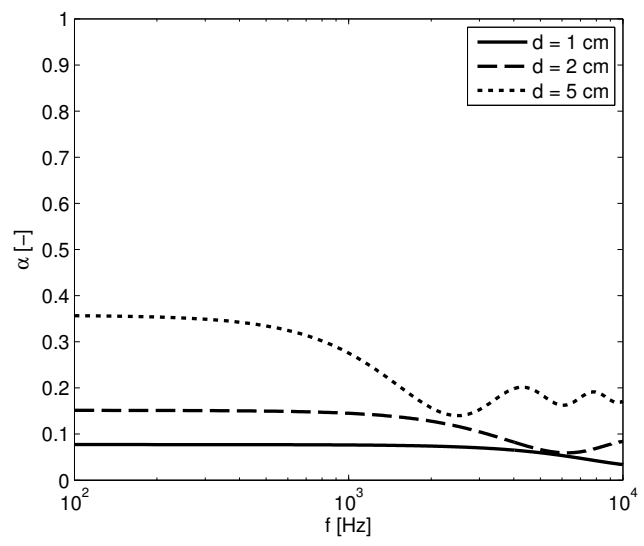

Figure 4.6: Analytical area-averaged effective sound absorption coefficient of a plane measurement surface, at distance $d$ from a plane acoustically hard surface, irradiated by a point source at a distance of $1 \mathrm{~m}$.
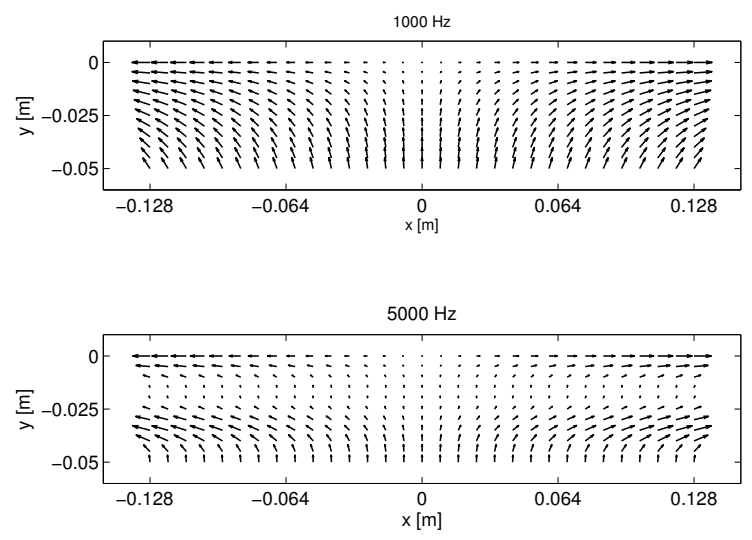

Figure 4.7: Distribution of the active acoustic intensity over the $x y$-plane within 5 $\mathrm{cm}$ from the material surface. Upper graph: $1000 \mathrm{~Hz}$. Lower graph: $5000 \mathrm{~Hz}$. The material surface is located at the line $y=0 \mathrm{~m}$.

where $W_{\text {ac }}$ is the active acoustic power absorbed by the material surface $S$, and the other powers are defined acc. Fig. 4.8. If measured accurately, $W_{\text {ac }}$ must equal zero, and thus $\alpha=0$.

As the contribution of the active acoustic power passing through the whole circumferential surface can be accounted for in this way, the question arises whether this approach should also be followed for the acoustic power that is incident upon this surface. For normal or near-normal incidence, it is expected that the contribution of the power incident upon $S_{\mathrm{c}}, W_{\mathrm{in}, \mathrm{c}}$, will be small compared to the power $W_{\mathrm{in}, \mathrm{p}}$ incident upon $S_{\mathrm{p}}$. To verify this, the analytical expressions for both powers were derived: 


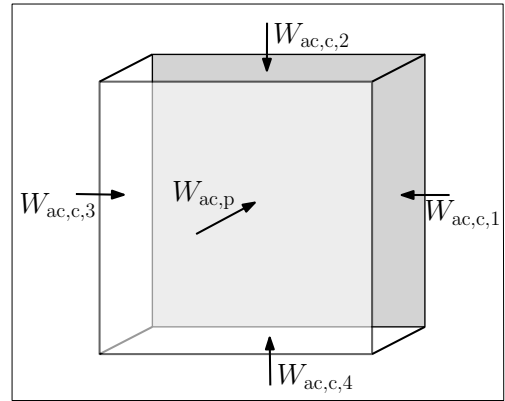

Figure 4.8: Active acoustic powers of each surface; each power is positive in the directions shown.

$$
\begin{gathered}
W_{\mathrm{in}, \mathrm{c}}=\frac{4|C|^{2}}{\rho_{0} c_{0}}\left\{\operatorname{atan}\left[\frac{2 h}{\sqrt{2 w^{2}+4 h^{2}}}\right]-\right. \\
\left.\operatorname{atan}\left[\frac{2(h-d)}{\sqrt{2 w^{2}+4(h-d)^{2}}}\right]\right\}, \\
W_{\mathrm{in}, \mathrm{p}}=\frac{2|C|^{2}}{\rho_{0} c_{0}} \operatorname{atan}\left[\frac{w^{2}}{2(h-d) \sqrt{2 w^{2}+4(h-d)^{2}}}\right],
\end{gathered}
$$

where $C$ is the complex amplitude of the acoustic pressure of a point source, as in $P(r, \omega)=\frac{C}{r} e^{-i k r}$ with $r=\sqrt{x^{2}+(y+h)^{2}+z^{2}}$. By evaluating these expressions, the ratio $W_{\text {in,c }} / W_{\text {in,p }}$ can be calculated. This ratio is a measure of the relative contribution of power incident upon the circumferential surface $S_{c}$. Fig. 4.9 shows this ratio for two source distances: $h=0.5 \mathrm{~m}$ and $h=1 \mathrm{~m}$. As expected, the relative contribution of $W_{\text {in,c }}$ decreases for an increasing source distance $h$. Furthermore, an approximately linear dependency on $d$ can be observed.

The measurements described in Section 4.4 were all performed with $d=0.02 \mathrm{~m}$ and $h=1 \mathrm{~m}$. According to Fig. 4.9, $W_{\text {in,c }}$ then equals ca. $4 \%$ of $W_{\text {in,p. }}$. Correspondingly, $\alpha$ will overestimate the area-averaged effective sound absorption coefficient of $S$ by ca. $4 \%$ if $W_{\text {in,c }}$ is neglected. Although this percentage is significant, for poorly absorbing material surfaces having a sound absorption coefficient below 0.25 , the absolute error will remain below 0.01 . In such cases, where the source distance is sufficiently large, it is justified to ignore the contribution of the acoustic power that is incident upon the circumferential surface.

Therefore, for the measurement of poorly absorbing surfaces using the configuration shown in Fig. 4.5, we propose to determine the active acoustic power upon $S_{\mathrm{p}}$ and $S_{\mathrm{c}}$, and determine the incident acoustic power upon $S_{\mathrm{p}}$ only. 


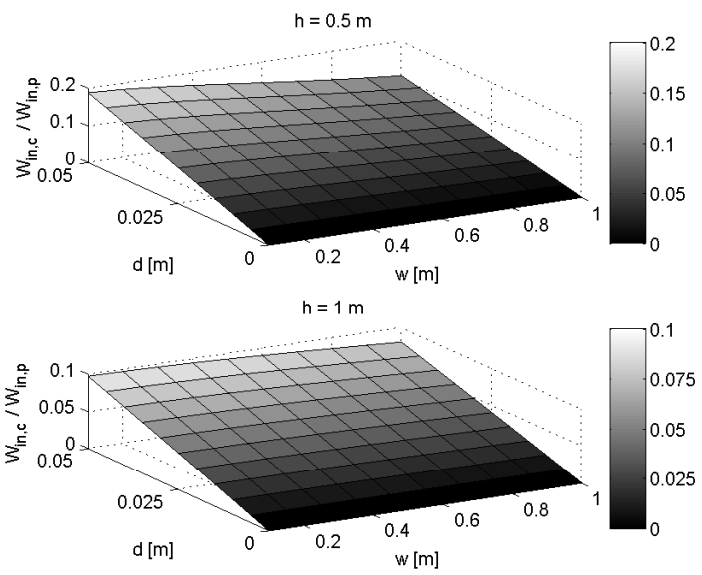

Figure 4.9: Ratio of $W_{\mathrm{in}, \mathrm{c}}$ and $W_{\mathrm{in}, \mathrm{p}}$, as a function of $w$ and the distance $d$.

\subsection{Experiments}

\subsubsection{Introduction}

In this chapter, the LPW-method is applied to determine the area-averaged normal incidence sound absorption coefficient of a poorly- and a well-absorbing surface. The effect of the proposed extension of the measurement surface, upon which the active acoustic power is determined, is investigated. In addition, the influence of the area of the measurement surface is analyzed.

\subsubsection{Aluminum plate}

The first sample is a $10 \mathrm{~mm}$ thick aluminum plate with dimensions $125 \times 74.5 \mathrm{~cm}$. The plate was positioned vertically in a well-absorbing, but not anechoic, room with approximate dimensions $6 \times 6 \times 5 \mathrm{~m}$. The measurement was performed with a newly developed 3D pp-probe, consisting of $4 \mathrm{pp}$ sound intensity probes each having 2 MEMSmicrophones spaced $20 \mathrm{~mm}$ apart, see Fig. 4.10. These omnidirectional microphones (ADMP441, Analog Devices, $4.7 \times 3.8 \times 1.0 \mathrm{~mm}$ ) offer a signal-to-noise ratio of $61 \mathrm{~dB}(\mathrm{~A})$ and have a dynamic range of $87 \mathrm{~dB}$. Data acquisition is performed using a 40-channel front-end and a PC.

The advantage of using very small microphones is that the acoustic center of a single microphone can be placed at only $10 \mathrm{~mm}$ from the plate surface while having sufficient play to avoid any collisions during movement of the probe. Despite the slenderness of the electronic prints and the spacers, calibration measurements showed that some diffraction occurs between 4 and $6 \mathrm{kHz}$. This diffraction is probably caused by the holder upon which the prints are mounted.

The measurement of the active acoustic intensity upon the four parts of the cir- 


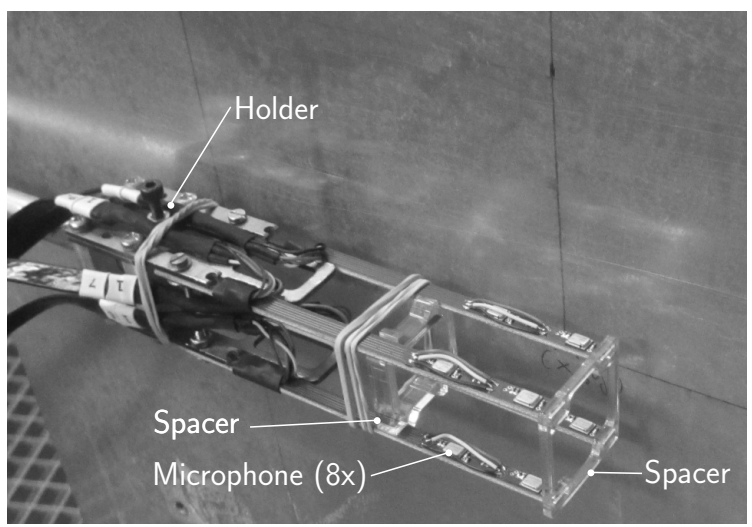

Figure 4.10: 3D sound intensity probe in front of an aluminum plate.

cumferential surface was performed using the four microphones of the probe that are nearest to the plate. As an example, Fig. 4.11 shows how microphones $M_{3}$ and $M_{4}$ are used to determine the active intensity upon $S_{\mathrm{c}, 3}$.

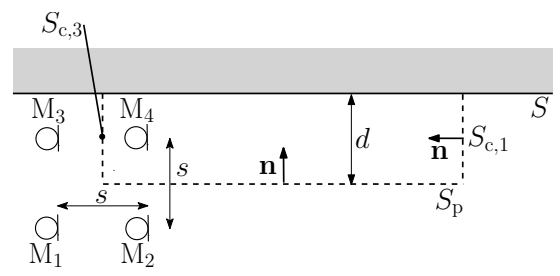

Figure 4.11: Schematic top view of 3D intensity probe in front of a planar surface.

A square measurement grid of $21 \times 21$ points with dimensions $256 \times 256 \mathrm{~mm}$ was defined upon the plate, resulting in a point spacing of $12.8 \mathrm{~mm}$. An automated scanning system with a positioning accuracy better than $1 \mathrm{~mm}$ was used to move the probe along over the surface of the plate. To approximate a point source, a small Eurofysica loudspeaker (membrane diameter $23 \mathrm{~mm}$, mounted in a cylindrical housing with a diameter of $80 \mathrm{~mm}$ ) was chosen as a sound source. This speaker was driven by white noise in wide frequency band, but due to its small dimensions, it hardly radiated sound at frequencies below $1 \mathrm{kHz}$. As a consequence, results are not shown below this frequency.

The source was positioned at $1 \mathrm{~m}$ from the plate, and oriented such that normal incidence occurs at the geometric center of the measurement region. Temperature, ambient pressure and relative humidity were recorded at the start of the scanning session. At each grid point a measurement of $10 \mathrm{~s}$ at a sample rate of $48 \mathrm{kHz}$ was taken. The data was processed in data blocks of 4096 points, with $80 \%$ overlap. The 
frequency resolution $\Delta f$ of all results equals $11.7 \mathrm{~Hz}$.

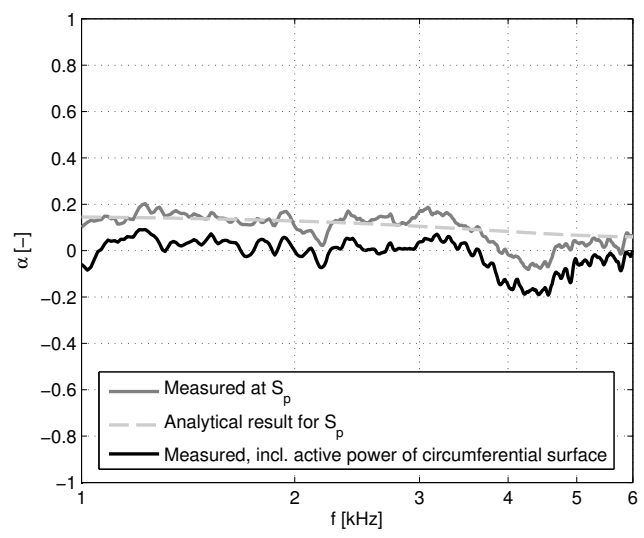

Figure 4.12: Area-averaged effective sound absorption coefficient of an aluminum plate.

Figure 4.12 shows the area-averaged sound absorption coefficient, determined using Eqs. (4.21) and (4.23). If the flow of active acoustic power through the circumferential area is not accounted for, the solid gray curve is obtained. This curve matches the theoretical, dashed gray, curve for $d=0.02 \mathrm{~m}$ taken from Fig. 4.6 quite well.

The black curve in Fig. 4.12 shows the same result, but now the measurement of the active acoustic power was extended with the circumferential surface. Up to $3.5 \mathrm{kHz}$, this curve represents zero sound absorption on average, as expected. The variations of both curves may be caused by edge-diffracted waves, acoustic radiation induced by modal response of the plate, or room reflections. Although the room is well-absorbing, such reflections could be induced by large mechanical equipment located in the room. The interferences caused by these phenomena may give rise to negative active acoustic power at some frequencies, therefore negative absorption values are present.

The black curve in Fig. 4.13 shows the active acoustic power flowing into $S_{\mathrm{p}}$. The gray curve represents the active acoustic power flowing out of the circumferential surface, i.e. oppositely to the definition in Fig. 4.8. Theoretically, for an acoustically hard material surface, both curves should coincide. This is approximately the case up to ca. $3 \mathrm{kHz}$; however, above this frequency, the active power flowing into $S_{\mathrm{p}}$ rapidly decreases and even becomes negative. As a result, the sound absorption curves in Fig. 4.12 show a dip between 3.5 and $5 \mathrm{kHz}$. The occurrence of negative active acoustic power in Fig. 4.13 can possibly be explained by amplitude and phase errors caused by the aforementioned diffraction between 4 and $6 \mathrm{kHz}$ of the probe. Jacobsen [16] found that measurement of the active acoustic intensity in reactive sound fields is very sensitive to such errors. 
Although not explicitly noticeable, the gray curve in Fig. 4.13 may be influenced by probe diffraction effects as well. A further possible source of inaccuracy of the active acoustic power flowing through the circumferential surface is the spatial integration of the active acoustic intensity. This integration becomes inaccurate when the variation of the active acoustic intensity with the $y$-coordinate cannot be represented by a linear function anymore between $y=0$ and $y=d$. Looking at Fig. 4.7, this will already be the case for frequencies starting at a frequency somewhat below $5000 \mathrm{~Hz}$ if $d=20 \mathrm{~mm}$.

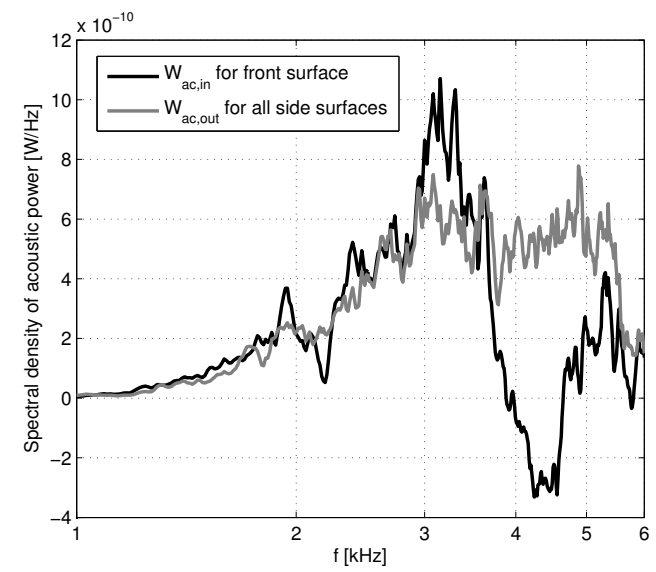

Figure 4.13: Active acoustic power flowing into $S \mathrm{p}$ and out of the side surfaces.

The influence of the dimensions of the projected surface was investigated by performing the same analysis as above, but for reduced surface areas, i.e. reduced point sets. Fig. 4.14 shows the area-averaged effective sound absorption coefficient for three different sizes of $S_{\mathrm{p}}$. This graph clearly illustrates that a larger surface leads to fewer variations in the sound absorption curve. The same behavior was observed in [19]. The explanation for this effect is that interferences (room reflections, diffracted waves) are averaged out more strongly as the surface area increases. All three curves in Fig. 4.14 represent the theoretical value $\alpha=0$ up to $3.5 \mathrm{kHz}$, on average, quite well.

\subsubsection{Foam sheet}

As a second example, an experiment was performed for a $50 \mathrm{~mm}$ thick sheet of melamine resin foam. Its dimensions are $625 \times 1250 \mathrm{~mm}$, and it was attached to the previously analyzed $10 \mathrm{~mm}$ thick aluminum plate using double-sided adhesive tape. The measurement procedure was identical to the procedure described in the preceding section. Figure 4.15 shows the area-averaged effective sound absorption coefficient for three cases: 1) only for the projected surface $S_{\mathrm{p}}$ using the $\sin (k s)$-formulation, 2) as proposed in section 4.3 with the extension of $S_{\mathrm{p}}$ with $S_{\mathrm{c}}$ for the active acoustic power using the $\sin (k s)$-formulation for both surfaces, and 3) with the extension, but using the FD-formulation for $S_{\mathrm{c}}$ and the $\sin (k s)$-formulation for $S_{\mathrm{p}}$. The latter curve 


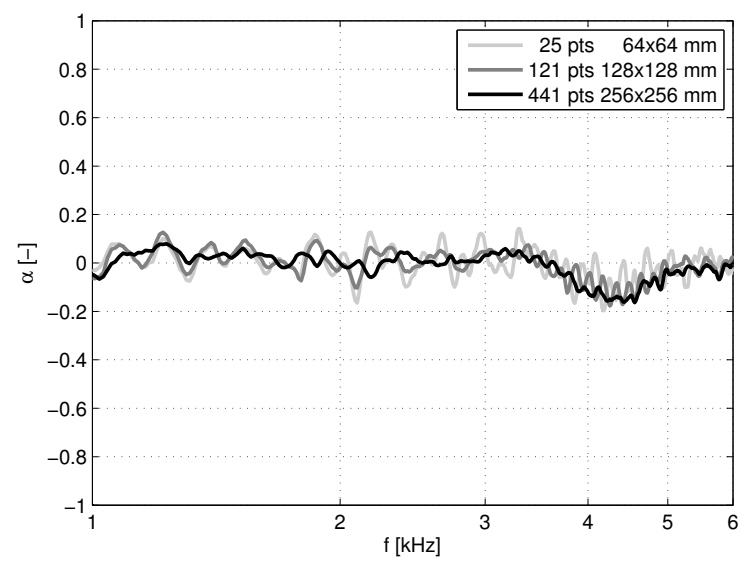

Figure 4.14: $\alpha$ for three different surface areas.

is included as the $\sin (k s)$-formulation becomes inaccurate for combinations of large incidence angles and high frequencies, see Appendix 4.B.

The difference between the black curve for $S_{\mathrm{p}}$ and those for $S_{\mathrm{p}}$ and $S_{\mathrm{c}}$, is smaller than observed for the aluminum plate. This can be explained by the orientation of the active acoustic intensity vector. This vector will mostly be parallel to the circumferential surface for a well-absorbing surface subjected to near-normal incidence, and hence the amount of active power passing through the circumferential surface is relatively less important. Furthermore, it is observed that the FD-formulation indeed leads to a different curve at frequencies exceeding $3 \mathrm{kHz}$.

Figure 4.16 shows the area-averaged effective sound absorption coefficient for three different sizes of surface $S_{\mathrm{p}}$ where the active acoustic power flowing through the circumferential surface was determined using the FD-formulation. As observed for the aluminum plate, the curves become smoother with increasing surface area. The lowering of the curves with decreasing surface area is probably caused by the variation of the angle of incidence over the surface. The smallest surface area experiences almost only normal incidence, whereas for the largest surface area the incidence angle reaches up to $7^{\circ}$, resulting in a somewhat different sound absorption coefficient.

The dips in the curves at approximately $2.27 \mathrm{kHz}$, and a similar one at $6.08 \mathrm{kHz}$ (not shown) are somewhat atypical for the sample under analysis. To investigate their cause, the local absorption coefficient $\alpha_{\text {loc }}$ acc. Eq. (4.14) was determined for all grid points for both frequencies and mapped spatially in Figs. 4.17 and 4.18. 


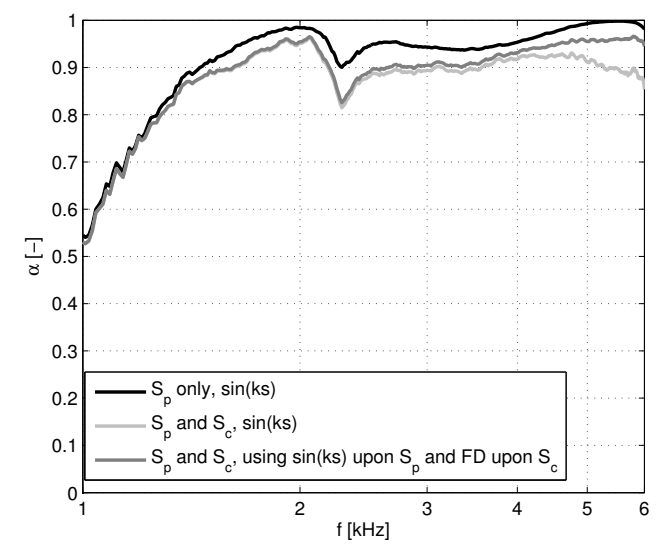

Figure 4.15: Area-averaged effective sound absorption coefficient of an area of $256 \times 256$ $\mathrm{mm}$ of a rigidly backed foam sheet.

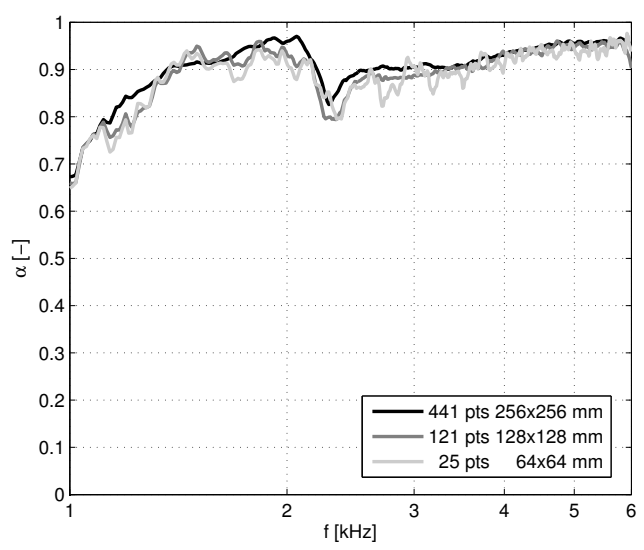

Figure 4.16: Influence of the surface area.

Both figures, but particularly Fig. 4.18, indicate that absorption locally deviates in the vertically oriented zone coinciding with with one strip of adhesive tape that was used to attach the foam. Inspection of the foam after the measurement revealed that it had locally loosened from the adhesive tape. Hence, a small cavity may have been present during the measurements, leading to local change of the sound absorption coefficient. The spatial extent of the absorption deviation is much larger at $2273 \mathrm{~Hz}$ than at 6082 $\mathrm{Hz}$. This might be related to the acoustical resolution, being dependent on the wavelength. By performing normal incidence sound absorption coefficient measurements for a sample within the affected zone and for a sample outside this zone, in a plane wave tube, it was verified that the variation in the local sound absorption coefficient was not caused by a variation of the material properties of the foam itself. 


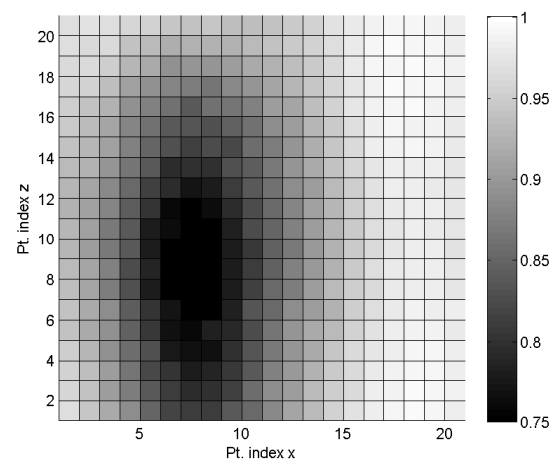

Figure 4.17: $\alpha_{\text {loc }}$ at $2273 \mathrm{~Hz}$

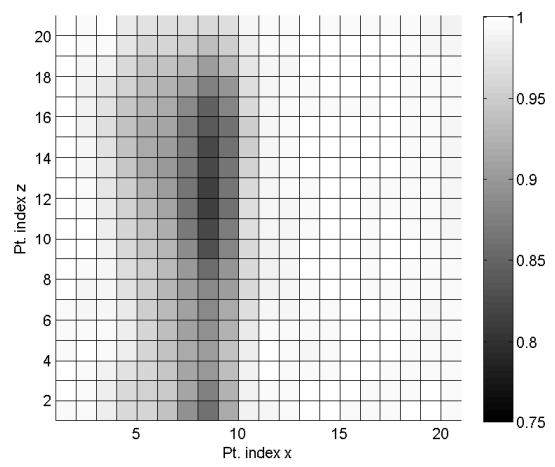

Figure 4.18: $\alpha_{\text {loc }}$ at $6082 \mathrm{~Hz}$

\subsection{Conclusions and further work}

In this paper, application of the LPW-method for sound absorption measurements is presented. Formulations of the LPW-method for pu- and pp-probes are given. It is shown that the area-averaged effective sound absorption coefficient increasingly rapidly deviates from the theoretical value with increasing distance from the material surface for an acoustically hard surface. It is proposed to compensate for this effect by additionally measuring the active acoustic power that passes through the circumferential surface.

In the determination of the active acoustic power passing through the circumferential surface, the FD-formulation should be preferred over the $\sin (k s)$-formulation as the active acoustic intensity vector generally is not oriented normally or near-normally to the circumferential surface. Furthermore, at the circumferential surface, the measurement grid should be sufficiently dense to avoid spatial integration errors. This requirement theoretically confines the usable frequency range to ca. $4-5 \mathrm{kHz}$ for an acoustically hard surface with the chosen set-up, provided that diffraction of the probe is absent as it may lead to amplitude and phase errors.

Experimental sound absorption measurement of a thick aluminum plate confirms the effectiveness of the proposed approach. The accuracy of the effective area-averaged sound absorption coefficient is increased for this sample. Experimental results for a foam sample showed that the proposed extension is less important for well-absorbing surfaces

Finally, we recommend that further investigations with respect to amplitude and phase errors be included in future work and that in situ measurements are conducted to gather experience with the method presented in this paper. 


\section{Acknowledgements}

The authors would like to thank CAE-Systems, Gütersloh, Germany, for supplying the prints with the MEMS-microphones. In addition, the support of the Engineering Fluid Dynamics group at the University of Twente during the experiments is gratefully acknowledged.

\section{A Formulations in terms of power spectral densities}

The process of switching from a formulation in terms of single-sided spectra to one in terms of single-sided power spectral densities is elucidated in this appendix. We start with Eq. (4.10) in which the dependency on the spatial coordinate $\mathbf{r}$ is omitted for briefness:

$$
I_{\mathrm{ac}}=\frac{1}{2} \operatorname{Re}(P \bar{U}) .
$$

This expression is based on the convention $p(t)=\operatorname{Re}\left(P e^{i \omega t}\right)$ and $u(t)=\operatorname{Re}\left(U e^{i \omega t}\right)$. In these conventions, the complex spectra $P, U$, and $I_{\mathrm{ac}}$ are single-sided Fourier transforms. To obtain the single-sided power spectral density (PSD) of the active acoustic intensity, we use the definition for the single-sided cross-power spectral density given by Bendat and Piersol [6, p.55]:

$$
G_{x y}(f)=\lim _{T \rightarrow \infty} \frac{2}{T} \mathrm{E}\left[\overline{X_{k}(f, T)} Y_{k}(f, T)\right] .
$$

where $X_{k}(f, T)$ and $Y_{k}(f, T)$ are the double-sided finite Fourier transforms over the $k^{\text {th }}$ record of length $T$. To be able to apply this expression, Eq. (4.28) must first be formulated in terms of double-sided spectra. Following Parseval's Identity, $P=2 P_{\mathrm{ds}}$, $U=2 U_{\mathrm{ds}}$, and $I_{\mathrm{ac}}=2 I_{\mathrm{ac}, \mathrm{ds}}$ where the subscript ${ }_{d s}$ denotes a double-sided spectrum. Eq. (4.28) then becomes:

$$
I_{\mathrm{ac}, \mathrm{ds}}=\operatorname{Re}\left(\overline{P_{\mathrm{ds}}} U_{\mathrm{ds}}\right),
$$

where the conjugation order has been reversed. The power spectral density of $I_{\mathrm{ac}, \mathrm{ds}}(\mathbf{r})$ is now obtained by application of Eq. (4.29):

$$
\begin{aligned}
\lim _{T \rightarrow \infty} \frac{2}{T} \mathrm{E}\left\{I_{\mathrm{ac}, \mathrm{ds}}\right\} & =\lim _{T \rightarrow \infty} \frac{2}{T} \mathrm{E}\left\{\operatorname{Re}\left[\overline{P_{\mathrm{ds}}} U_{\mathrm{ds}}\right]\right\} \\
& =\operatorname{Re}\left[\lim _{T \rightarrow \infty} \frac{2}{T} \mathrm{E}\left\{\overline{P_{\mathrm{ds}}} U_{\mathrm{ds}}\right\}\right] \\
& =\operatorname{Re}\left[G_{\mathrm{pu}}\right],
\end{aligned}
$$


where the latter expression is generally simply expressed as: $I_{\mathrm{ac}}=\operatorname{Re}\left[G_{\mathrm{pu}}\right]$ [13]. Therefore, the relation between the single-sided spectra $P$ and $U$, and the single-sided cross-power spectral density is:

$$
\bar{P} U \approx 2 G_{\mathrm{pu}} .
$$

where the approximate equal sign can be replaced with an equal sign, under the assumption that the $G_{\mathrm{pu}}$ is obtained by taking the average of a sufficient number of measurements of an ergodic process. The above procedure may be followed to re-formulate any similar product in terms of single-sided power spectral densities.

\section{B Accuracy of measurement of the active acoustic intensity for oblique incidence}

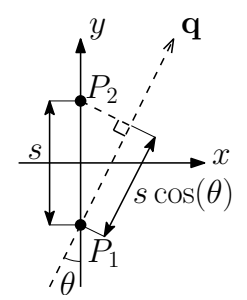

Figure 4.19: A unidirectional pp-probe (microphones represented by the two black dots) oriented at an angle $\theta$ with respect to the propagation direction $\mathbf{q}$ of a plane wave.

Equation (4.23) for the active acoustic intensity using the $\sin (k s)$-formulation, is exact for a set of two plane waves, traveling in direction $\mathbf{n}$ and $-\mathbf{n}$. In this appendix, the accuracy of this expression for oblique incidence is analyzed for the case of a single plane wave with complex amplitude $C$, propagating at an angle $\theta$ with respect to the $y$-axis, see Fig. 4.19. The acoustic pressure and particle velocity can be written as:

$$
\begin{aligned}
P & =C e^{-i k[x \sin (\theta)+y \cos (\theta)]}, \\
U_{y} & =\frac{\cos (\theta)}{Z_{0}} C e^{-i k[x \sin (\theta)+y \cos (\theta)]} .
\end{aligned}
$$

The true active acoustic intensity associated with this wave in the $y$-direction is equal to:

$$
I_{\text {ac,true }}=\frac{|C|^{2}}{2 \rho_{0} c_{0}} \cos (\theta) .
$$

Using the $\sin (k s)$-formulation in Eq. (4.23), the estimate for the active acoustic intensity becomes: 


$$
I_{\mathrm{ac}}=\frac{|C|^{2}}{2 \rho_{0} c_{0}} \frac{\sin [k s \cos (\theta)]}{\sin (k s)} .
$$

Defining the relative error of $I_{\mathrm{ac}}$ as $\varepsilon_{\sin (\mathrm{ks})}=\left(I_{\mathrm{ac}}-I_{\mathrm{ac}, \text { true }}\right) / I_{\mathrm{ac}, \text { true }}$, one obtains:

$$
\varepsilon_{\sin (\mathrm{ks})}=\frac{\sin [k s \cos (\theta)]}{\sin (k s) \cos (\theta)}-1 .
$$

Similarly, for the finite-difference (FD) formulation, using Eq. (4.17), it becomes:

$$
\varepsilon_{\mathrm{FD}}=\frac{\sin [k s \cos (\theta)]}{k s \cos (\theta)}-1 .
$$

Figure 4.20 shows both relative errors as a function of frequency and incidence angle for a pp-probe with a microphone spacing of $20 \mathrm{~mm}$. Whereas the FD-formulation leads to an underestimation, the $\sin (k s)$-formulation overestimates the active acoustic intensity. For a combination of normal incidence and high frequencies, the $\sin (k s)$ formulation is more accurate than the FD-approach. At large angles of incidence and high frequencies the opposite holds.

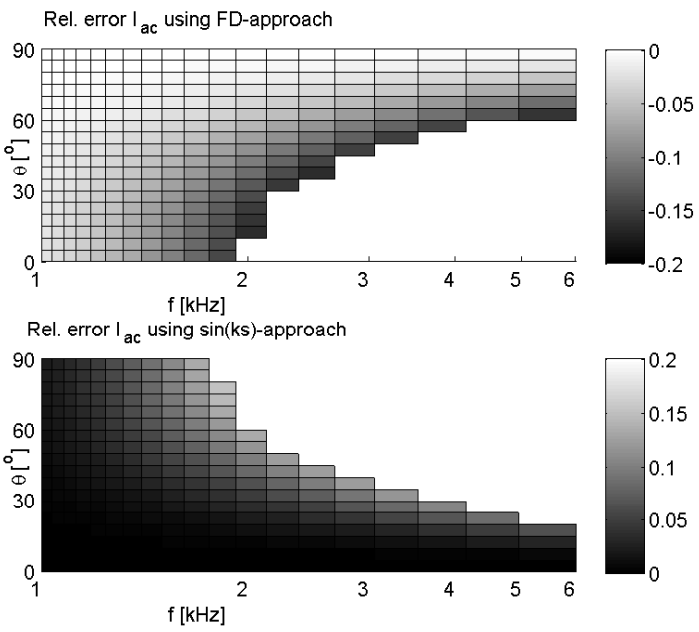

Figure 4.20: Rel. error $\varepsilon_{\mathrm{FD}}$ and $\varepsilon_{\sin (\mathrm{ks})}$ of the active acoustic intensity vs. frequency and incidence angle for the FD-formulation (upper graph) and the $\sin (k s)$-formulation (lower graph). Data omitted for relative errors greater than \pm 0.2 .

\section{References}

[1] ISO 10534-1: Acoustics - Determination of sound absorption coefficient and impedance in impedance tubes - Part 1: Method using standing wave ratio, 1996. 
[2] ISO 10534-2:1998: Acoustics - Determination of sound absorption coefficient and impedance in impedance tubes - Part 2: Transfer-function method, 1998.

[3] ISO 354:2003: Acoustics - Measurement of sound absorption in a reverberation room, 2003.

[4] J.F. Allard and B. Sieben. Measurements of acoustic impedance in a free field with two microphones and a spectrum analyzer. J. Acoust. Soc. Am., 77(4):1617-1618, 1985.

[5] K. Attenborough. Propagation of sound above a porous half-space. J. Acoust. Soc. Am., 68(5):1493-1501, 1980.

[6] J.S. Bendat and A.G. Piersol. Engineering applications of correlation and spectral analysis. J. Wiley and Sons, New York, 1993.

[7] E. Brandão, E. Tijs, A. Lenzi, and H.-E. de Bree. A Comparison of three methods to calculate the surface impedance and absorption coefficient from measurements under free field or in situ conditions. Acta Acust. Acust., 97(6):1025-1033, 2011.

[8] Y. Champoux, J. Nicolas, and J.F. Allard. Measurement of acoustic impedance at low frequencies. J. Sound Vib., 125(2):313-323, 1988.

[9] H.-E. de Bree. An overview of Microflown technologies. Acta Acust. Acust., 89:163-172, 2003.

[10] P. Dietrich, M. Aretz, M Müller-Trapet, J. van Gemmeren, and M. Vorländer. Uncertainty factors in the determination of acoustic reflection factors with pu-probes. In DAGA 2012, pages 325-326, Darmstadt, 2012. DEGA, Berlin.

[11] N.B.C. Din, T. Otsuru, R. Tomiku, N. Okamoto, and K. Asniawaty. Measurement method with a pressure-velocity sensor for measuring surface normal impedance of materials using ensemble averaging: Comparison with other methods and its geometrical configuration. Acoust. Sci. Tech., 33(2):86-95, 2012.

[12] G. Dutilleux, T.E. Vigran, and U.R. Kristiansen. An in situ transfer function technique for the assessment of the acoustic absorption of materials in buildings. Appl. Acoust., 62:555-572, 2001.

[13] F.J. Fahy. Sound intensity. E \& FN Spon, London, 2nd edition, 1995.

[14] M. Garai. Measurement of the sound-absorption coefficient in situ: The reflection method using periodic pseudo-random sequences of maximum length. Appl. Acoust., 39:119-139, 1993.

[15] K. Hirosawa, K. Takashima, H. Nakagawa, M. Kon, A. Yamamoto, and W. Lauriks. Comparison of three measurement techniques for the normal absorption coefficient of sound absorbing materials in the free field. J. Acoust. Soc. Am., 126(6):3020-3027, 2009.

[16] F. Jacobsen. A note on finite difference estimation of acoustic particle velocity. $J$. Sound Vib., 256(5):849 - 859, 2002.

[17] R. Kruse. Application of the two-microphone method for in-situ ground impedance measurements. Acta Acust. Acust., 93:837 - 842, 2007.

[18] E.R. Kuipers, Y.H. Wijnant, and A. de Boer. Theory and application of a new method for the in-situ measurement of sound absorption. In DAGA 2011, pages 723-724, Düsseldorf, 2011. DEGA, Berlin.

[19] E.R. Kuipers, Y.H. Wijnant, and A. de Boer. A numerical study of a method for measuring the effective in situ sound absorption coefficient. J. Acoust. Soc. Am., 132(3):EL236-42, 2012.

[20] E.R. Kuipers, Y.H. Wijnant, and A. de Boer. In situ sound absorption measurement: investigations on oblique incidence. In DAGA 2012, number 3, pages 351-352, Darmstadt, 2012. DEGA, Berlin. 
[21] R. Lanoye, G. Vermeir, W. Lauriks, R. Kruse, and V. Mellert. Measuring the free field acoustic impedance and absorption coefficient of sound absorbing materials with a combined particle velocity-pressure sensor. J. Acoust. Soc. Am., 119(5):2826-2831, 2006.

[22] E. Mommertz. Angle-dependent in-situ measurements of reflection coefficients using a subtraction technique. Appl. Acoust., 46(3):251-263, 1995.

[23] C. Nocke. In-situ acoustic impedance measurement using a free-field transfer function method. Appl. Acoust., 59(3):253-264, 2000.

[24] T. Otsuru, R. Tomiku, N.B.C. Din, N. Okamoto, and M. Murakami. Ensemble averaged surface normal impedance of material using an in-situ technique: preliminary study using boundary element method. J. Acoust. Soc. Am., 125(6):3784-91, 2009.

[25] A.F. Seybert. Two-sensor methods for the measurement of sound intensity and acoustic properties in ducts. J. Acoust. Soc. Am., 83(6):2233-2239, 1988.

[26] Y. Takahashi, T. Otsuru, and R. Tomiku. In situ measurements of surface impedance and absorption coefficients of porous materials using two microphones and ambient noise. Appl. Acoust., 66(7):845-865, 2005.

[27] E. Tijs and E. Druyvesteyn. An intensity method for measuring absorption properties in situ. Acta Acust. Acust., 98(2):342-353, 2012.

[28] Y.H. Wijnant, E.R. Kuipers, and A. de Boer. Development and application of a new method for the in-situ measurement of sound absorption. In ISMA 31, Leuven,

Belgium, 2010. 


\section{Chapter 5}

\section{Measuring oblique incidence sound absorption using a local plane wave assumption $^{1}$}

\section{Abstract}

In this paper, a method for the measurement of the oblique incidence sound absorption coefficient is presented. It is based on a local field assumption, in which the acoustic field is locally approximated by one incident- and one specularly reflected plane wave. The amplitudes of these waves can be determined with a unidirectional sound intensity probe. The local active- and incident acoustic intensity are straightforwardly obtained. The area-averaged sound absorption coefficient is calculated after spatial integration of these quantities over the surface area of interest. Alternatively, one may use a threedimensional intensity probe. In that case, the determination of the amplitudes of the plane waves can be formulated as a least-squares problem. Measurements performed for a sound absorbing foam demonstrate that accurate results can be obtained, even under non-ideal acoustic conditions. Measurements carried out for a periodic absorber show that the method is accurate below the cut-on frequency of scattering as long as the amplitude of the evanescent surface waves is significantly smaller than that of the specularly reflected wave.

\footnotetext{
${ }^{1}$ Reproduced from: E.R. Kuipers, Y.H. Wijnant, and A. de Boer, Measuring oblique incidence sound absorption using a local plane wave assumption. (Submitted to Acta Acustica united with Acustica)
} 


\subsection{Introduction}

Multiple methods $[5,2,9,21,22,17,12,23]$ can be applied to determine the oblique incidence sound absorption coefficient. These methods mostly determine the specific acoustic surface impedance or the complex sound pressure reflection coefficient, using a model that typically describes the overall acoustic field in front of a planar surface of infinite extent in a semi-free field. In addition, plane- or spherical wave incidence, and a local- or extended reaction surface is assumed. For overviews of acoustic field models the reader is referred to two recent works, by Liu and Li [19] and Li and Liu [18].

As a result of using an overall model, the directivity characteristics of the source have to be known, large sample sizes are required, and room reflections have to be absent. Whereas the latter requirement can be reasonably fulfilled by measuring in a semi-anechoic room or by employing a time-windowing technique, it is difficult to obtain pure plane- or spherical wave incidence. Furthermore, the finite dimensions of the sample put a limit on the lowest frequency at which results can be obtained, and the sample's edges give rise to the presence of diffracted waves. Finally, a used localor extended reaction assumption may not be valid. Therefore, a high chance exists that the actual acoustic field deviates from the ideal field represented by the model, and the obtained acoustic surface impedance or sound absorption coefficient may be inaccurate to a greater or lesser extent.

A possible strategy to reduce the susceptibility of a measurement method to the aforementioned aspects, is to apply area-averaging. In an earlier paper [14], we numerically showed that this approach is effective in reducing the influence of room reflections. It is in contrast to currently available methods which rely on measurements using a spatially fixed set up, being more susceptible to local deviations in the acoustic field that may be caused by edge-diffracted waves or room reflections. Practical use of area-averaging for measurements in a non-ideal acoustic field has firstly been reported by the authors [16]. In that paper, the LPW-method (Local Plane Wave method) $[24,13,15,14]$ was used. This method is suitable for normal and near-normal incidence.

To also be able to perform area-averaged oblique incidence measurements in non-ideal acoustic fields, we have developed a novel method. This method is the substance of this paper. It is based on a local field assumption, and is referred to as the LSPW (Local Specular Plane Wave) assumption. Accordingly, the novel method is called the LSPW-method. The use of the LSPW assumption allows determining the oblique incidence sound absorption coefficient without using an overall field model.

This paper is structured as follows: first, the theory will be presented in Sec. 5.2. Details about the specific implementation for a three-dimensional sound intensity probe, as used by the authors, are given in Sec. 5.3. In Sec. 5.4, measurement results for 
an extended reaction sound absorbing foam and a periodic absorber will be presented. Finally, conclusions and recommendations for further work are given in Sec. 5.5.

\subsection{Theory of the LSPW-method}

In the following, we assume that the acoustic field satisfies the Helmholtz equation. The $e^{i \omega t}$-convention is used, i.e. $p(t)=\operatorname{Re}\left[P(\omega) e^{i \omega t}\right]$, vector quantities are boldfaced, and the explicit dependence of $\omega$ is omitted for quantities in the frequency domain.

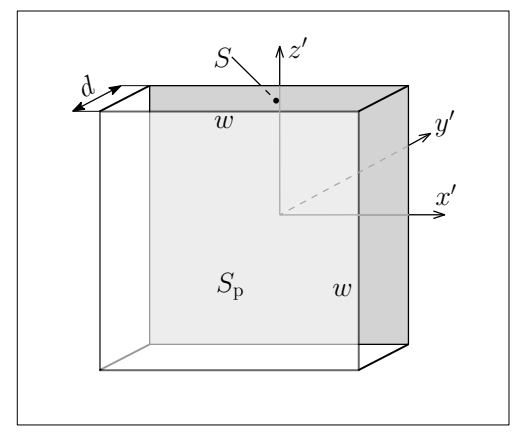

Figure 5.1: A square, planar material surface $S$ (dark gray), with the measurement surface $S_{\mathrm{p}}$ (light gray) at a distance $d$. the $y^{\prime}$-direction points normally into the material surface.

The theory is presented based on the configuration shown in Fig. 5.1. We want to obtain an accurate estimate for the oblique incident sound absorption coefficient of the material surface $S$. To this purpose, we define a measurement surface $S_{\mathrm{p}}$, at a small distance $d$ from the material surface $S$.

The effective, area-averaged, oblique incidence sound absorption coefficient for the surface $S_{\mathrm{p}}$ is defined as the ratio of the active (absorbed) acoustic power and the incident power:

$$
\alpha=\frac{W_{\mathrm{ac}}}{W_{\mathrm{in}}}
$$

where $W_{\text {ac }}$ and $W_{\text {in }}$ are the active- and incident acoustic power, respectively. $\alpha$ is an effective sound absorption coefficient, as the angle of incidence typically varies over the measurement surface when a spatially fixed source is used. To obtain the areaaveraged oblique incidence sound absorption coefficient $\alpha(\psi)$ for a well-defined angle of incidence $\psi$, one must either realize plane wave incidence over the whole surface area of $S_{\mathrm{p}}$, or determine the active- and incident acoustic power associated with a sub-area of $S_{\mathrm{p}}$, at which the angle of incidence lies within small tolerances of the desired angle of incidence. 
In the following, it is assumed that the sound source is spatially fixed, and that the source distance and the dimensions of $S_{\mathrm{p}}$ are chosen such that the angle of incidence $\psi$ only varies minimally over the surface $S_{\mathrm{p}}$ of interest, and we define $\tilde{\psi}$ to be the spatially averaged angle of incidence. Then, the active- and incident acoustic power for angle of incidence $\psi$ are obtained by spatial integration of the corresponding intensities over surface $S_{\mathrm{p}}$ :

$$
\begin{aligned}
& W_{\mathrm{ac}}(\tilde{\psi})=\int_{S_{\mathrm{p}}} I_{\mathrm{ac}}(\psi) \mathrm{d} S, \\
& W_{\mathrm{in}}(\tilde{\psi})=\int_{S_{\mathrm{p}}} I_{\mathrm{in}}(\psi) \mathrm{d} S,
\end{aligned}
$$

where $I_{\text {ac }}(\tilde{\psi})$ and $I_{\text {in }}(\tilde{\psi})$ are active- and incident acoustic intensity in direction $\mathbf{n}$. The local angle of incidence $\psi$ is a function of the spatial position, defined by a spatial vector $\mathbf{r}$ in an overall coordinate system, of the measurement point: $\psi=\psi(\mathbf{r})$. The measurement of the active acoustic intensity can be performed using a unidirectional sound intensity probe, typically being either a pu-probe [6], or a pp-probe [8].

To determine the incident acoustic intensity, one could perform a prior, separate, measurement in a free field. However, such an approach demands a stable power output of the source, and requires that this measurement is performed at the same position relative to the sound source. To avoid this additional effort, one must determine the active- and incident acoustic intensity from a single measurement. Whereas the measurement methods referred to in the introductory section of this paper employ an overall field model, we propose that a local field assumption is used.

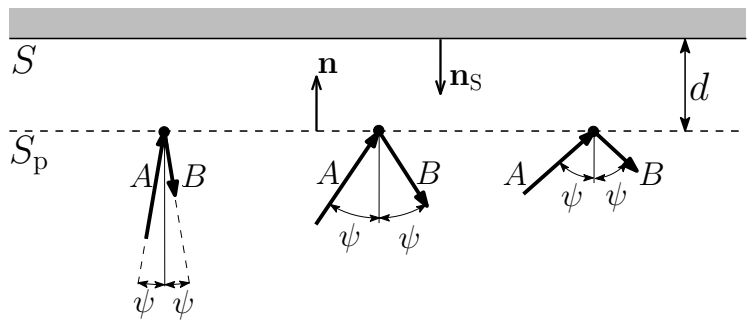

Figure 5.2: A planar material surface $S$, with the measurement surface $S_{\mathrm{p}}$ at a distance $d$. $\mathbf{n}_{\mathrm{S}}$ is the surface normal of $S$, and $\mathbf{n}$ is the surface normal vector of $S_{\mathrm{p}}$ (directed towards $S$ ). In each point upon $S_{\mathrm{p}}$, the acoustic field is locally approximated with two waves with complex amplitudes $A$ and $B$, where $\psi$ is equal to the local angle of incidence.

This assumption is illustrated in Fig. 5.2. In each point upon $S_{\mathrm{p}}$, the acoustic field is locally approximated by an incident plane wave with complex amplitude $A$, and 
a specularly reflected plane wave with complex amplitude $B$, as shown in Fig. 5.2. Variations of the angle of incidence, and of the complex amplitudes with space are explicitly allowed.

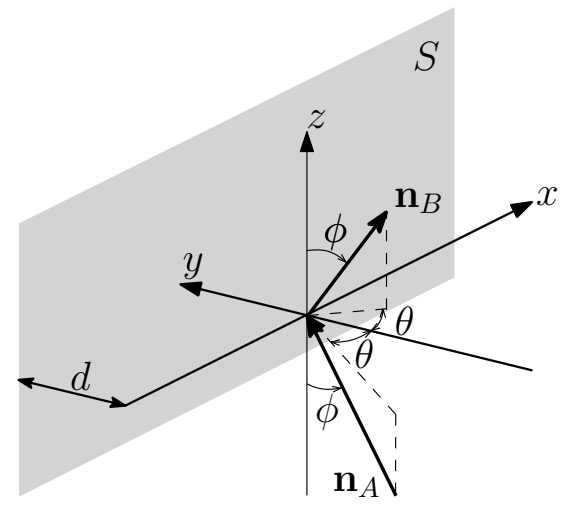

Figure 5.3: Convention of the propagation direction vectors of $A$ and $B$.

For three dimensions, the direction convention is shown in Fig. 5.3. It follows that the angle of incidence of the incident wave propagating in direction $\mathbf{n}_{\mathrm{A}}$ with respect to the outward surface normal $\mathbf{n}_{\mathrm{S}}$ (See Fig. 5.4) equals:

$$
\psi=\arccos (\sin \phi \cos \theta),
$$

so that the propagation directions $\mathbf{n}_{\mathrm{A}}$ and $\mathbf{n}_{\mathrm{B}}$ are separated by an angle $2 \psi$, see Fig. 5.4. If, at the measurement point defined by a spatial vector $\mathbf{r}$, the angle of incidence $\psi(\mathbf{r})$ is known, one can determine $A$ and $B$ by using a unidirectional pu- or pp-probe. For a pu-probe, we demand that, in every spatial point upon $S_{\mathrm{p}}$, the approximated field, represented by $A(\mathbf{r})$ and $B(\mathbf{r})$, yields the same acoustic pressure and particle velocity as in the actual field. Hence, we obtain

$$
\left[\begin{array}{cc}
1 & 1 \\
\frac{\cos (\psi)}{Z_{0}} & \frac{-\cos (\psi)}{Z_{0}}
\end{array}\right]\left[\begin{array}{c}
A(\mathbf{r}) \\
B(\mathbf{r})
\end{array}\right]=\left[\begin{array}{c}
P(\mathbf{r}) \\
U_{\mathbf{n}}(\mathbf{r})
\end{array}\right]
$$

where $Z_{0}=\rho_{0} c_{0}$ is the specific characteristic acoustic impedance of air. $A(\mathbf{r})$ and $B(\mathbf{r})$ become:

$$
\begin{aligned}
& A(\mathbf{r})=\frac{1}{2}\left[P(\mathbf{r})+Z_{0} \frac{U_{n}(\mathbf{r})}{\cos \psi(\mathbf{r})}\right], \\
& B(\mathbf{r})=\frac{1}{2}\left[P(\mathbf{r})-Z_{0} \frac{U_{n}(\mathbf{r})}{\cos \psi(\mathbf{r})}\right] .
\end{aligned}
$$

For a pp-probe with microphones $\mathrm{M}_{1}$ and $\mathrm{M}_{2}$, spaced a distance $s$ apart, see Fig. 5.4, we equate the acoustic pressures of the approximated- and the actual field, and obtain 


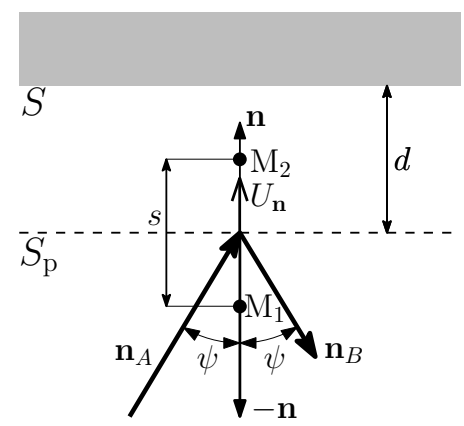

Figure 5.4: Orientation of the propagation directions of wave $A$ and wave $B$ with respect to the surface normal of surface $S_{\mathrm{p}}$. The positions of the microphones $\mathrm{M}_{1}$ and $\mathrm{M}_{2}$ are depicted by the circular markers.

$$
\left[\begin{array}{ll}
e^{i k \frac{s}{2} \cos (\psi)} & e^{-i k \frac{s}{2} \cos (\psi)} \\
e^{-i k \frac{s}{2} \cos (\psi)} & e^{i k \frac{s}{2} \cos (\psi)}
\end{array}\right]\left[\begin{array}{c}
A(\mathbf{r}) \\
B(\mathbf{r})
\end{array}\right]=\left[\begin{array}{c}
P_{1}(\mathbf{r}) \\
P_{2}(\mathbf{r})
\end{array}\right]
$$

where $k$ is the wavenumber, and $P_{1}(\mathbf{r})=P\left(\mathbf{r}-\frac{s}{2} \mathbf{n}\right)$ and $P_{2}=P\left(\mathbf{r}+\frac{s}{2} \mathbf{n}\right)$ are the complex acoustic pressures measured by microphones $\mathrm{M}_{1}$ and $\mathrm{M}_{2}$, respectively. It follows that

$$
\begin{aligned}
& A=\frac{i}{D}\left[P_{2} \exp \left(-i k \frac{s}{2} \cos \psi\right)-P_{1} \exp \left(i k \frac{s}{2} \cos \psi\right)\right], \\
& B=\frac{i}{D}\left[P_{1} \exp \left(-i k \frac{s}{2} \cos \psi\right)-P_{2} \exp \left(i k \frac{s}{2} \cos \psi\right)\right],
\end{aligned}
$$

where $D=2 \sin (k s \cos \psi)$. The solutions for $A(\mathbf{r})$ and $B(\mathbf{r})$ become singular for frequencies

$$
f_{q}=\frac{q c_{0}}{2 s \cos \psi}
$$

where $q=1,2,3, \ldots$. For a microphone spacing $s=20 \mathrm{~mm}$, the lowest frequency $f_{1}$ at which the singularity occurs equals ca. $8600 \mathrm{~Hz}$ for normal incidence. $f_{1}$ increases with increasing angle of incidence. Having determined the complex amplitudes $A(\mathbf{r})$ and $B(\mathbf{r})$ either with a pu- or a pp-probe, the incident acoustic intensity in the direction $\mathbf{n}$ (towards the material surface $S$ ) and the reflected acoustic intensity in the opposite direction, can be calculated according to 


$$
\begin{aligned}
I_{\text {in }}(\mathbf{r}) & =\frac{|A(\mathbf{r})|^{2}}{2 \rho_{0} c_{0}} \cos \psi, \\
I_{\text {refl }}(\mathbf{r}) & =\frac{|B(\mathbf{r})|^{2}}{2 \rho_{0} c_{0}} \cos \psi .
\end{aligned}
$$

The active acoustic intensity in direction $\mathbf{n}$ can be calculated with the well-known formula by Fahy [8]:

$$
I_{\mathrm{ac}}(\mathbf{r})=\frac{1}{2} \operatorname{Re}\left[P(\mathbf{r}) \overline{U_{\mathrm{n}}(\mathbf{r})}\right] .
$$

Whereas application of this equation is straightforward for a pu-probe, for a pp-probe it is less obvious. If we would use the finite difference (FD) approximation to determine the particle velocity for use in Eq. (5.14), see Fahy [8]:

$$
U_{n}(\mathbf{r}) \approx \frac{i}{Z_{0} k s}\left[P_{2}(\mathbf{r})-P_{1}(\mathbf{r})\right]
$$

our formulation would become inconsistent. One can use the FD-approximation in Eq. (5.15) and then use Eq. (5.14) to determine the active acoustic intensity, but then one should have used Eq. (5.6) to determine $A(\mathbf{r})$ using the formulation for a pu-probe to calculate the incident acoustic intensity. However, in that case, both the activeand the incident acoustic intensity will suffer from the finite difference error, known for pp-probes [8].

Instead, we determine the particle velocity at the geometric center of the pp-probe in direction $\mathbf{n}$ using the complex wave amplitudes $A(\mathbf{r})$ and $B(\mathbf{r})$ according to the LSPW assumption:

$$
U_{\mathbf{n}}(\mathbf{r})=\frac{\cos (\psi)}{Z_{0}}[A(\mathbf{r})-B(\mathbf{r})],
$$

so that, with Eq. (5.14), it follows that the active acoustic intensity equals the difference between the incident- and reflected acoustic intensity:

$$
I_{\mathrm{ac}}(\mathbf{r})=\frac{|A(\mathbf{r})|^{2}-|B(\mathbf{r})|^{2}}{2 Z_{0}} \cos (\psi)
$$

Having estimated the active- and incident acoustic intensity by the above procedure, the area-averaged oblique sound absorption coefficient can straightforwardly be calculated with Eq. (5.1) after spatial integration of both intensities according to Eqs. (5.2) and (5.3), respectively. It is pointed out that the estimated intensities will be exact if the actual acoustic field matches with the field described by the local specular plane wave assumption. 


\subsection{Implementation}

The measurements presented in this paper were performed using a newly developed 3D pp-sound intensity probe, see Fig. 5.5. The 8 microphones used in this probe are digital, omnidirectional, MEMS-microphones (ADMP441, Analog Devices, 4.7×3.8×1.0 $\mathrm{mm}$ ). They have a signal-to-noise ratio of $61 \mathrm{~dB}(\mathrm{~A})$ and a dynamic range of $87 \mathrm{~dB}$. The microphones are spaced $20.0 \mathrm{~mm}$ in the $x$ - and $y$-direction, and $23.1 \mathrm{~mm}$ in the z-direction. As reported in an earlier paper [16], some diffraction effects between 4 and $6 \mathrm{kHz}$ were observed during a series of calibration measurements. The resulting phaseand amplitude errors at these frequencies can, particularly for poorly absorbing samples, result in noticeable inaccuracies in the sound absorption curve, as observed in the same paper. However, the samples described in Sec. 5.4 are good sound absorbers, and the obtained absorption curves do not seem to be influenced by phase- and amplitude errors.

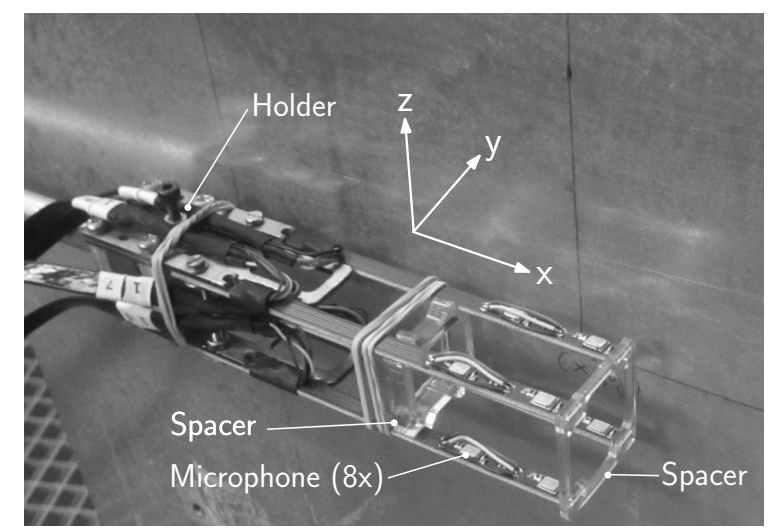

Figure 5.5: 3D sound intensity probe in front of a plate. The y-direction points normally into this plate.

Due to the particular design of the probe, we have chosen an implementation of the LSPW-method that is somewhat different from the theory in the preceding section. The first aspect of this implementation is the application of a least-squares method to obtain the complex amplitudes $A$ and $B$. Instead of using Eq. (5.8), we have chosen to solve $A$ and $B$ from the following set of equations:

$$
\mathbf{M v}=\mathbf{P}
$$

in which

$$
\mathbf{M}=\left[\begin{array}{cc}
M_{11} & M_{12} \\
\vdots & \vdots \\
M_{N 1} & M_{N 2}
\end{array}\right], \mathbf{v}=\left[\begin{array}{c}
A \\
B
\end{array}\right], P=\left[\begin{array}{c}
P 1 \\
\vdots \\
P_{N}
\end{array}\right]
$$


where $N$ is the number of microphones. The elements of the first and second column of the matrix $\mathbf{M}$ are given by

$$
\begin{aligned}
& M_{j 1}=e^{-i k\left[x_{j} \sin \phi \sin \theta+y_{j} \sin \phi \cos \theta+z_{j} \cos \phi\right]}, \\
& M_{j 2}=e^{-i k\left[x_{j} \sin \phi \sin \theta-y_{j} \sin \phi \cos \theta+z_{j} \cos \phi\right]},
\end{aligned}
$$

where $x_{j}, y_{j}$, and $z_{j}$ are the spatial coordinates of microphone $j$ relative to the geometric center of probe according to Fig. 5.5. One can solve the overdetermined system of equations in Eq. (5.18) for the complex amplitudes in $\mathbf{v}$ in a least-squares sense [3] by pre-multiplication of the left- and right-hand side with the Hermitian transpose $\mathbf{M}^{\mathrm{H}}$, and then solving for $\mathbf{v}$, according to:

$$
\mathbf{v}=\left(\mathbf{M}^{\mathrm{H}} \mathbf{M}\right)^{-1} \mathbf{M}^{\mathrm{H}} \mathbf{P} .
$$

By doing so, the real-valued, semi-positive definite functional

$$
F=(\mathbf{M v}-\mathbf{P})^{\mathrm{H}}(\mathbf{M v}-\mathbf{P}),
$$

being the sum of all squared errors, is minimized. That is, the above procedure tries to determine $A$ and $B$, such that a least-squares fit to the measured acoustic pressures is obtained. The above solving procedure has to be repeated for every discrete frequency in the complex spectrum $\mathbf{P}$ that falls within the frequency range of interest.

The second aspect of our implementation is an adaption of the system of equations (5.18). The measurement of the acoustic pressures in Sec. 5.4 is performed without a reference signal. Therefore, spectral averaging of the complex spectrum of each of the acoustic pressures $P_{1} \ldots P_{N}$ is useless. In such cases, one defines one of the data channels to be the reference signal and calculates the transfer functions or cross-power spectra, which are suitable for spectral averaging. Without loss of generalization, we have defined channel 1 as the reference signal. If cross-power spectra are used, the system of equations (5.18) can be formulated as

$$
\left[\begin{array}{cc}
M_{11} & M_{12} \\
\vdots & \vdots \\
M_{N 1} & M_{N 2}
\end{array}\right]\left[\begin{array}{c}
A^{\prime} \\
B^{\prime}
\end{array}\right]=\left[\begin{array}{c}
\overline{P_{1}} P 1 \\
\vdots \\
\overline{P_{1}} P_{N}
\end{array}\right]
$$

where $A^{\prime}=\overline{P_{1}} A$ and $B^{\prime}=\overline{P_{1}} B$, the overbar denotes complex conjugation, and the explicit dependence on $\mathbf{r}$ has been omitted. As the solving procedure now yields $A^{\prime}$ and $B^{\prime}$ instead of $A$ and $B$, one has to divide the right-hand side of Eqs. (5.12), (5.13) and (5.17) by the auto-power spectrum of the reference channel $\left|P_{1}\right|^{2}$ to obtain the correct incident, reflected, and active intensity, respectively. Once the active- and incident intensity are known, one can proceed to calculate the area-averaged sound absorption coefficient, as outlined in Sec. 5.1. 


\subsection{Measurements}

\subsubsection{Sample 1: sound absorbing foam}

The measurements described in this section were performed for a $50 \mathrm{~mm}$ thick sheet of melamine resin foam, Basotect $G$, backed by a $10 \mathrm{~mm}$ thick aluminum plate, see Fig. 5.6. The dimensions of the foam sheet are $1250 \times 625 \mathrm{~mm}$, whereas the dimensions of the aluminum plate are slightly larger. The foam was attached to the plate using double-sided adhesive tape.

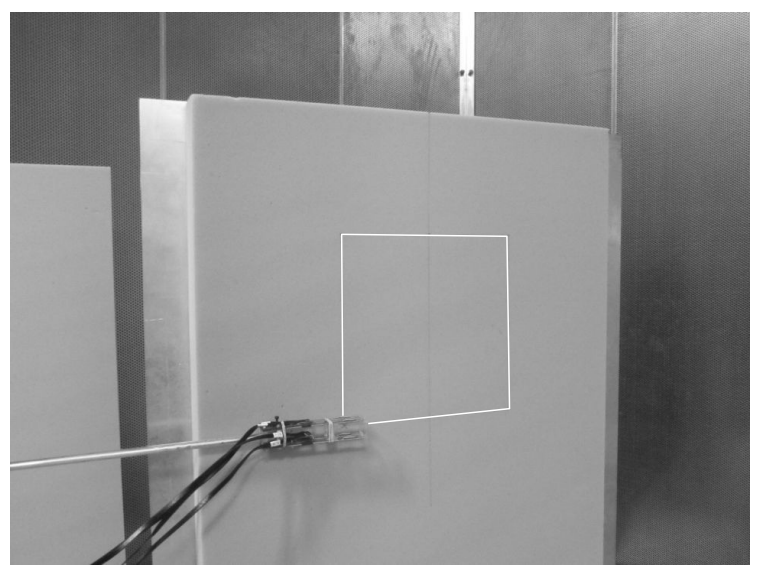

Figure 5.6: Probe in front of foam sample backed by a thick plate. The scanning area is indicated in white.

The sample was positioned vertically in a well-absorbing, but not anechoic, room with approximate dimensions $6 \times 6 \times 5 \mathrm{~m}$. The measurement was performed using the 3D sound intensity probe shown in Fig. 5.5. The probe was moved along the surface of the sample by means of a PC-controlled scanning system, maintaining a distance $d=20 \mathrm{~mm}$ of the geometric center of the probe to the surface of the sample. The positioning accuracy of the scanning system is less than $1 \mathrm{~mm}$. A square, equidistant grid of $21 \times 21$ points spaced at $12.8 \mathrm{~mm}$ was defined upon the foam surface, resulting in a measurement surface of $256 \times 256 \mathrm{~mm}^{2}$. At each point, the acoustic pressures were recorded during $10 \mathrm{~s}$. After each moving step of the scanning system, sufficient time was allowed for residual vibration to dampen out before the start of a new recording.

A small loudspeaker, with a membrane diameter of $23 \mathrm{~mm}$ and a circular housing having a diameter of $80 \mathrm{~mm}$, served as a sound source. It was positioned at $1 \mathrm{~m}$ from the plate such that the desired angle of incidence occurs at the geometric center of the measurement region. Temperature, ambient pressure and relative humidity were recorded at the start of the scanning session. Data acquisition is performed using a 40-channel digital front-end and a PC. The signals were processed in data blocks 
of 4096 points, with $80 \%$ overlap. The frequency resolution $\Delta f$ of all results shown hereafter, equals $11.7 \mathrm{~Hz}$. The lower frequency limit of the results is set to $1300 \mathrm{~Hz}$ as the small speaker did not radiate sufficient acoustic power to maintain a coherence between the microphone signals above 0.9 .

Two measurements were carried out: a normal incidence and a $45^{\circ}$ incidence measurement. To verify the results, the Delany-Bazley model [7] is used. First, the model is fitted to normal incidence sound absorption curve by varying the flow resistivity. Then, the normal specific acoustic surface impedance of the rigidly backed foam layer is calculated with the model. Having obtained this impedance, we calculated two predictions of the sound absorption curve for the second measurement, i.e. for $45^{\circ}$ incidence. One prediction assumes local reaction, and the second prediction assumes extended reaction. Both predicted curves are compared with the curve for $45^{\circ}$ incidence obtained with the LSPW-method.

In the first, normal incidence, measurement, the effective area-averaged sound absorption coefficient was determined with the LSPW-method while accounting for the variation of the angle of incidence with position. The maximum angle of incidence equals $10^{\circ}$, occurring at the corners of the square measurement grid. A separate analysis, for subsets of points having the same angle of incidence, showed that the variation of the area-averaged sound absorption coefficient with incidence angle was not noticeable, as expected. Therefore, the effective area-averaged sound absorption coefficient can be interpreted as the result of a purely normal incidence measurement.

Figure 5.7 shows the sound absorption curve obtained with the LSPW-method, a theoretical curve based on the model by Delany and Bazley [7], and impedance tubebased data from the manufacturer of the foam. The theoretical curve was determined by fitting the Delany-Bazley model to the measurement results by varying the flow resistivity, being the case for a flow resistivity $\sigma$ of $8000 \mathrm{Ns} / \mathrm{m}^{4}$. This value is realistic as Garai and Pompoli [10] reported an average of ca. $\sigma=10000 \mathrm{Ns} / \mathrm{m}^{4}$ from an inter-laboratory test (round robin) for a Basotect foam with a mass density of $10 \pm 1.5 \mathrm{~kg} / \mathrm{m}^{3}$, whereas the Basotect $\mathrm{G}$ foam in our measurements is specified as having a mass density of $9+2 /-1 \mathrm{~kg} / \mathrm{m}^{3}$. Furthermore Kino et al. [11] reported $\sigma=6197$ $\mathrm{Ns} / \mathrm{m}^{4}$ for Basotect TG with a mass density of $8.77 \mathrm{~kg} / \mathrm{m}^{3}$. Please note that we have extrapolated the theoretical curve obtained with the Delany-Bazley model up to 12 $\mathrm{kHz}$, whereas Delany and Bazley indicated validity of their model up to $f / \sigma=1$, being $8 \mathrm{kHz}$ in our case.

The black solid curve in Fig. 5.7 is obtained with the LSPW-method. The distinct dips in this curve at 2273 and $6080 \mathrm{~Hz}$ are related to a variation of the local sound absorption coefficient within a part of the area of the measurement surface. This variation is caused by local detachment of the foam from the adhesive tape, and was analyzed more in detail by the authors in [16]. 


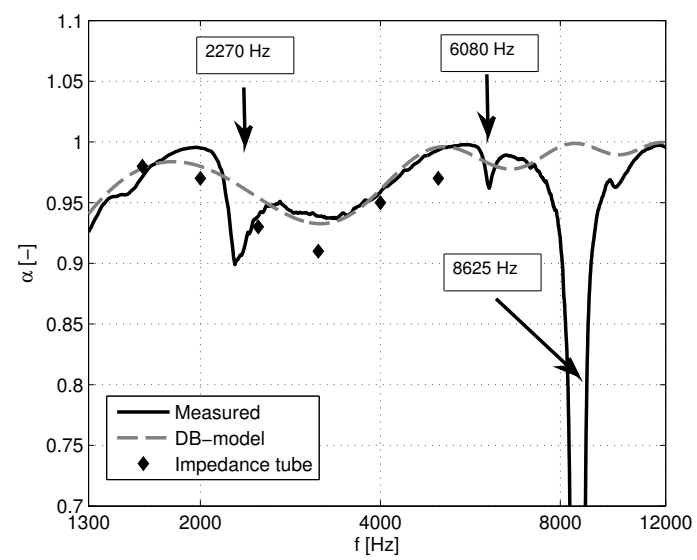

Figure 5.7: Normal incidence sound absorption coefficient vs. frequency, measured with the LSPW-method, calculated with the model of Delany and Bazley (DB-model), and measured with an impedance tube acc. ISO 10534-2 [1] for a layer thickness of $51 \mathrm{~mm}$ (manufacturer data, 1/3-octave values).

The Delany-Bazley model predicts the measured curve very well, and agreement with the impedance tube results is quite good. The strong dip at $8625 \mathrm{~Hz}$ in the measured curve is caused by the singularity of $A$ and $B$ in Eqs. (5.9) and (5.10). At this frequency, one-half wavelength equals the microphone spacing in the surface normal direction, i.e. the $y$-direction in Fig. 5.5.

The Delany-Bazley model will now be used to predict the sound absorption curve for the second measurement having $45^{\circ}$ incidence. To this purpose, the specific normal acoustic surface impedance for the rigidly-backed foam layer is calculated first, using

$$
Z_{\mathrm{S}}=-i Z_{\mathrm{c}} \cot \left(k_{\mathrm{c}} t\right)
$$

where $t$ is the thickness of the layer of foam. $Z_{\mathrm{c}}$ and $k_{\mathrm{c}}$ are the characteristic specific acoustic impedance and complex wavenumber of the foam obtained from the DelanyBazley model, respectively. We will now use the calculated specific normal acoustic surface impedance obtained with Eq. (5.24) to predict the sound absorption coefficient for $45^{\circ}$ incidence. This prediction allows us to verify the sound absorption coefficient measured with the LSPW-method for that angle in the second measurement. Two predictions, $\alpha_{\mathrm{LR}}$ and $\alpha_{\mathrm{ER}}$, are calculated, where the subscripts indicate locally- or extended reaction. The first prediction assumes a locally reacting surface, so that the following equation can be used to calculate the sound absorption coefficient: 


$$
\alpha_{\mathrm{LR}}(\psi)=\frac{4 \operatorname{Re}\left(Z_{\mathrm{S}}^{\prime}\right) \cos \psi}{\left[1+\operatorname{Re}\left(Z_{\mathrm{S}}^{\prime}\right) \cos \psi\right]^{2}+\left[\operatorname{Im}\left(Z_{\mathrm{S}}^{\prime}\right) \cos \psi\right]^{2}},
$$

where $Z_{\mathrm{S}}^{\prime}=Z_{\mathrm{S}} / Z_{0}$. The second prediction is performed for an extended reaction surface and hence, we first have to calculate the normal specific acoustic surface impedance for oblique incidence. To this purpose we use Eq. (8) in Davies and Mulholland [5] for an isotropic rigidly-backed absorbing layer, originating from Brekshovskikh [4]:

$$
\begin{aligned}
Z_{\mathrm{S}}^{\prime}(\psi)= & \frac{Z_{\mathrm{c}}}{Z_{0}} \frac{i}{\left[1-\left(\frac{k}{k_{\mathrm{c}}} \sin \psi\right)^{2}\right]} \times \\
& \cot \left[k_{\mathrm{c}} t\left(1-\frac{k}{k_{\mathrm{c}}} \sin \psi\right)^{1 / 2}\right] .
\end{aligned}
$$

The second prediction, $\alpha_{\mathrm{ER}}(\psi)$, is then calculated by substituting $Z_{\mathrm{S}}^{\prime}(\psi)$ obtained with Eq. (5.26) in Eq. (5.25).

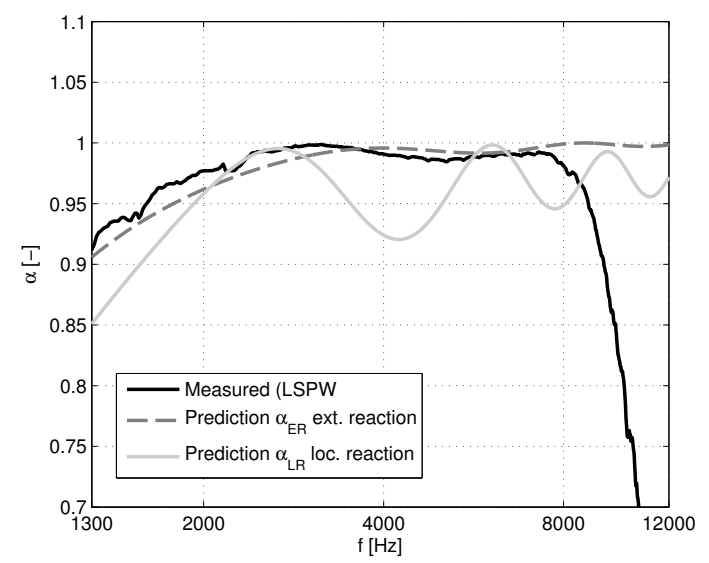

Figure 5.8: Oblique incidence sound absorption coefficient for $45^{\circ}$ incidence vs. frequency, measured with the LSPW-method, predicted for a locally-reacting surface $\alpha_{\mathrm{LR}}$, and predicted for an extended reaction surface $\alpha_{\mathrm{ER}}$.

Both predictions, and the curve for $45^{\circ}$ incidence determined with the LSPW-method, are shown in Fig. 5.8. The measurement result indicates that the melamine resin foam is rather of the extended reaction type than of the locally reacting type, which is plausible as its flow resistivity is low. The measured curve agrees quite well with the extended reaction prediction. Although the qualitative course of the predicted and measured curve match very well, the frequencies at which maximum absorption occurs, do not coincide. This could indicate that the angle of refraction inside the 
material is smaller in reality than predicted by the extended reaction model.

The measured (black) curve rapidly already starts to deviate from its expected course above $8 \mathrm{kHz}$. However, the singularity in the complex amplitudes $A$ and $B$ occurs only at $12.2 \mathrm{kHz}$. The cause of the deviation lies in the presence of phase errors of the probe. The sensitivity to such errors increases with an increasing angle of incidence. To obtain accurate results at large angles of incidence, a microphone spacing larger than $20 \mathrm{~mm}$ is necessary given the phase errors of the probe. However, a larger spacing causes the frequency at which singularity occurs to decrease, so that accurate measurements that involve combinations of large angles of incidence and high frequencies are difficult to realize.

Besides the purpose of the prediction of the sound absorption curve for the second measurement, we can also use the calculated specific normal acoustic surface impedance according to Eq. (5.24) to demonstrate that area-averaging is also useful when measuring the specific normal acoustic surface impedances in non-ideal fields. To this purpose, the complex wave amplitudes $A$ and $B$, obtained with the LSPWmethod, are used to determine the specific normal acoustic surface impedance of the rigidly-backed layer of foam.

First, the local normal specific acoustic surface impedance at the geometric center of the probe is determined. Using the LSPW assumption, this impedance can be expressed in terms of $A^{\prime}$ and $B^{\prime}$, as obtained by solving the system of equations in Eq. (5.23):

$$
Z_{\mathrm{M}}=\frac{Z_{0}}{\cos (\psi)} \frac{A^{\prime}+B^{\prime}}{A^{\prime}-B^{\prime}}
$$

Assuming plane wave propagation between the measurement surface and the material surface, the specific normal acoustic surface impedance can be calculated from $Z_{\mathrm{M}}$, using Eq. (4) in [2] by Allard et al.:

$$
Z_{\mathrm{S}}(\psi)=\frac{Z_{0}}{\cos \psi}\left[\frac{Z_{\mathrm{M}} \cos \psi-i Z_{0} \tan (k d \cos \psi)}{Z_{0}-i Z_{\mathrm{M}} \cos \psi \tan (k d \cos \psi)}\right]
$$

Figure 5.9 shows the specific normal acoustic surface impedance as calculated with the Delany-Bazley model, using Eq. (5.24), and as determined from the measurements using Eq. (5.28). The gray bands indicate the envelope that contains the curves for all 441 measurement points. The agreement of the mean value of these sets of curves (solid black line) with the calculated curve (dashed line) is very good, for both the real and imaginary part. Hence, we conclude that area-averaging is also effective in measuring the normal acoustic surface impedance in non-ideal fields. 

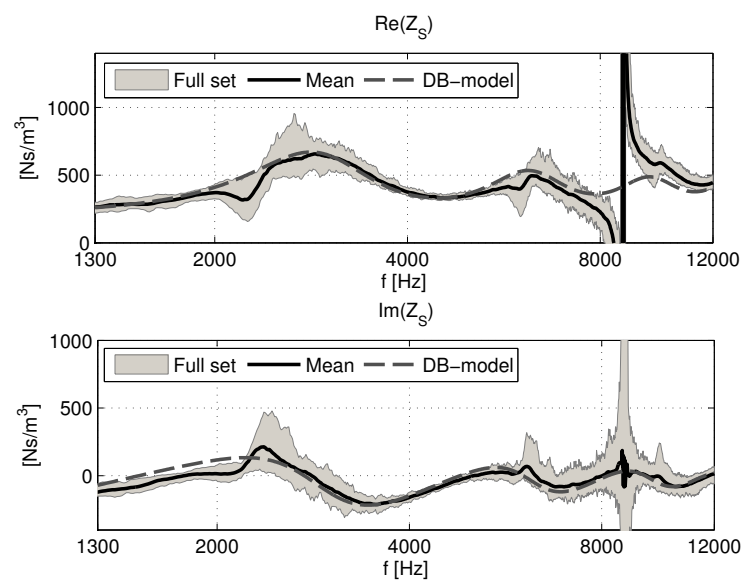

Figure 5.9: Normal specific acoustic surface impedance, measured with the LSPWmethod and calculated with the model of Delany and Bazley. Upper graph: real part. Lower graph: imaginary part.

\subsubsection{Sample 2: periodic absorber}

The second sample is a periodic absorber, see Fig. 5.10. This type of absorber was chosen to investigate how the LSPW-method deals with acoustic fields that locally differ strongly from the field assumed by the LSPW assumption. This is the case for the periodic absorber investigated here. Periodic absorbers are characterized by discrete frequencies at which scattering of so-called radiating harmonics at non-specular angles is cut-on. At- and beyond the first cut-on frequency, the acoustic field consists of an incident wave, a specularly reflected wave, and one or multiple scattered waves. In addition, evanescent surface waves are present in the near-field.

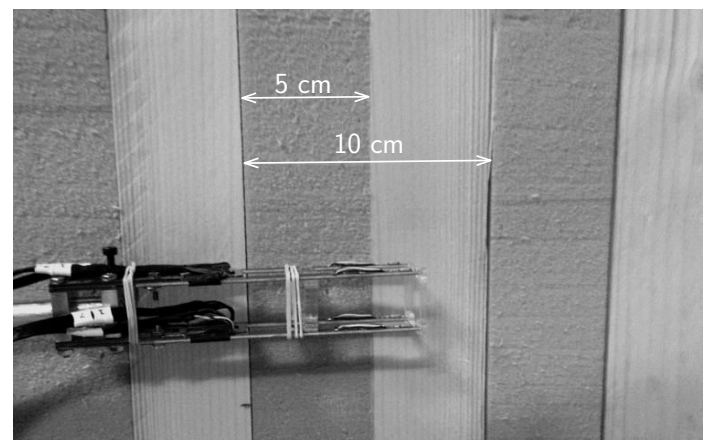

Figure 5.10: Probe in front of periodic absorber.

The dimensions of the sample are $120 \times 120 \mathrm{~cm}$. The wooden ribs are $50 \mathrm{~mm}$ wide and are spaced $50 \mathrm{~mm}$ apart. The thickness of the wooden ribs varies between 46.5 and 


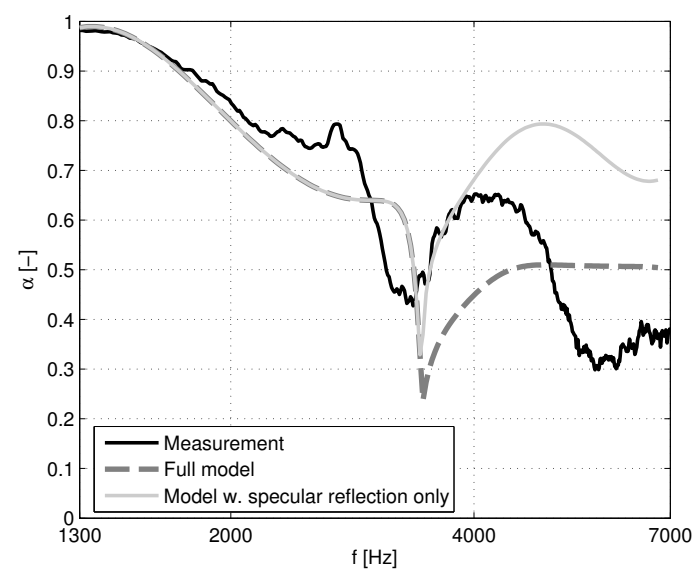

Figure 5.11: Normal incidence sound absorption coefficient vs. frequency, measured with the LSPW-method, predicted using a full model including scattering, and predicted using a model that only includes the specularly reflected wave.

$48.5 \mathrm{~mm}$. The melamine resin foam that has been analyzed in the preceding section is used to fill the slots between the ribs, where a thickness of $47.5 \mathrm{~mm}$ was chosen. The backing of the whole plate can be considered to be rigid. It consists of 2 layers of a $12 \mathrm{~mm}$ thick MDF-board (medium density fiber board).

Two measurements were performed: a normal incidence and a $30^{\circ}$ incidence measurement. A square scanning area, centered on the sample's surface, with a width of $0.2 \mathrm{~m}$ (2 spatial periods) was defined. All other parameters of the setup are identical to the setup described in Sec. 5.4.1. In this section, results are presented up to $7000 \mathrm{~Hz}$ as there is no point in extending this frequency for the phenomena that we are discussing in this section. The predictions are based again on the model by Delany and Bazley [7] where $\sigma=8000 \mathrm{Ns} / \mathrm{m}^{4}$.

Figure 5.11 shows the area-averaged normal incidence sound absorption coefficient along with two theoretical predictions. Both predictions were calculated using the approach by Mechel [20] for a semi-free field bounded by a periodic absorber that is subjected to plane wave incidence. The first prediction, indicated by the dashed gray curve, accounts for scattered waves and includes radiating harmonics up to $4^{\text {th }}$ order. The second prediction only includes the first order radiating harmonic and thus only accounts for specular reflection. It is represented by the solid, light gray curve.

Up to $2 \mathrm{kHz}$ the agreement is very good. Beyond this frequency, the measured curve deviates from the predicted curves. This deviation is almost certainly caused by the presence of evanescent surface waves that exist for every order of the radiating harmonics below their cut-on frequency. Consequently, the estimates for both the activeand incident acoustic intensity will be more or less inaccurate as the probe is located 
in the near-field. This field is very different from the set of two waves assumed by the local specular plane wave assumption.

At $3450 \mathrm{~Hz}$, oblique scattering into the far-field occurs. The LSPW-method is quite accurate at this frequency, although the acoustic field differs much from the local specular wave assumption. Even in the presence of two obliquely scattered waves, the LSPW-method seems to be capable of determining the amplitude of the specularly reflected wave as the measured curve agrees well with the specular wave-based prediction up to $3900 \mathrm{~Hz}$. It is pointed out that the amplitude of the next order evanescent surface waves is still relatively low in this frequency range, but steadily increases with increasing frequency up to the frequency at which a new radiating harmonic is cut on.

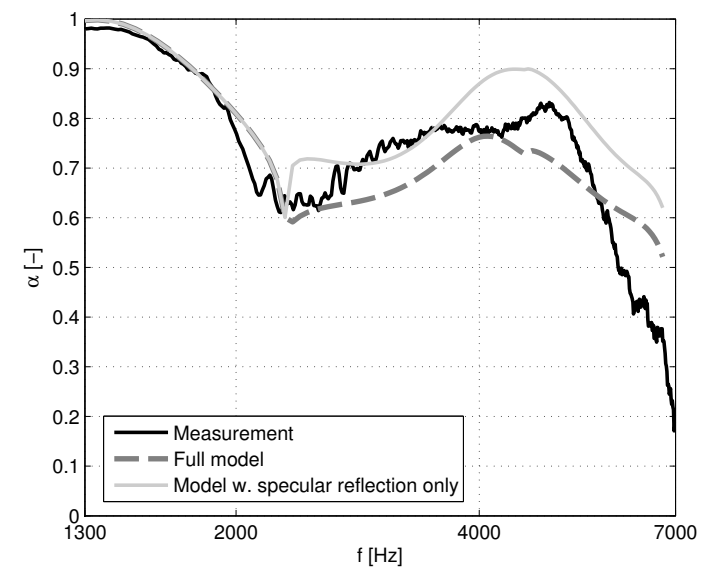

Figure 5.12: Sound absorption coefficient vs. frequency for $30^{\circ}$ incidence, measured with the LSPW-method, predicted using a full model including scattering, and predicted using a model that only includes the specularly reflected wave.

Figure 5.12 shows the same curves for $30^{\circ}$ incidence. The observations stated for normal incidence up to the cut-on frequency, $2300 \mathrm{~Hz}$, of the first scattered wave also seem to be valid here. Above this frequency, however, the measured curve agrees less well with the specular reflection-based prediction (light-gray curve) than for the normal incidence case. This can be explained by the relatively higher amplitude of the evanescent surface waves compared to the normal incidence case, as verified by the model. To obtain an accurate estimate for the sound absorption coefficient, the complex wave amplitudes $A$ and $B$ must be determined in the far-field.

From the results, we conclude that the LSPW-method works well as long as scattering does not occur and as long as the measurement is not influenced by evanescent surface waves. To be able to measure the sound absorption coefficient of the periodic absorber up to the first cut-on frequency, the measurement has to be performed at a greater distance $d$ from the sample's surface. Furthermore, the results seem to indicate 
that the LSPW-method is also capable of determining the amplitude of the specularly reflected wave above the first cut-on frequency, provided that the measurement is not influenced by evanescent surface waves.

\subsection{Conclusions}

In this paper, the LSPW-method for the measurement of the area-averaged oblique incidence sound absorption coefficient is presented. Its underlying assumption assumes that, locally, the acoustic field can be approximated by a set of two plane waves that represent local specular reflection. There is no need for an overall model of the acoustic field in which one has to account for the physical behavior of the sample and/or for the directivity characteristics of the source.

To ensure that the angle of incidence is about constant over the measurement surface, the dimensions of the measurement surface must be significantly smaller than the source distance. If this is not the case, one obtains an effective sound absorption coefficient. The LSPW-method does not account for geometrical spreading of the waves between the measurement surface and the surface of the sample, so that a large source distance is also helpful in reducing errors that may be caused by neglecting geometrical spreading.

Measurements performed for a foam sample subjected to normal and $45^{\circ}$ incidence show that the LSPW-method yields accurate results, although these measurements were performed in a non-ideal acoustic field. Effects that typically negatively influence the results of single point-based measurements, such as the presence of room reflections, are effectively reduced by employing area-averaging. It is also shown that the LSPW-method can be used to determine the specific normal acoustic surface impedance, and that area-averaging is also useful for this purpose. Measurements for a periodic absorber indicate that the LSPW-method can be used up to the cut-on frequency of scattering, provided that the measurement is not performed in the near-field of the absorber due to the presence of evanescent surface waves.

We conclude that the LSPW-method is a useful alternative for measuring the oblique incidence sound absorption coefficient while avoiding the effort of generating an overall model of the acoustic field.

Future work may include investigations for large angles of incidence and investigations of the effects of phase- and amplitude errors of the probe.

\section{Acknowledgements}

The authors would like to thank CAE Software \& Systems GmbH, Gütersloh, Germany, for supplying the prints with the MEMS-microphones. In addition, the support of the 
Engineering Fluid Dynamics group at the University of Twente during the measurements is gratefully acknowledged.

\section{References}

[1] ISO 10534-2:1998: Acoustics - Determination of sound absorption coefficient and impedance in impedance tubes - Part 2: Transfer-function method, 1998.

[2] J.F. Allard, R. Bourdier, and A.M. Bruneau. The measurement of acoustic impedance at oblique incidence with two microphones. J. Sound Vib., 101(1):130-132, 1985.

[3] A. Björck. Numerical methods for least squares problems. SIAM, 1996.

[4] L.M. Brekhovskikh. Waves in layered media. Academic Press, New York, 1960.

[5] J.C. Davies and K.A. Mulholland. An impulse method of measuring normal impedance at oblique incidence. J. Sound Vib., 67(1):135-149, 1979.

[6] H.-E. de Bree. An overview of Microflown technologies. Acta Acust. Acust., 89:163-172, 2003.

[7] M.E. Delany and E.N. Bazley. Acoustical properties of fibrous absorbent materials. Appl. Acoust., 3:105-116, 1970.

[8] F.J. Fahy. Sound intensity. E \& FN Spon, London, 2nd edition, 1995.

[9] M. Garai. Measurement of the sound-absorption coefficient in situ: The reflection method using periodic pseudo-random sequences of maximum length. Appl. Acoust., 39:119-139, 1993.

[10] M. Garai and F. Pompoli. A European inter-laboratory test of airflow resistivity measurements. Acta Acust. Acust., 89:471-478, 2003.

[11] N. Kino, T. Ueno, Y. Suzuki, and H. Makino. Investigation of non-acoustical parameters of compressed melamine foam materials. Appl. Acoust., 70(4):595-604, 2009.

[12] R. Kruse. Application of the two-microphone method for in-situ ground impedance measurements. Acta Acust. Acust., 93:837 - 842, 2007.

[13] E.R. Kuipers, Y.H. Wijnant, and A. de Boer. Theory and application of a new method for the in-situ measurement of sound absorption. In DAGA 2011, pages 723-724, Düsseldorf, 2011. DEGA, Berlin.

[14] E.R. Kuipers, Y.H. Wijnant, and A. de Boer. A numerical study of a method for measuring the effective in situ sound absorption coefficient. J. Acoust. Soc. Am., 132(3):EL236-42, 2012.

[15] E.R. Kuipers, Y.H. Wijnant, and A. de Boer. In situ sound absorption measurement: investigations on oblique incidence. In DAGA 2012, pages 351-352, Darmstadt, 2012. DEGA, Berlin.

[16] E.R. Kuipers, Y.H. Wijnant, and A. de Boer. Measuring sound absorption: considerations on the measurement of the active acoustic power (submitted). Acta Acust. Acust., 2013.

[17] R. Lanoye, G. Vermeir, W. Lauriks, R. Kruse, and V. Mellert. Measuring the free field acoustic impedance and absorption coefficient of sound absorbing materials with a combined particle velocity-pressure sensor. J. Acoust. Soc. Am., 119(5):2826-2831, 2006.

[18] K.M. Li and S. Liu. Propagation of sound from a monopole source above an impedance-backed porous layer. J. Acoust. Soc. Am., 131(6):4376-4388, 2012. 
[19] S. Liu and K.M. Li. Efficient computation of the sound fields above a layered porous ground. J. Acoust. Soc. Am., 131(6):4389-4398, 2012.

[20] F.P. Mechel. Sound fields at periodic absorbers. J. Sound Vib., 136(3):379-412, January 1990.

[21] E. Mommertz. Angle-dependent in-situ measurements of reflection coefficients using a subtraction technique. Appl. Acoust., 46(3):251-263, 1995.

[22] C. Nocke. In-situ acoustic impedance measurement using a free-field transfer function method. Appl. Acoust., 59(3):253-264, 2000.

[23] E. Tijs and E. Druyvesteyn. An intensity method for measuring absorption properties in situ. Acta Acust. Acust., 98(2):342-353, 2012.

[24] Y.H. Wijnant, E.R. Kuipers, and A. de Boer. Development and application of a new method for the in-situ measurement of sound absorption. In ISMA 31, Leuven, Belgium, 2010. 


\section{Chapter 6}

\section{Conclusions and recommendations}

\subsection{Conclusions}

The present research has led to new insights in the way sound absorption measurements can be performed. It has led to the development of two novel sound absorption measurement methods, the development of a novel 3D sound intensity probe, and new insights with respect to the role of area-averaging in sound absorption measurements. These elements are described and discussed in four research papers $[1,2,3,4]$.

In the first paper, reproduced in chapter two, a novel intensity probe, consisting of eight MEMS-microphones, is described. Due to its compactness, it allows for measuring the 3D acoustic intensity vector nearer to surfaces than would be possible with conventional 3D sound intensity probes based on $1 / 2$-inch microphones. It is shown that the intensity vector can be straightforwardly calculated once the cross-spectral matrix is obtained from the measurement. In addition, a novel calibration method has been developed. In order to determine the source characteristics, calibration measurements are performed at multiple distances from the source in a non-anechoic room. It is shown that the effects caused by room reflections are reduced by averaging over multiple measurement points.

Chapter three introduces a first new method, the so-called Local Plane Wave method or: LPW-method, for the measurement of the sound absorption coefficient that is based on a local field assumption only. By numerical analyses, it is shown that the spatial distribution of the incident acoustic intensity can be recovered accurately, even in the presence of another reflective surface near the surface of interest. The obtained area-averaged sound absorption coefficients are, in fact, effective sound absorption coefficients as the field is not well-defined. Nevertheless, these coefficients approach the theoretical values of the surface of interest for normal incidence very well. It is 
observed that for a poorly absorbing surface, the distance between the measurement surface and the material surface has a greater influence on the accuracy of the sound absorption coefficient than for a well-absorbing surface. Accordingly, it is advantageous to minimize the distance of the measurement surface to the material surface.

The effect of the distance of the measurement surface to the material surface has been investigated in chapter four. In this chapter, it is shown that leakage of acoustic power through the circumferential surface, surrounding the space between the measurementand material surface, leads to an overestimation of the sound absorption coefficient of the surface of interest. This phenomenon is particularly significant for poorly absorbing surfaces. By additionally measuring the active acoustic power passing through the circumferential surface, this error can be compensated for. Near-normal incidence measurements performed for an acoustically hard surface showed the usefulness of this approach. Experiments performed for both samples showed that an increase of the area of the measurement surface leads to smoother results, confirming that the effectiveness of area-averaging increases with increasing surface area.

The LPW-method is well-suited for near-normal incidence measurements. However, the estimated incident acoustic intensity becomes increasingly inaccurate for increasing angles of incidence. To be able to also perform measurements for larger angles of incidence, a different local assumption was conceived: the local specular plane wave assumption. The method that is based on this assumption, the LSPW-method, is described in chapter five. A least-squares method is used to determine the amplitudes of the incident and reflected wave using the intensity probe described in chapter two. Measurements performed for a well-absorbing porous absorber showed that the LSPW-method is capable of producing credible results. Measurements performed for a periodic absorber also confirm this, at least up to frequencies where the amplitude of evanescent waves near the absorber's surface is smaller than those of the incidentand specularly reflected wave.

Summarizing, it is concluded that the objective of this research has been met. With the development of the LPW- and LSPW-method in this work, two new methods are available that do not require an overall model of the acoustic field in front of the sample. The LPW-method is suitable for normal- and near-normal incidence, whereas the LSPW-method can be applied for normal- and oblique incidence measurements. The local approaches adopted in both methods allow for measurements in non-ideal acoustic fields. Due to the chosen approach, the obtained sound absorption coefficient is that of the measurement surface, lying at a small distance to the material surface. For non-plane wave incidence, or reflection of non-plane waves, it is advisable to account for leakage of active acoustic power through the circumferential surface. The newly developed 3D sound intensity probe is of great utility for this purpose. Its design allows for measuring the active acoustic intensity that passes through the circumferential surface that surrounds the space between the measurement- and material surface. 
Furthermore, the concept of area-averaging has proven to be very useful in reducing unwanted effects caused by room reflections and edge-diffracted waves. It has been shown that this concept is also effective when measuring the normal acoustic surface impedance assuming plane wave propagating between the measurement- and the material surface. Considering area-averaging, the measurement methods developed in this work have the advantage of ease and rapidity over currently existing methods that employ iterative fitting procedures, as the computational effort associated with the latter can already be significant for a single measurement point.

Finally, this research demonstrates the effectiveness of using a local approach. In a general sense, one can conclude that when a field assumption can locally approximate the acoustic field well, it can also be used to locally decompose a field into incident and reflected waves. As such, there is no need for establishing an overall model of the acoustic field.

\subsection{Recommendations and outlook}

The two new methods developed in this work show that it is possible to determine the sound absorption coefficient without the use of an overall model, and thus without the need for a well-defined measurement setup. The LSPW-method encompasses the LPW-method and should therefore be taken as a starting point for further research. Currently open questions that demand further investigations are presented in the following list.

- Amplitude- and phase errors are bias errors that are known to strongly influence the accuracy of acoustic intensity measurements. It is therefore recommended to analyze their influence on the accuracy of the sound absorption coefficient.

- Without dedicated models, it is, currently, hardly possible to determine the (areaaveraged) sound absorption coefficient of non-locally reactive surfaces. Investigations on application of the LSPW-method or development of other methods to this purpose is therefore desired.

- The LSPW-method has been applied for angles up to $45^{\circ}$. It is recommended to investigate application of the LSPW-method for larger angles of incidence. A particular issue herein is that, for low frequencies, the phase difference between the measured acoustic pressures will decrease, thus making the measurement more sensitive to phase errors.

- Quantitative analysis of the effect of area-averaging in different environments and for different surface types is necessary to be able to relate the attainable accuracy with the dimensions of the measurement surface.

- Application of the LSPW-method would be more convenient if a manual scanning process could replace the current automated sequence of point measurements. 
Therefore, it would be useful so investigate the accuracy of a manual scanning procedure.

- The concept of area-averaging is a beneficial factor in reducing the influence of reflections from surfaces other than from the surface of interest. Therefore, the LSPW-method is a good candidate for in situ measurements as well. Investigations of application of this method in situ, including even more or less reverberant rooms, first have to be performed in order to evaluate the potential for this purpose.

Finally, it is stressed that the LPW- and LSPW-method in fact are elementary realizations of the general concept of local wave decomposition. This concept allows the inclusion of more waves, provided that the acoustic pressure is measured at a sufficient number of spatially distributed points, and advanced numerical solving techniques are applied to solve the resulting system of non-linear equations. The expected development of commercially available arrays of MEMS-microphones will certainly be very beneficial to this purpose. By doing so, the measurement of the area-averaged oblique incidence sound absorption coefficient of non-locally reactive surfaces, such as diffusers or periodic absorbers, may become possible in the near future without having to establish dedicated overall field models.

\section{References}

[1] E.R. Kuipers, Y.H. Wijnant, and A. de Boer. A numerical study of a method for measuring the effective in situ sound absorption coefficient. J. Acoust. Soc. Am., 132(3):EL236-42, 2012.

[2] E.R. Kuipers, Y.H. Wijnant, and A. de Boer. Characterization of a MEMS-microphone based 3D sound intensity probe by means of a free-field calibration method (submitted). Appl. Acoust., 2013.

[3] E.R. Kuipers, Y.H. Wijnant, and A. de Boer. Measuring oblique incidence sound absorption using a local plane wave assumption (submitted). Acta Acust. Acust., 2013.

[4] E.R. Kuipers, Y.H. Wijnant, and A. de Boer. Measuring sound absorption: considerations on the measurement of the active acoustic power (submitted). Acta Acust. Acust., 2013. 


\section{Nomenclature}

\section{Greek}

$\begin{array}{ll}\alpha & \text { sound absorption coefficient } \\ \alpha_{\mathrm{ER}} & \text { sound absorption coefficient for a locally reactive surface } \\ \alpha_{\mathrm{LR}} & \text { sound absorption coefficient for an extensively reactive surface } \\ \alpha_{\mathrm{m}} & \text { effective mean sound absorption coefficient } \\ \alpha_{\mathrm{S}} & \text { statistical sound absorption coefficient } \\ \Delta f & \text { frequency resolution } \\ \lambda & \text { wavelength } \\ \phi & \text { angle of incidence w.r.t. } \text { y-axis } \\ \psi & \text { angle of incidence } \\ \tilde{\psi} & \text { average angle of incidence } \\ \theta & \text { angle of incidence w.r.t. to z-axis } \\ \rho_{0} & \text { mass density of air } \\ \sigma & \text { flow resistivity } \\ \omega & \text { radial frequency }\end{array}$

\section{Scalars}

$\begin{array}{ll}a & \text { distance } \\ c_{0} & \text { speed of sound } \\ d & \text { distance } \\ f & \text { frequency } \\ h & \text { distance } \\ k & \text { acoustic wavenumber } \\ k_{\mathrm{c}} & \text { (complex) acoustic wavenumber of porous material } \\ p & \text { acoustic pressure } \\ q & \text { counter } \\ s & \text { microphone spacing } \\ w & \text { distance } \\ A & \text { complex amplitude of incident wave } \\ B & \text { complex amplitude of reflected wave } \\ F & \text { Functional }\end{array}$

[m] [m/s]

[m]

[Hz]

[m] $[\mathrm{rad} / \mathrm{m}]$ $[\mathrm{rad} / \mathrm{m}$ ]

[Pa] 


$\begin{array}{llr}G & \text { single-sided power spectral density } & {\left[\mathrm{Pa}^{2} / \mathrm{Hz}\right]} \\ I_{\text {ac }} & \text { directional active acoustic intensity (or its spectral density) } & {\left[\mathrm{W} / \mathrm{m}^{2}\right]} \\ I_{\text {in }} & \text { directional incident acoustic intensity (or its spectral density) } & {\left[\mathrm{W} / \mathrm{m}^{2}\right]} \\ I_{\text {re }} & \text { directional reactive acoustic intensity (or its spectral density) } & {\left[\mathrm{W} / \mathrm{m}^{2}\right]} \\ I_{\text {refl }} & \text { directional reflected acoustic intensity (or its spectral density) } & {\left[\mathrm{W} / \mathrm{m}^{2}\right]} \\ N & \text { counter } & {[-]} \\ P & \text { complex acoustic pressure } & {[\mathrm{Pa}]} \\ S & \text { surface } & {\left[\mathrm{m}^{2}\right]} \\ S_{\text {abs }} & \text { absorbing surface area } & {\left[\mathrm{m}^{2}\right]} \\ S_{\mathrm{p}} & \text { projected surface } & {\left[\mathrm{m}^{2}\right]} \\ T & \text { time duration } & {[\mathrm{s}]} \\ T_{60} & \text { reverberation time } & {[\mathrm{s}]} \\ U_{\mathrm{n}} & \text { particle velocity in direction n } & {[\mathrm{m} / \mathrm{s}]} \\ V & \text { volume } & {\left[\mathrm{m}^{3}\right]} \\ W_{\text {ac }} & \text { acoustic power } & {[\mathrm{W}]} \\ W_{\text {in }} & \text { incident acoustic power } & {[\mathrm{W}]} \\ Z & \text { specific acoustic impedance } & {\left[\mathrm{Ns} / \mathrm{m}^{3}\right]} \\ Z_{0} & \text { characteristic specific acoustic impedance of air } & {\left[\mathrm{Ns} / \mathrm{m}^{3}\right]} \\ Z_{\mathrm{c}} & \text { characteristic specific acoustic impedance of porous material } & {\left[\mathrm{Ns} / \mathrm{m}^{3}\right]} \\ Z_{\mathrm{S}} & \text { normal specific acoustic surface impedance } & {\left[\mathrm{Ns} / \mathrm{m}^{3}\right]} \\ Z_{\mathrm{S}}^{\prime} & \text { normalized normal specific acoustic surface impedance } & {[-]}\end{array}$

\section{Vectors and matrices}

$\begin{array}{llr}\mathbf{n} & \text { normal surface direction } & {[\mathrm{m}]} \\ \mathbf{n}_{\mathrm{A}} & \text { propagation direction of incident wave } & {[\mathrm{m}]} \\ \mathbf{n}_{\mathrm{B}} & \text { propagation direction of reflected wave } & {[\mathrm{m}]} \\ \mathbf{r} & \text { spatial position vector } & {[\mathrm{m}]} \\ \mathbf{I}_{\mathrm{ac}} & \text { active acoustic intensity vector } & {\left[\mathrm{W} / \mathrm{m}^{2}\right]} \\ \mathbf{I}_{\mathrm{re}} & \text { reactive acoustic intensity vector } & {\left[\mathrm{W} / \mathrm{m}^{2}\right]} \\ \mathbf{M} & \text { matrix containing phase relationships between acoustic pres- } & {[-]} \\ & \text { sures } & {[\mathrm{Pa}]} \\ \mathbf{P} & \text { vector of measured complex pressures } & {[\mathrm{m} / \mathrm{s}]} \\ \mathbf{U} & \text { particle velocity vector } & \end{array}$

\section{Abbreviations}

$8 p$-probe sound intensity probe consisting of 8 microphones

pp-probe 2-microphone sound intensity probe

pu-probe sound intensity probe consisting of one microphone and one particle velocity sensor

DB-model Delany-Bazley model

dBFS dB Full Scale 
EIN Equivalent Input Noise

LPW Local Plane Wave

LSPW Local Specular Plane Wave

MEMS Micro-Electro Mechanical Systems

SNR Signal-to-Noise Ratio

SPL Sound Pressure Level

THD Total Harmonic Distortion 


\section{Publications}

\section{Journal papers - refereed}

1. E.R. Kuipers, Y.H. Wijnant, A. de Boer, and N. Zurmühlen. Development and calibration of a MEMS-microphone based 3D sound intensity probe. (submitted to Appl. Acoust.). (Chapter 2 of this thesis)

2. E.R. Kuipers, Y.H. Wijnant, and A. de Boer. A numerical study of a method for measuring the effective in situ sound absorption coefficient. J. Acoust. Soc. Am., 132(3):EL236-42, 2012. (Chapter 3 of this thesis)

3. E.R. Kuipers, Y.H. Wijnant, and A. de Boer. Measuring sound absorption: considerations on the measurement of the active acoustic power. (submitted to Acta Acust. Acust). (Chapter 4 of this thesis)

4. E.R. Kuipers, Y.H. Wijnant, and A. de Boer. Measuring oblique incidence sound absorption using a local plane wave assumption. (submitted to Acta Acust. Acust.). (Chapter 5 of this thesis)

\section{Journal papers - non refereed}

1. E.R. Kuipers, Y.H. Wijnant, A. de Boer. Meting van de geluidsabsorptiecoëfficient zonder globaal model van het geluidsveld. Bouwfysica, NVBV, Arnhem, The Netherlands, 2013.

\section{Conference papers}

1. Y.H. Wijnant, E.R. Kuipers, and A. de Boer. Development and application of a new method for the in-situ measurement of sound absorption. In ISMA 31 Leuven, Belgium, 2010.

2. E.R. Kuipers, Y.H. Wijnant, and A. de Boer. Theory and application of a new method for the in-situ measurement of sound absorption. In DAGA 2011 Düsseldorf, Germany, 723-724, DEGA, Berlin, 2011. 
3. E.R. Kuipers, Y.H. Wijnant, and A. de Boer. In situ sound absorption measurement: investigations on oblique incidence. In DAGA 2012 Darmstadt, Germany, 351-352, DEGA, Berlin, 2012.

4. E.R. Kuipers, Y.H. Wijnant, and A. de Boer. Measuring the angle-dependent sound absorption coefficient with a small microphone array. In AIA-DAGA 2012 Merano, Italy, 642-645, DEGA, Berlin, 2013.

\section{Posters}

1. E.R. Kuipers, Y.H. Wijnant, and A. de Boer. Development of a new method for the in-situ measurement of sound absorption. In $13^{\text {th }}$ Engineering Mechanics Symposium, Lunteren, The Netherlands, Engineering Mechanics, Eindhoven, The Netherlands, 2010.

2. E.R. Kuipers, I. van Rij, and Y.H. Wijnant. A new method to determine sound transmission loss. In $14^{\text {th }}$ Engineering Mechanics Symposium, Lunteren, The Netherlands, Engineering Mechanics, Eindhoven, The Netherlands, 2011.

3. E.R. Kuipers, Y.H. Wijnant, and A. de Boer. Measuring sound absorption with the Local Plane Wave method. In $15^{\text {th }}$ Engineering Mechanics Symposium, Lunteren, The Netherlands, Engineering Mechanics, Eindhoven, The Netherlands, 2012.

\section{Presentations}

1. E.R. Kuipers, Measurement of the sound absorption coefficient in situ, presented at Herbsttagung SGA-SSA, Dübendorf, Switzerland, Swiss acoustical society SGA-SSA, Switzerland (2012).

2. E.R. Kuipers, Meting van de geluidsabsorptiecoëfficient zonder globaal model van het geluidsveld, presented at 5e NVBV-Kennisdag Bouwfysica, Delft, The Netherlands, (2013). 


\section{Dankwoord}

Gezien de lengte van het proefschrift zou dit een vrij beknopt dankwoord moeten worden. Daarmee zou ik echter de vele personen tekort doen die bewust of onbewust een bijdrage hebben geleverd aan mijn onderzoek!

Allereerst wil ik Ysbrand Wijnant bedanken. Tenslotte ben jij diegene die met de oorspronkelijke ideeën kwam waarop dit werk grotendeels is gebaseerd. Door je kritische vragen en jouw kunst buiten het vaste stramien te denken hebben we samen mooie resultaten behaald. Jouw positieve instelling en jouw inspirerende woorden waren een uitstekende katalysator om 's-ochtends nog voor de kinderen op te staan om vervolgens in alle vroegte naar de UT te fietsen.

Ook André de Boer wil ik bedanken, speciaal voor het risico dat jij met deze 'op leeftijd zijnde student' wilde ingaan. Dat je een man van je woord bent bleek 2 dagen na mijn komst, toen het oorspronkelijke voorziene project niet meer bleek te bestaan en jij me garandeerde dat ik kon blijven. Bedankt voor al je vertrouwen!

Veel praktische hulp heb ik gekregen van Bert Wolbert en Axel Lok, jullie kennis en vindingrijkheid waren onmisbaar als het ging om de voorbereiding van mijn metingen en van mijn meetobjecten. Spontane acties zoals de wat te sterk ronkende Connexxion bus, de galmende oefenzaal in De Lutte en de nagalmtijdmeting in de windtunnel vormden een interessante afwisseling op mijn eigenlijke onderzoek.

Norbert Spikker bedank ik voor zijn kunststukjes op de lasersnijmachine en Martin Sprenkeler voor zijn bereidheid mij wegwijs te maken in de werkplaats. Hulp kreeg ik ook van de EFD groep van Harry Hoeijmakers. Harry toonde begrip voor mijn wens bijna 2 maanden lang metingen (in plaats van de voorziene 2 weken) uit te voeren in de windtunnel. Ook Herman Stobbe en Wouter den Breeijen bedankt voor jullie ondersteuning in die tijd!

Als bijzonder goed heb ik de sfeer op de groepen op de $\mathrm{N}$-gang ervaren. Vele liters koffie en kilo's verjaardags- en ander gebak zijn er door gegaan. Vele gesprekken, over de meest uiteenlopende onderwerpen, zorgden ervoor dat de jaren bij de vakgroep TM zijn omgevlogen. Gezellig was het altijd! Marten, Samuele, Arjan, Emre, 
Pieter, Alexandre, Mahmoud, Derek, Dirk, Anne, Andrea en van de staf Ruud, Richard, Arthur, Tiedo en Marcel, bedankt! Een speciale plaats in deze groep verdienen mijn (ex-) kamergenoten Ronald, Didem, Lambert, Marieke en Jurnan. Bedankt voor jullie gezelligheid en hulp! Ik hoop dat ik jullie af en toe ook heb kunnen helpen.

Dat dynamica en akoestiek niet direct met de activiteiten van de NSM- en de OPM/PTgroep verbonden waren hinderde niet. In tegendeel, de gesprekken waren daardoor vaak al voorbestemd niet al te technisch te zijn. Jan Harmen, Johan, Daan, Jos, Chao, Bert, Semih, Ton, Ted, Sebastiaan, Bo, Ulli, Wouter, Sybren, Bert R., Bert V., Ilona, Remko, Roy, Arnoud, Timo, Johan en Emiel: bedankt voor jullie hulp en leuke gesprekken.

Verder hebben Marwin Frauenlob en Ineke van Rij mij met hun bachelor- en masteropdracht enorm geholpen door nieuwe inzichten te winnen. Stuk voor stuk goed werk. Bovendien was het erg plezierig om met jullie samen te werken.

Een dankwoord van een TM-promovendus kan niet compleet zijn zonder Debbie en invalster Belinda te noemen. Voor elk probleem hebben jullie een oplossing. Bedankt voor jullie inzet!

Een bijzonder treurige gebeurtenis was het overlijden van Peter van der Hoogt. Peter heeft mij met zijn boeiende colleges al vanaf het begin enthousiast gemaakt voor de dynamica. Een liefde die in de loop van de jaren misschien niet zo sterk zou zijn geworden als hij niet bijgedragen zou hebben aan zo'n goede basis.

Tenslotte gaat mijn aller-, allergrootste dank naar Isabelle. Toen ik over een promotieonderzoek begon heb jij me verder gestimuleerd deze stap ook werkelijk te zetten. Eenmaal verhuisd naar Twente, heb jij je eigen interesses naar de achtergrond geschoven om mijn wens werkelijkheid te kunnen laten worden. Jij vormt samen met Femke, Maaike en Nienke het beste team dat ik me kan wensen!

Erwin Kuipers, augustus 2013. 


\section{UNIVERSITY OF TWENTE.}

